\title{
Growing in the city: \\ Analyzing public urban agriculture in Ottawa
}

by

Lauren Allen

A thesis submitted to the Faculty of Graduate and Postdoctoral Affairs in partial fulfillment of the requirements for the degree of

Master of Arts

in

Geography

Carleton University

Ottawa, Ontario

(C) 2015, Lauren Allen 


\begin{abstract}
This thesis sought to explore the spatial and social distribution of publicly accessible urban agriculture in Ottawa, drawing on a conceptual framework linking concepts of food justice, the right to the city, and social capital. This study mapped existing food production practices in relation to local demographic conditions, revealing associations between the locations of community gardens and lower socio-economic indicators, and between the locations of school gardens and food-bearing trees with higher socio-economic indicators. A secondary area of focus considered the potential for increasing urban agriculture in Ottawa, through the creation of a GIS-based land inventory identifying vacant or underutilized land that could be available for food production. The inventory, a preliminary assessment of suitable land, revealed 1,380 hectares potentially available. Whether a dedicated or interim land use, or an integrated part of multifunctional spaces, there may be significant potential to increase the amount of urban agriculture in Ottawa.
\end{abstract}




\section{Acknowledgements}

This thesis would not have been possible without the contributions of many people. I am sincerely grateful to Dr. Patricia Ballamingie and Dr. Scott Mitchell for their guidance in completing this thesis. I am thankful to both of you for your kind encouragement, and feel fortunate to have had the opportunity to benefit from your combined and diverse expertise and insight.

I would also like to thank the staff, faculty, and students in the Carleton Department of Geography and Environmental Studies, who create a supportive, challenging, and enjoyable environment in which to pursue graduate studies.

I am very appreciative of the individuals who participated in interviews, who demonstrate a passion for urban agriculture in their work, and who are working towards a more sustainable and just food system in Ottawa. Their willingness to generously share their knowledge, perspective, and vision helped to make this thesis possible.

I am grateful to Cadence Allen-Crawley and Karen Allen for being wonderful sisters. To Dustin Valen, I am thankful for your sense of humour, perspective, and encouragement. Finally, I would like to express my gratitude to my parents, Heather and Rick Allen, for their lifelong love and support. I dedicate this thesis to them. 


\section{Table of Contents}

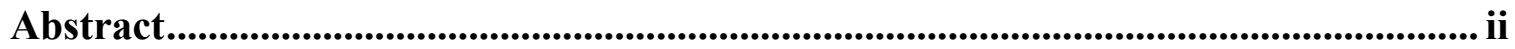

Acknowledgements ......................................................................................................ii

Table of Contents ............................................................................................................ iv

List of Tables ................................................................................................................. vii

List of Illustrations............................................................................................................... ix

List of Appendices....................................................................................................... xi

List of Acronyms ............................................................................................................................ xii

1 Chapter: Introduction ........................................................................................................ 1

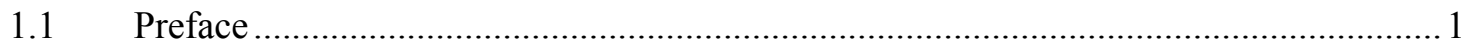

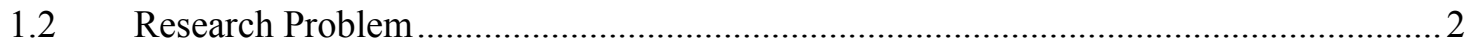

1.2.1 Research Justification......................................................................................

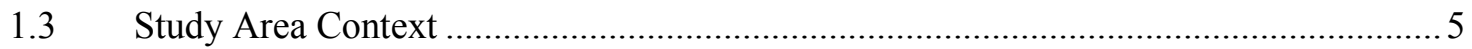

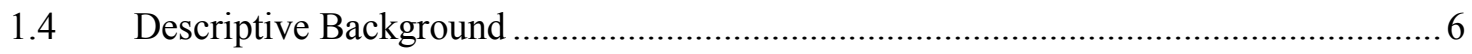

1.4.1 Food Systems and Urban Agriculture ………………………………………..... 6

1.4.2 Urban Agriculture Initiatives in Ottawa............................................................. 8

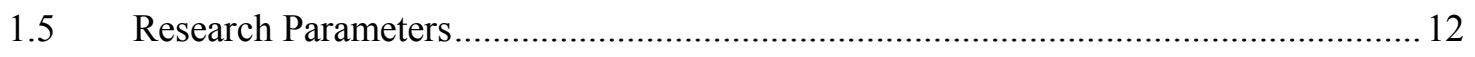

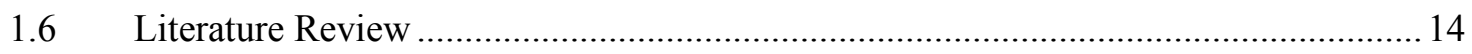

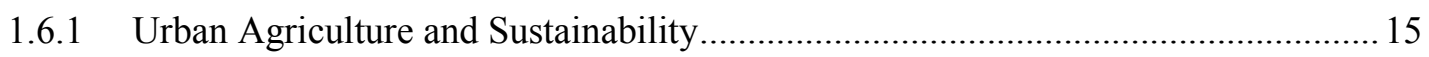

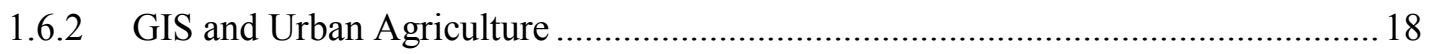

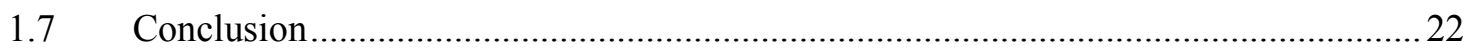

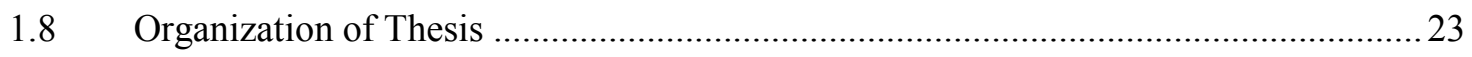

2 Chapter: Conceptual Framework .............................................................................. 24

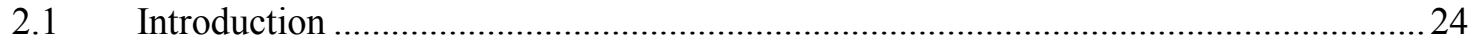

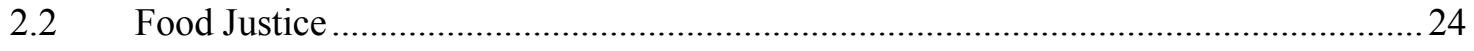




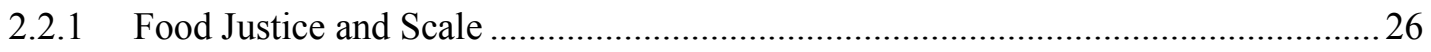

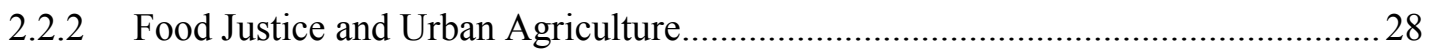

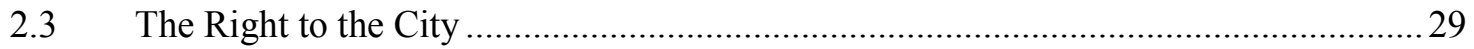

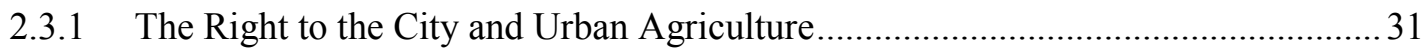

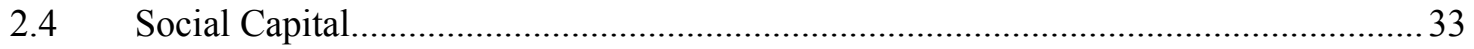

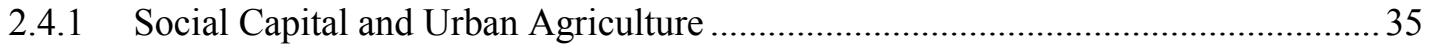

2.5 Food Justice, the Right to the City, and Social Capital ............................................... 36

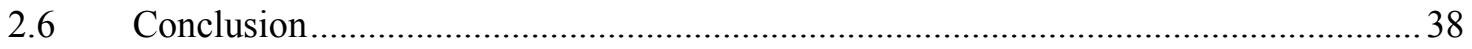

3 Chapter: Methodological Approach ............................................................................ 40

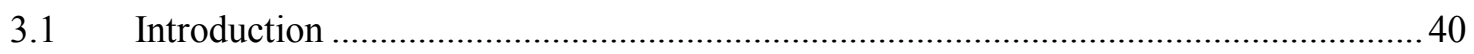

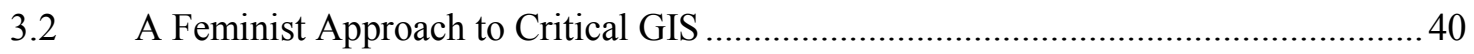

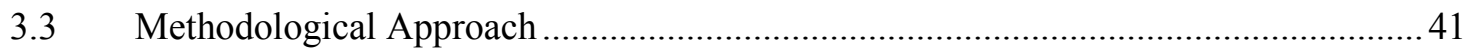

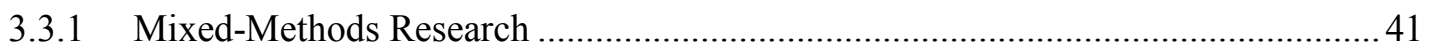

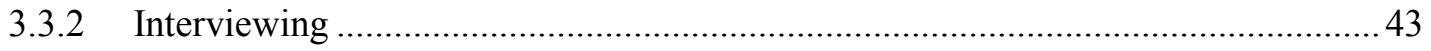

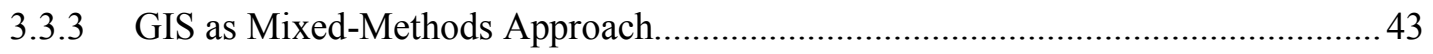

3.3.4 Participatory Action Research \& Participatory GIS ............................................ 45

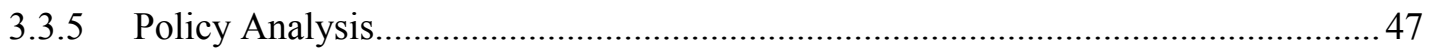

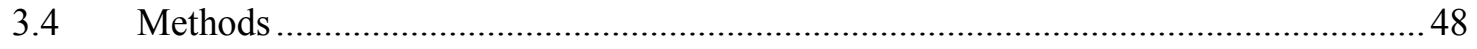

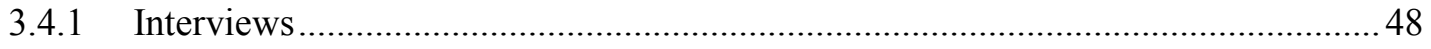

3.4.2 Assessing Demand for Urban Agriculture ........................................................ 49

3.4.3 Mapping Existing Urban Agriculture Practices .....................................................50

3.4.4 Spatial Analysis of Urban Agriculture Data ......................................................... 52

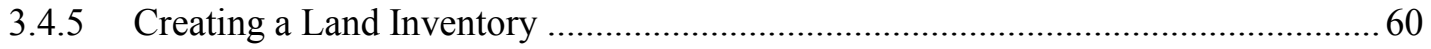

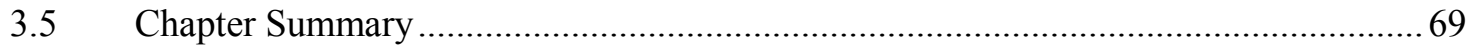

4 Chapter: Results and Discussion ............................................................................... 71

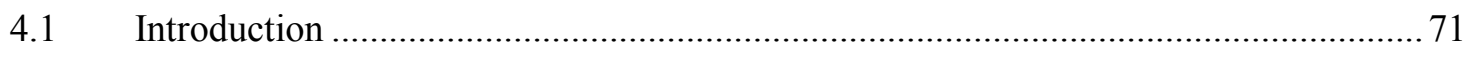


4.2 Descriptive Account of Urban Agriculture in Ottawa........................................... 71

4.2.1 Organizational Network of Urban Agriculture .................................................. 71

4.2.2 Spaces of Interaction, Community Development, and Food Justice........................77

4.2.3 Conceptualizations of Public Access in Community Gardens ................................ 81

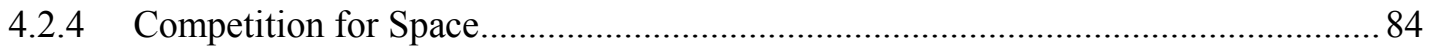

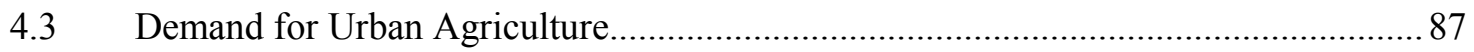

4.4 Spatial Analysis of Urban Agriculture Locations....................................................... 90

4.4.1 Initial Mapping of Urban Agriculture Activities.................................................. 90

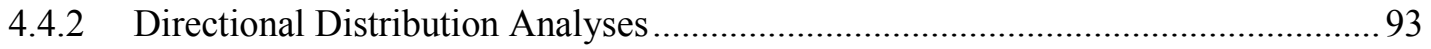

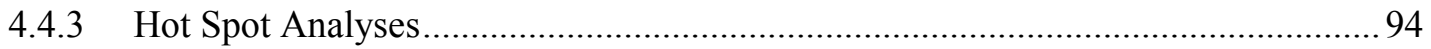

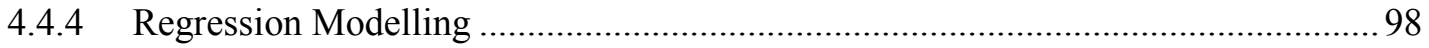

4.5 Limitations of Regression Modelling of Social Processes ...................................... 112

4.6 Inventory of Land Potentially Available for Urban Agriculture .............................. 113

4.6.1 Comparison of land inventory results to lands identified through interactive

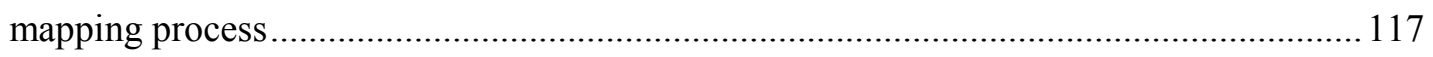

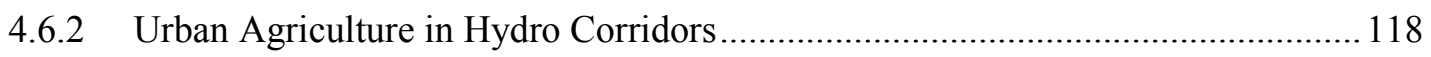

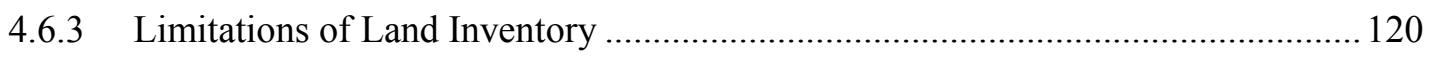

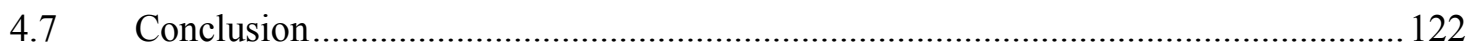

5 Chapter: Policy Considerations................................................................................ 125

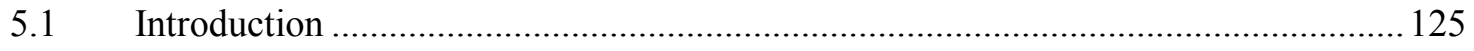

5.2 Municipal and Federal Policies Affecting Urban Agriculture in Ottawa ................... 125

5.3 Further Considerations for Supporting Urban Agriculture in Ottawa ........................ 134

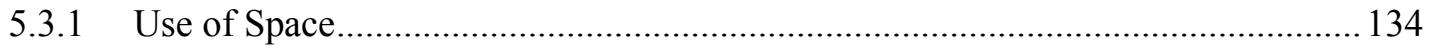

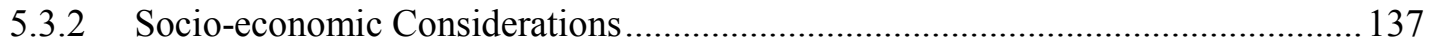

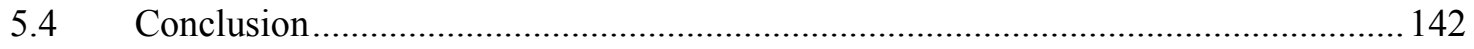




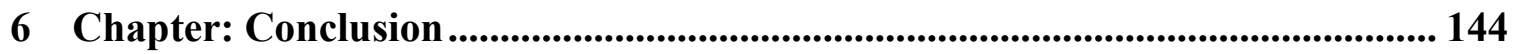

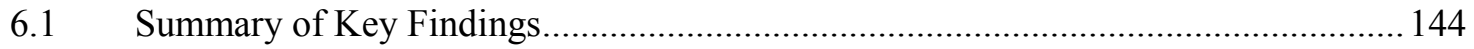

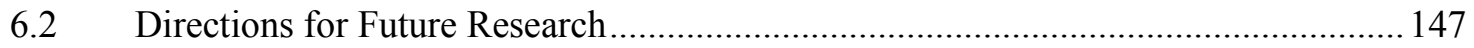

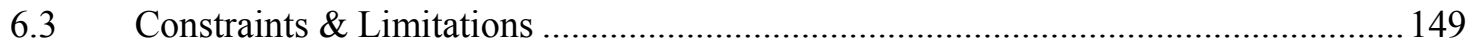

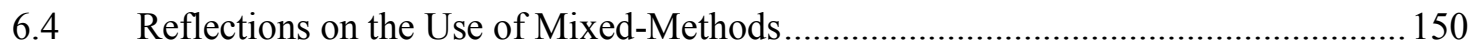

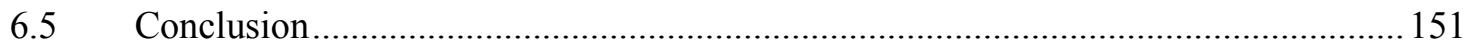

Appendices ........................................................................................................................ 153

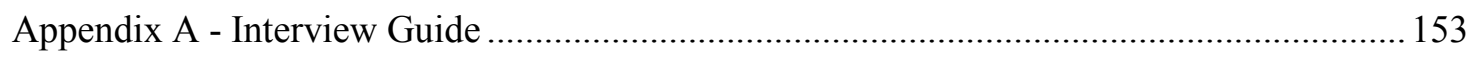

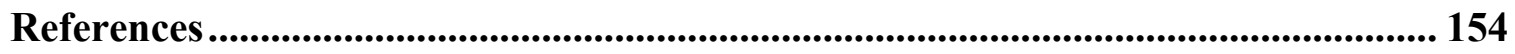




\section{List of Tables}

Table 1 - List of potentially fruit- and nut-bearing tree species................................. 52

Table 2 - Demographic and non-demographic factors considered as potential explanatory variables. 55

Table 3 - Fixed distance band used for each of the hot spot analyses.

Table 4 - Variables identified through interviews as important considerations for urban agriculture

Table 5 - Summary of best-performing OLS model for each dependent variable. 99

Table 6 - GWR and OLS coefficients for the local and global regression models 104

Table 7 - Sites potentially suitable for urban agriculture by land use category.

Table 8 - Sites potentially suitable for urban agriculture by land ownership.

Table 9 - Sites potentially suitable for urban agriculture by size. 


\section{List of Illustrations}

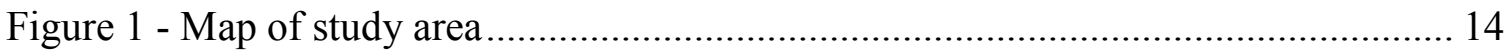

Figure 2 - Google Earth images showing raised garden beds and the in-ground plots of an

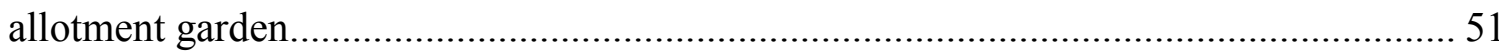

Figure 3 - Organizational network of urban agriculture related initiatives in Ottawa..... 72

Figure 4 - The Debra Dynes "Giving Garden” ......................................................... 79

Figure 5 - Example of typical allotment garden plot .................................................... 81

Figure 6 - Community garden with sign indicating video surveillance and the Robert

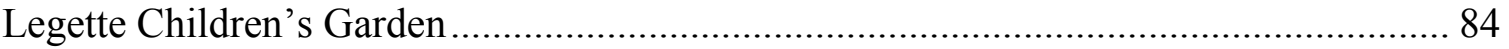

Figure 7 - Community garden locations, symbolized based on length of waiting list...... 88

Figure 8 - Locations identified by interviewees as places where increased urban

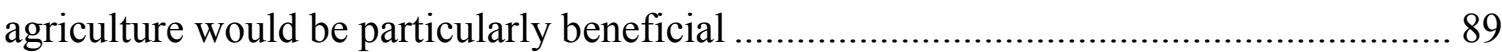

Figure 9 - Percentage low income by census tract according to after-tax low-income

measure, overlaid with locations of community and school gardens ............................... 92

Figure 10 - Directional distribution analysis (based on one standard deviation) for

community gardens, school gardens, and edible trees.................................................... 94

Figure 11 - Hot spot analysis for number of community garden locations per population

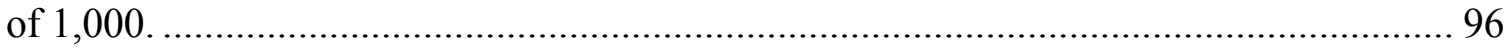

Figure 12 - Hot spot analysis for number of community garden plots per population of

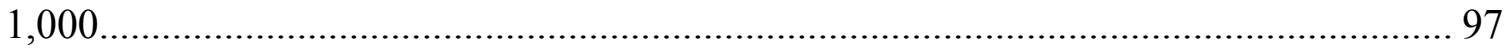

Figure 13 - Hot spot analysis for number of school garden locations per population of

1,000 
Figure 14 - Hot spot analysis for number of fruit- or nut-bearing trees per population of

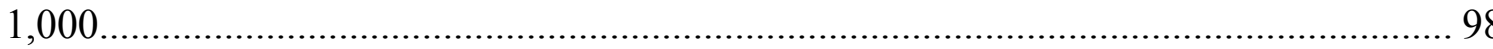

Figure 15 - Standardized residuals of the GWR model......................................... 105

Figure 16 - Coefficient map of the percentage of the population that is a visible minority variable 106

Figure 17 - Coefficient map of the median household income variable....................... 106

Figure 18 - Coefficient map of the median dwelling value variable. ........................... 107

Figure 19 - Coefficient map of the distance to urban centre variable........................... 107

Figure 20 - Coefficient map of the average residential parcel size variable.................. 108

Figure 21 - Coefficient map of the percentage of the population that holds a Bachelor's degree or higher variable. ............................................................................. 108

Figure 22 - Median household income of study area (by census tract)....................... 111

Figure 23 - Percentage of population with a Bachelor's degree or higher..................... 111

Figure 24 - Sites identified as potentially suitable for urban agriculture through the land

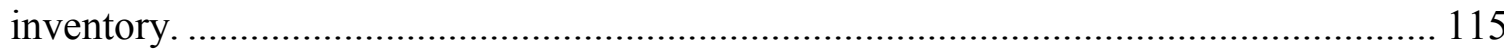

Figure 25 - Land identified in inventory by ownership........................................ 127

Figure 26 - Land identified in inventory by land use............................................... 137 


\section{List of Appendices}

Appendix A - Interview Guide. ......................................... 153 


\section{List of Acronyms}

$\begin{array}{ll}\text { AICc } & \text { Akaike's Information Criterion } \\ \text { CCOC } & \text { Centretown Citizens Ottawa Corporation } \\ \text { CGAP } & \text { Community Garden Action Plan } \\ \text { CGDF } & \text { Community Garden Development Fund } \\ \text { CGN } & \text { Community Gardening Network } \\ \text { CHRC } & \text { Community Health and Resource Centre } \\ \text { CMA } & \text { Census Metropolitan Area } \\ \text { COG } & \text { Canadian Organic Growers } \\ \text { CULMP } & \text { Capital Urban Lands Master Plan } \\ \text { DEM } & \text { Digital elevation model } \\ \text { GIS } & \text { Geographic information systems } \\ \text { GWR } & \text { Geographically weighted regression } \\ \text { LIM-AT } & \text { After-tax low-income measure } \\ \text { NCC } & \text { National Capital Commission } \\ \text { OCH } & \text { Ottawa Community Housing } \\ \text { OFP } & \text { Ottawa Food Policy Council } \\ \text { Otdinary least squares }\end{array}$




\section{Chapter: Introduction}

\subsection{Preface}

Increasing concerns related to the industrial food system and a desire for greater food security have contributed in recent years to renewed interest in urban agriculture (Newman, 2008; Colasanti et al., 2012). Urban agriculture is often defined simply as the production of food within city limits, but can also refer to related processes, such as food processing, distribution, and disposal. Examples of urban food production are numerous, including private gardens, community and school gardens, edible green roofs, urban farms and orchards, and beekeeping. Aside from the environmental benefits related to shortened supply chains and food distribution networks, and urban green space, urban agriculture also provides a wide array of social, community, and health benefits, and has received support from urban planners (Roehr \& Kunigk, 2009), health professionals (Brown \& Jameton, 2000; Wakefield, Yeudall, Taron, Reynolds, \& Skinner, 2007), food security / food justice advocates (Corrigan, 2011; Milbourne, 2012), and community organizers (Larson, 2006).

Although geographical concepts of place are important to the study of local food systems, the use of spatial analysis for understanding these systems in more detail is not well developed (Kremer \& DeLiberty, 2011). Technologies associated with geographical inquiry, including geographic information systems (GIS) and remote sensing technologies, may have the potential to provide a means of identifying, visualizing and analyzing sociospatial aspects of urban food systems. Several recent studies have found GIS and remote sensing to be useful in mapping existing or potential urban agriculture locations (e.g. McClintock et al., 2013; Taylor \& Lovell, 2012), while others have used GIS to study food 
deserts $^{1}$ and accessibility (e.g. Hubley, 2011; Russell \& Heidkamp, 2011).

Working within critical geography, this research will adopt a mixed-methods approach including GIS, interviews, and policy analysis to inform the understanding of growing food in public spaces in Ottawa. Questions related to social justice will permeate this research, which will explore how accessibility of urban agriculture relates to power, privilege and inequality.

\subsection{Research Problem}

Globally, population growth continues to occur mainly in cities; consequently, urban food production has been positioned as a partial solution to urban sustainability. Urban agriculture can contribute to urban sustainability and community development by easing food security and mobilizing community assets (Weigeldt, 2012). This research seeks to contribute to the understanding of urban agriculture in Ottawa. Existing urban agriculture activities in the city will be mapped and analyzed in relation to socio-economic conditions, and potential sites for urban agriculture expansion will be identified through the creation of a GIS-based land inventory. Based on information gleaned through GIS analysis, interviews with urban agriculture practitioners, and policy analysis, recommendations to promote a more equitable system of urban agriculture in the City of Ottawa will be formulated.

This research seeks to consider how urban agriculture contributes to the local food system in Ottawa, by asking where and in what form urban agriculture currently exists.

\footnotetext{
${ }^{1} \mathrm{~A}$ food desert is defined as an area where healthy and affordable food is difficult to obtain, due to a combination of socio-economic disadvantages and physical distance (Russell \& Heidkamp, 2011).
} 
Having mapped existing urban agriculture practices, a secondary question will ask: how are urban agriculture activities distributed spatially, and how do these patterns relate to local socio-economic conditions?

This research will then examine the potential for increasing the amount of urban agriculture in Ottawa, asking what potential there is for increased food production in public spaces in Ottawa, in terms of land availability and suitability. In order to address that question, it will first be necessary to ask what environmental and social factors determine whether a location would be suitable for urban agriculture.

Finally, this research will turn to the role of public policy in promoting urban agriculture, asking what city policies guide the implementation of urban agriculture in Ottawa, and how these compare with successful policies in other municipalities. Based on primary and secondary research findings, what policy changes could government agencies implement to further promote urban agriculture?

\subsubsection{Research Justification}

While urban agriculture has been the focus of a growing body of research in many disciplines, within the field of urban geography, "an analysis of the specific geography of urban food cultivation and its relations with the politics of space is still a neglected field" (Tornaghi, 2014, p. 3). Further, Tornaghi (2014) argues that providing land for urban food production does not necessarily mean that it is accessible across the spectrum of the population, and calls for a critical geography of urban agriculture that "goes beyond the naive and unproblematic representation of urban food production practices, able to expose the socio-environmental exclusionary dynamics which are embedded into them" (p. 11). 
Through this research, I hope to contribute to this critical geography of urban agriculture, by questioning who has access to public land for food production in Ottawa, and whether there are geographic or social spaces that are lacking in publicly accessible urban agriculture initiatives.

With some recent and notable exceptions that will be discussed in Section 1.6: Literature Review, despite the potential of geospatial technologies to contribute to an understanding of local food systems, limited research has been conducted to date applying these tools to urban agriculture (Kremer \& DeLiberty, 2011). In Ottawa (and elsewhere), community groups and local food advocates have taken advantage of web mapping to visualize and disseminate locations of urban agriculture activities; however, an initiative to identify and map potential locations for urban agriculture in Ottawa has not been undertaken. The utility of such an initiative has been recognized, with a prominent food justice organization, Just Food ${ }^{2}$, recommending (as part of a series of recommendations to promote urban agriculture in Ottawa) that the City of Ottawa develop an inventory of vacant and underutilized lands that may be suitable for urban food production (Just Food, 2014a).

A further justification lies in the policy realm. Elwood (2006a) argues that GIS-based analyses and visualizations can be an effective means of influencing policy making. By mapping the potential for increased food production in Ottawa, and considering existing and potential urban agriculture locations in the context of socio-economic conditions, this research aims to formulate policy recommendations for a more equitable system of urban

2 To be fully transparent, I should note that my co-supervisor, Patricia Ballamingie, serves as volunteer Chair of the Board of Just Food. 
agriculture in the city.

\subsection{Study Area Context}

Ottawa, the capital of Canada and the largest city in eastern Ontario, has a gently undulating topography representative of the St. Lawrence Lowlands Ecoregion. The climate of the area is characterized by cold, snowy winters and warm summers (Ecological Stratification Working Group, 1995). The historic Rideau Canal bisects the city, joining to the Ottawa River, which runs west to east along the northern boundary of the city.

Ottawa is surrounded to the east, south, and west by the National Capital Greenbelt (hereafter referred to as "the Greenbelt"), a land designation created in the 1950 s to protect agricultural lands from urban sprawl, while also securing a reserve land base for future governmental and institutional use (Taylor, Paine, \& Fitzgibbon, 1995). At 20,000 hectares in area, the Greenbelt incorporates a variety of land uses, including agriculture, recreation, natural areas, government research facilities, and the Ottawa Airport (Taylor et al., 1995).

According to the most recent estimates, the population of Ottawa is approximately 943,000 (City of Ottawa, 2014). The city has a relatively high standard of living, with a personal income per capita that, at $\$ 45,477$, is the third highest among major Canadian cities (City of Ottawa, 2014). Major employment sectors include the public service and the high-technology industry. The city of Gatineau, Quebec is located across the Ottawa River from Ottawa, and together, the two cities make up the Ottawa-Gatineau census metropolitan area (CMA). Collectively, the cities of Ottawa and Gatineau are often referred to as "Canada's Capital Region". 
Two factors combine to make the City of Ottawa rather unique among other urban centres. First, in an effort to streamline municipal governance, the City of Ottawa and surrounding areas underwent a major restructuring in 2001, resulting in the amalgamation of twelve local governments. As a result, the current boundaries of the city include not only the urban area of downtown Ottawa, but also surrounding suburban and rural areas. Agriculture is a major land use in rural parts of the city, with over 120,000 hectares of farmland within the city's boundaries (City of Ottawa, 2011).

Second, as a national capital, Ottawa has a large base of federal lands under the management of a Crown corporation, the National Capital Commission (NCC). The NCC, which traces its origins to the Ottawa Improvement Commission of 1899 and the Federal District Commission of 1927, was created by Parliament in 1959 (National Capital Commission, n.d.). Its mandate involves the planning, management, development, and conservation of federal land in the national capital region (National Capital Commission, n.d.). The NCC is a major landowner in the city, and is responsible for the management of the Greenbelt, as well as other land assets. As a result of these two factors, Ottawa differs from many other metropolitan areas in that there are ample natural and agricultural areas within the boundaries of the city.

\subsection{Descriptive Background}

\subsubsection{Food Systems and Urban Agriculture}

A food system can be defined as "an interdependent web of activities that include the production, processing, distribution, consumption, and disposal of food" (Sumner, 2012, p. 327). A distinction can be made between two main types of food systems: the industrial 
(or global) food system, and sustainable food systems. The industrial food system that dominates much of North America today is characterized by large-scale production and complex food distribution networks. While this system allows consumers to enjoy a variety of food products regardless of season, it does have drawbacks. A study of commonly consumed foods in Waterloo, Ontario found that foods travel an average of nearly 4,500 km from their point(s) of origin to their point(s) of consumption (Xuereb, 2005). With over $80 \%$ of Canada's population currently residing in urban areas (Statistics Canada, 2014), and concerns about climate change and food safety, many have begun to question the environmental and social sustainability of such a system.

In contrast to the industrial food system, Sumner (2012) defines a sustainable food system as involving "an interdependent web of activities that build the civil commons [emphasis added] with respect to the production, processing, distribution, consumption, and disposal of food" (p. 330). This distinction emphasizes the importance of sustainable food systems not only in environmental terms, but also to contribute to the greater social good. The terms sustainable food system and alternative food system are often used interchangeably; however, it should be noted that alternative food systems are not inherently more sustainable, as will be discussed in the subsequent chapter.

In order for a food system to be more sustainable, it is necessary to consider issues of equity. Equity in the food system refers to both the material distribution of resources, as well as inclusive and democratic participation in decision-making processes (Allen, 2010). Equity is a key consideration in the concept of food justice, "a broad term that encompasses many practical and conceptual ideas about an ideal food system" (Bedore, 2010, p. 1422). The concept of food justice, which will be discussed in greater detail in Chapter 2, 
envisions a system that is not only environmentally and economically sustainable, but also socially just. The concept also realizes the importance of policy in working towards such a system.

Though not synonymous, in broad terms, a vibrant and just local food system is an important component of a more sustainable food system. A theme of the sustainable food system is the promotion of local food systems, such as farmers' markets, CSAs, and food policy councils (Allen, 2004). The interest in locally-sourced food in recent years has also led to an increase in urban agriculture in many North American cities (Newman, 2008). Proponents of urban agriculture point to its ability to build communities, improve health, contribute to food security, provide environmental services, build skills and create jobs, and reduce fossil fuel use by shortening food distribution networks. However, while local food systems often create opportunities for participation and inclusion, it is important to realize that people within a community have different interests, priorities, and access to power, and ultimately, to avoid romanticizing the movement towards local food (Allen, 2010).

\subsubsection{Urban Agriculture Initiatives in Ottawa}

In parallel with other North American cities, urban agriculture has increased in Ottawa in recent years, gaining support from governments, non-profit organizations, and citizens. Governmental support of local food systems in Ottawa is high (Ballamingie \& Walker, 2013), and several local non-profit organizations work to promote urban agriculture in the city, notably Just Food and the recently established Ottawa Food Policy Council (OFPC). Just Food is a community-based, non-profit organization working towards more vibrant, 
just and sustainable food and farming systems in Ottawa (Just Food, 2014b). The OFPC was founded in 2013, with a mission to work towards a food system that is socially, environmentally, and economically viable (OFPC, 2013). Additionally, a variety of urban agriculture initiatives are present in the city. Several rooftop gardens exist on community housing developments, and over thirty local elementary and secondary schools run school gardens through a partnership with the Ottawa Chapter of Canadian Organic Growers (COG). Another innovative form of urban agriculture involves 'gleaning' edible products from food-bearing city trees on city property. Hidden Harvest Ottawa is a social enterprise that organizes volunteers to harvest urban trees, sharing produce with the nearest food agencies, harvesters, and homeowners.

One of the most common means of growing food for individual consumption in publicly accessible areas is in the form of community gardening. Community gardens exist in a variety of forms, but tend to be organized and managed by a group of community members, and receive financial and logistical support from the City of Ottawa, food justice organizations, or community organizations. Community gardens often consist of plots that are individually maintained by garden members, although some are maintained and shared collectively. In Ottawa, there are over forty community gardens, with new gardens created each year. In fact, Mayor Jim Watson recently announced a plan to establish twenty new community gardens in the city over the next four years (Willing, 2014). Community gardens can be found in both urban and suburban areas, and may be located on the grounds of public parks, churches, community health centres, schools, and community housing properties. 
The City of Ottawa supports the development of community gardens through the Community Garden Action Plan (CGAP), which was approved by Ottawa City Council in 2004. Through the CGAP, the City provides annual funding for the development of new gardens and the enhancement of existing gardens, and assists in the identification of space for new community gardens. The City also allows community gardens to be included in their group liability coverage, and allows gardens to have water access where infrastructure currently exists.

The City works closely with Just Food to administer the Community Gardening Network (CGN), which is an information and resource-sharing network that supports the sustainable development of community gardens within the City (Just Food, 2014b). The CGN helps new community gardens become established each year, and facilitates information exchange between organizations and individuals involved with community gardening. They help to build skills and capacity through gardening workshops, and also work with both private and public landowners to help secure access to land for gardening.

Within the boundaries of the City of Ottawa, there are also three allotment gardens: the Kilborn Allotment Garden, Nepean Allotment Gardens, and Gloucester Allotment Gardens. ${ }^{3}$ Allotment gardens differ from community gardens in that both the overall garden area and the individual plots tend to be larger in size, enabling a more significant contribution to a gardener's personal food supply. Due to their size, allotment gardens are generally not located in the urban core where space is limited; rather, they tend to be located in peri-urban areas, often requiring gardeners to travel some distance between home and

\footnotetext{
${ }^{3}$ Only two of these gardens (Kilborn and Nepean) are within the boundaries of the study area for
} this research. 
garden. A further distinction is that allotment gardens are not necessarily organized by members of the local community. In Ottawa, one (the Kilborn Allotment Garden) is cityrun, while the other two are independently organized by their respective associations.

The forms of urban agriculture mentioned thus far are important components of the local food movement in Ottawa; however, there are other noteworthy initiatives that lie beyond the scope of this research. A brief mention of these follows, in order to provide context for the broader food system within which urban agriculture in Ottawa is situated.

Ottawa is home to a growing number of community-supported agriculture (CSA) ${ }^{4}$ operations and farmers' markets, with 2015 marking the opening of the first year-round farmers' market in the city, located in the Aberdeen Pavilion at Lansdowne Park. While these initiatives serve an important role in promoting local food and connecting consumers and producers, they do not necessarily serve the population as a whole, as studies have shown that participation in CSA programs and farmers' markets tends to be associated with higher than average income levels (Hinrichs \& Kremer, 2002; Kremer \& DeLiberty, 2011). To help fill this gap, a triad of "Good Food" programs exists in Ottawa. The Ottawa Good Food Box is a community-based initiative that brings individuals together to buy fresh (often local) produce at wholesale prices. Deliveries are made monthly, and boxes can be picked up at dozens of distribution sites throughout the city. A related program, the Good Food Market, was launched in 2012, and acts as a 'pop-up' or temporary market where people can buy fresh, affordable produce in areas where access to food is limited. In 2014,

${ }^{4}$ A CSA represents a contract between consumers and farmers. Typically, members purchase a share in the CSA at the beginning of the growing season, and receive a weekly or bi-weekly delivery of farm products as they become available throughout the season. The up-front provision of funds allows farmers to better plan their operating budget. 
the most recent program to address accessibility to healthy food was launched. The 'MarketMobile' is a city bus that travels to food insecure communities, selling fresh, healthy produce at affordable prices.

In addition to their work supporting community gardens, Just Food is actively involved in supporting and promoting local producers, and providing access to resources and training for start-up farmers in the Ottawa area. Just Food also operates a farm located on NCC property in the Greenbelt, which hosts a start-up farmer training program, and also supports the farming endeavours of other non-profit community groups and social enterprises.

Another innovative program that helps connect people and food is the Ottawa Food Bank's Community Harvest Program. Through this program, the Ottawa Food Bank grows their own food on donated farmland, and collects donated produce from farmers and gardeners. They also attain fresh produce by gleaning crops from local farms that are not economically viable for farmers to harvest. Together, these initiatives yielded over 100,000 pounds of produce to support the Food Bank's operations in 2013 (Ottawa Food Bank, n.d.).

While the initiatives mentioned in this section are not exhaustive, they provide context for this research and help to illustrate that there are many intertwined components that contribute to a sustainable local food system. The following section will better define the specific area of focus of this research.

\subsection{Research Parameters}

As discussed above, the term urban agriculture encompasses a wide range of activities 
related to growing, processing, and distributing food. This research will focus on growing food for individual or collective benefit on public land in urban spaces. For the purposes of this research, public land includes land owned by government bodies (mainly municipal and federal, in this context), as well as land that could be considered 'semi-public'. For instance, while the grounds of institutions such as schools, hospitals, and churches may not be publically owned, the public has some degree of access to these spaces. Examples of growing food on public land include community gardens in municipal parks, gathering fruit and nuts from food-bearing trees along city streets, and school or institutional gardens. It is important to note that while these forms of urban agriculture occur in public or semipublic spaces, it does not necessarily mean that they are equally accessible to the general public. Although a community garden, for example, may be located in a public park, plots are generally allocated to individual garden members (although they may have broader benefits to the community as a whole).

As discussed earlier in this chapter, the boundaries of the City of Ottawa include a large area of rural land outside of the urban centre. This research will focus on the region within the boundaries of the National Capital Greenbelt (see Figure 1), since this is the area that is most densely populated. Further, since the keeping of livestock and fowl is prohibited in urban and suburban areas not zoned for agriculture in Ottawa, this research will focus on (allowable) horticultural activities.

A further research parameter relates to interview participants. For the purposes of this research, participants will be limited to urban agriculture practitioners, including municipal employees and representatives of non-profit and community-based organizations. While there are many other actors involved in food production in public spaces, notably gardeners 
and the general public, interviews for this research seek to gain insight on urban agriculture from an urban sustainability, planning and community development perspective.

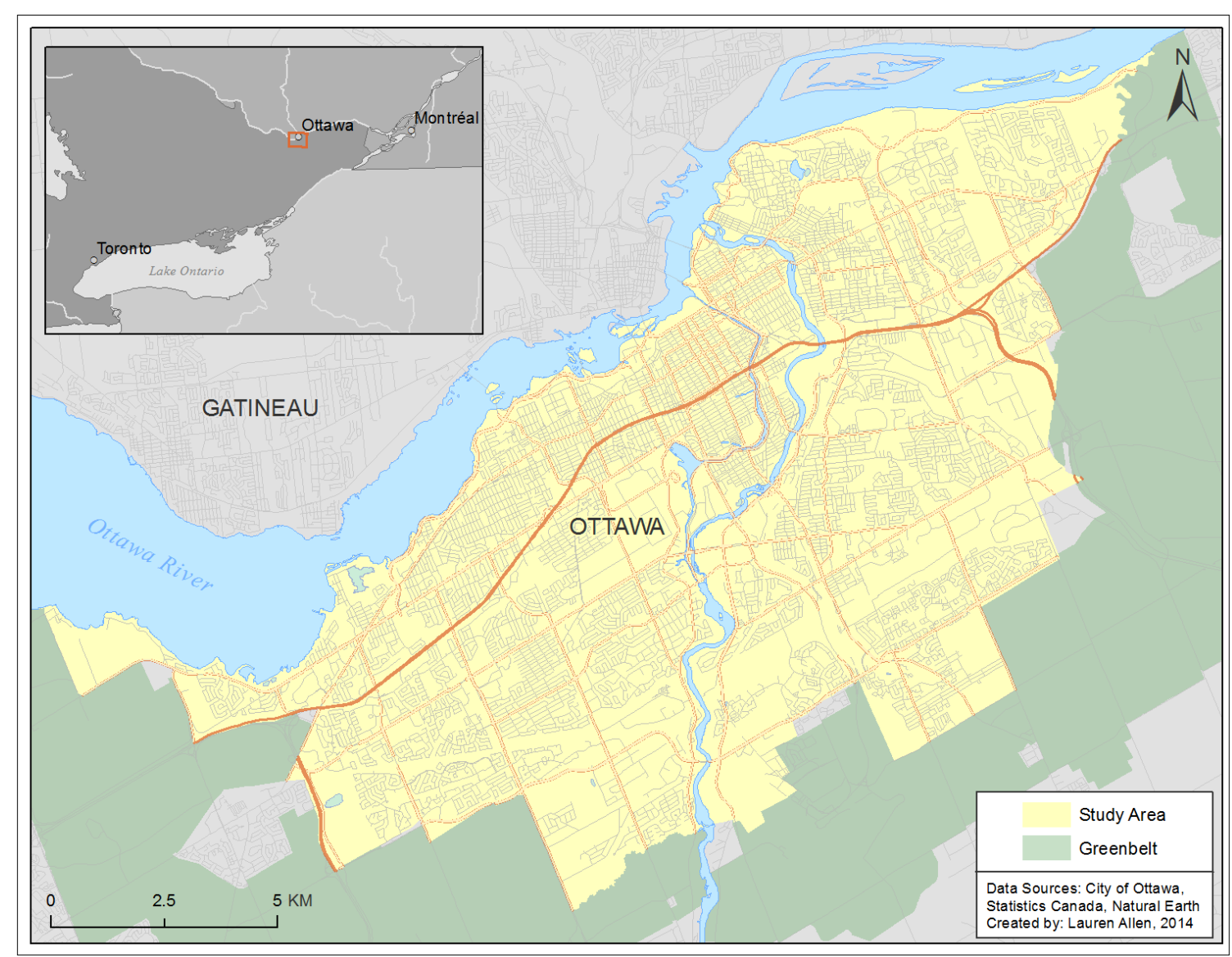

Figure 1 - Map of study area

\subsection{Literature Review}

There are two main bodies of literature that apply to this research. The first relates to the role that urban agriculture can play in promoting sustainable cities, while the second considers the use of geospatial analysis in studying urban agriculture. Each of these will be considered in turn. 


\subsubsection{Urban Agriculture and Sustainability}

Since urban agriculture is a multidisciplinary topic, this review ${ }^{5}$ will draw on literature from several fields, including geography, planning, public health, leisure, and ecological agriculture, among others, with a particular focus on geographical concepts relating to space and place. In recent years, a substantial amount of research has explored the potential contribution of urban agriculture towards the goal of more sustainable cities. Due to the myriad of benefits attributed to urban agriculture, these practices are often positioned as contributing to each of the three dimensions associated with sustainability: environmental, social, and economic. However, a more recent line of inquiry takes a more critical look at the reasons behind food production in cities, arguing that by filling a gap left by receding public support for social services, urban agriculture, and in particular, community gardens, "can serve to entrench neoliberalism" (Jermé \& Wakefield, 2013, p. 309) - if only inadvertently.

Some of the earliest work linking urban agriculture with sustainability focused on the environmental benefits of the practice. Smit and Nasr (1992) argue that urban agriculture can "convert urban wastes into resources, put vacant and under-utilized areas into productive use, and conserve natural resources outside cities while improving the environment for urban living" (p. 141). They point to the ability of urban agriculture to facilitate nutrient cycling and divert waste materials from landfills through the reuse of organic urban waste. Further, it has been argued that the production of food within a city

\footnotetext{
${ }^{5}$ This review of urban agriculture and sustainability will focus on research pertaining to the practice in the Global North; however, it should be noted that there is a substantial body of work devoted to urban agriculture and its potential to improve local food supplies, health conditions, and economies in the Global South. For a review of urban agriculture in the developing world, see Orsini et al. (2013).
} 
can reduce the distance that food travels, helping to save energy related to transportation and packaging (Lovell, 2010). However, some theorists have contested the notion of 'food miles' as being too simplistic a measure of environmental impact (Mok et al., 2014), since uncertainty exists regarding the carbon footprint of urban agriculture.

The public health and food security benefits of urban agriculture are also advocated by a number of authors. Community gardens can help improve fresh produce intake among gardeners by addressing impediments to healthy eating, such as access, cost, cultural preferences, and transportation (Alaimo, Packnett, Miles, \& Kruger, 2006). Consequently, Vitiello (2008) argues that household and community gardens "remain critical venues for individual and collective actions that increase local food supply" (p. 274). A study of community gardens in low-income Toronto neighbourhoods found that gardeners attribute various health benefits to gardening, including improved access to food, improved nutrition and mental health, and increased physical activity (Wakefield et al., 2007). Brown and Jameton (2000) concur that urban agriculture can provide physical and therapeutic health benefits, and argue for stronger policies in support of urban gardening as a way to improve public health.

Another area of research focuses on the social and community development benefits of urban agriculture. Several studies have considered community gardens as places where social capital is produced, accessed and used. By bringing together people who share a common purpose and creating a physical meeting space where people from different backgrounds can interact, community gardens can build trust and contribute to community building (Glover, 2004; Firth, Maye, \& Pearson, 2011). Glover (2004) is careful to point out, however, that social capital is not inherently beneficial; depending on 
the position that an individual holds in a social network, he or she may not have access to the same degree of social capital as others. In their interviews with community gardeners, Wakefield et al. (2007) found that gardens provided places:

[...] where communication with people from other cultures could begin, using food and shared experience as a starting point for understanding. This was seen to help to bring people out of isolation, and served as a starting point for broader discussions of community issues (p. 100).

Several studies have analyzed urban agriculture, and particularly the phenomenon of community gardens, through the lens of environmental justice. Ferris, Norman, and Sempik (2001) argue that using public urban spaces for community gardens is closely linked to environmental justice and equity, while Milbourne (2012) positions community gardens as a way to address social and environmental injustices and inequalities at the local scale through the everyday practice of gardening. However, community gardens can also exacerbate spaces of environmental injustice, pointing to the need to use caution when developing community garden policies at the municipal level (Jermé \& Wakefield, 2013).

Although much of the urban agriculture literature focuses on the benefits of the practice, another line of inquiry argues that urban gardens are spaces that arose as a result of "roll-back" neoliberalism, with individuals and non-profit organizations filling a need left by receding public support (Pudup, 2008). McClintock (2014) agrees that by addressing issues such as food production and nutrition that have traditionally been the domain of the state, urban agriculture "ultimately fills in gaps left by the rolling back of the social safety net" (p. 148); however, he argues that in order to move forward and realize the full potential of urban agriculture, scholars and activists must come to terms with urban agriculture's contradictions by recognizing that "urban agriculture is not simply radical or 
neoliberal, but both, operating at multiple scales" (p. 165). In their study of communitybased food initiatives in eastern Ontario, Andrée, Ballamingie, and Sinclair-Waters (2014) reach a similar conclusion, arguing that while a neoliberal lens can be productively applied to understand alternative food practices, care must be taken to ensure this critique does not "create closures" (p. 17) against progressive and transformative directions in the food movement.

A key concern for urban agriculture practitioners and policy-makers is access to land. While some scholars contend that a lack of land security and tenure is detrimental to the longevity of urban agriculture, others argue that urban agriculture is best suited as an interim use for vacant land, particularly where property values are deflated (Smit \& Nasr, 1992; Mougeot, 2006). Mougeot (2006) argues that in order to take full advantage of the benefits of urban agriculture, municipal governments need to ask:

How much land is there really, and where is it?... in most cities there is far more land available than is generally recognized by city managers and elected officials. There are vacant lots, public lands around buildings such as schools and hospitals, undeveloped or abandoned sites, and so on. Perhaps the first lesson, then, is the importance of taking stock - creating an inventory of all the land in the city that could be used for some form of production, whether permanently or temporarily ( $\mathrm{p}$. 50-51).

Tornaghi (2014) asserts that space for growing food is not always equally accessible across the whole population; she contends that urban geographers must ask: "Is access to urban land for food-growing guaranteed across the spectrum of society?" (p. 3). GIS is wellsuited to begin to address both this question, and the question of land availability.

\subsubsection{GIS and Urban Agriculture}

A geographic information system can be defined as a "computer system for capturing, 
storing, querying, analyzing, and displaying geospatial data" (Chang, 2010). As a result of its ability to process and integrate large amounts of data and its utility in creating maps and visualizations, GIS has emerged as an important and useful tool in geographical research in recent decades. Despite the importance of geography in studying local food systems, GIS has traditionally had relatively little use in this sphere (Kremer \& DeLiberty, 2011). In recent years, however, scholars have begun to use GIS and related technologies to develop a better understanding of local food systems. Perhaps the most prevalent use of GIS in this context has been in the analysis of 'food deserts' and to answer questions related to food access (see for example, Hubley, 2011; Russell \& Heidkamp, 2011). Other lines of inquiry include the use of GIS to map local food production patterns and distribution (Ostry \& Morrison, 2008), and to better understand existing and potential urban agriculture initiatives. This review will focus on the latter application.

Several recent studies have utilized GIS to map locations of urban food production and to estimate potential production. While much of this research focuses on public spaces of food production, some studies have considered food production in private spaces, such as residential yards. One of the earliest studies using GIS to map the potential for urban food production reported on results of land inventories for urban agriculture on city-owned land in Portland, Oregon and Vancouver, British Columbia, concluding that land inventories are one tool that can help plan for urban agriculture (Mendes, Balmer, Kaethler, \& Rhoads, 2008). A subsequent study investigated the vegetable production potential of commercial agriculture opportunities in the city of Toronto, comparing potential production estimates to vegetable consumption estimates (MacRae et al., 2010). Colasanti and Hamm (2010) compared potential food production on publically-owned, vacant 
properties in Detroit to consumption needs, concluding that in post-industrial cities with large amounts of vacant land, urban agriculture can make a significant contribution to fresh produce needs. Similarly, a GIS-based study of the potential contribution of urban agriculture in Oakland, California found that urban agriculture could contribute up to $7.3 \%$ of vegetables based on current consumption levels (McClintock, Cooper \& Khandeshi, 2013). The authors concede, however, that "ultimately, the delineation of polygons [in the land inventory approach] is only a preliminary step in the long process of mapping the agricultural potential of a city... the real work in planning for urban agriculture lies in identifying and negotiating the varied interests of multiple stakeholders" (p. 55).

The majority of studies looking at the potential for food production in urban areas have a local focus. However, a recent global study using satellite imagery to estimate productive potential concludes that while urban agriculture would not be adequate as a primary source of food in the urban areas of most countries due to population density and a lack of physical space, it may be able to make a more sizable contribution to food supplies in smaller urban areas where land is at less of a premium (Martezello, 2014). Therefore, urban agriculture policies should target smaller urban areas that have more physical space available (Martezello, 2014), a conclusion that may apply to Ottawa, with its relatively small population and abundant green space.

In addition to the scholarly literature, a number of North American municipalities have also undertaken land inventories to identify potential locations for urban agriculture, including Calgary, Alberta (Calgary Food Committee, 2012) and Seattle, Washington (Horst, 2008). Each of the scholarly and municipal approaches differs in scope; for instance, whether public or private spaces are considered, and whether food production is 
for commercial or individual purposes. In some instances, particularly in cities with large amounts of vacant land, urban agriculture is conceived as fulfilling a sole land use; in others, it is one activity in a multi-functional space. Further, there are variations in the methodological GIS approach of each study, which provide guidance for this research. These methodological differences often derive from the particularities of the geographical location in question and the scope of the research, and reflect the geospatial data available.

While the use of land inventories to plan for urban agriculture seems to be gaining momentum, Napawan (2014) identifies potential shortcomings of this approach, arguing that "the 'available land' method does not provide the most effective means of meeting both city and community goals through urban agriculture" (p. 2). Using a case study in San Francisco, he argues that spatial criteria and land availability are not the only considerations; rather, stakeholder capacity and community involvement are equally important. While not denouncing the land inventory approach, Napawan (2014) argues for the recognition of a greater range of urban agriculture typologies that "might alter the criteria utilized for land audit and site analysis, thereby identifying additional or alternative sites for consideration" (p. 16); in particular, he advocates for the inclusion of edible landscapes and streetscapes or other multi-functional uses.

While the majority of work in this area has considered the potential for urban agriculture, a smaller body of work also considers the socio-spatial implications of existing urban agriculture initiatives. In addition to outlining a procedure combining GIS and remote sensing to identify land available for growing food in residential Philadelphia, Pennsylvania yards, Kremer and DeLiberty (2011) also map practices related to the local food system of the city, such as community gardens and farmers' markets. In comparing 
existing practices to socio-economic data, they find that the "socio-spatial organization of different components in the city supports the notion that the local food movement targets middle and high income populations... personal food production in community gardens is filling the [local food] gap in low-income, inner city neighbourhoods" (p. 1260). Similarly, Smith, Greene, \& Silbernagel (2013), in their study of community food production in Madison, Wisconsin, found an association between historical community garden placement and areas with low household incomes; however, they also noted a recent trend towards garden placement in neighbourhoods with above average household income.

A study conducted by Taylor and Lovell (2012) in Chicago used high-resolution aerial photography to verify whether reported sites of urban agriculture actually produced food, and to identify existing sites of food production at a fine scale, in both public and private spaces. They argue that:

Developing coherent and effective urban agriculture policies and programs at the city level demands as a first step the accurate mapping of both public and private forms of urban agriculture, including food production at the parcel level... Knowing where urban agriculture is currently occurring and in what forms can help planners, government officials, and advocates identify gaps in the spatial distribution of existing sites - where urban agriculture is not occurring but possibly should be because of poverty, lack of food access, or public health problems.... (p. $58)$.

\subsection{Conclusion}

Urban agriculture is often advocated as a partial solution to making cities more sustainable, contributing positively to the three pillars of sustainability: environmental, economic, and social. However, within urban geography, there has been a call to consider urban agriculture through a more critical lens (Tornaghi, 2014).

In Ottawa, a variety of organizations and initiatives seek to create a more 
sustainable local food system. The production of food in urban spaces is one response to the growing local food movement. This research aims to analyze the socio-spatial implications of existing urban agriculture practices in Ottawa, and map locations that may be suitable for further urban food production. Using a mixed-methods approach, I hope to provide policy recommendations for a more equitable system of urban agriculture in Ottawa.

\subsection{Organization of Thesis}

This chapter has introduced the objectives of the thesis and provided a brief contextual background, while providing a review of the relevant urban agriculture literature to help situate this research within a larger body of work. Chapter 2 outlines the key analytical concepts that inform the remainder of this thesis, including social capital, food justice, and the right to the city. Chapter 3 delineates the methodological framework and provides an account of the methods used. Critical GIS and feminism will be drawn on while employing a mixed-methods approach, combining GIS, interviews, and policy analysis. Chapters 4 and 5 present the results of interviews and spatial analysis, and resulting policy implications for a more equitable system of urban agriculture in Ottawa, respectively. Finally, Chapter 6 summarizes the key findings of this research, while suggesting possible directions for future research, identifying constraints and limitations, and concluding with a reflection on the use of a mixed-methods approach. 


\section{Chapter: Conceptual Framework}

\subsection{Introduction}

This chapter will introduce the three analytical concepts that my research draws on: food justice, social capital, and the right to the city. For each, I begin by providing an overview of the concept, and then examine links between each concept and the study of urban agriculture. I conclude this chapter by discussing possible points of connection between each of these frameworks, including the use of urban space based on its social use value, collective action for the public good, a vision of urban citizens as producers of food and space, and an acknowledgement of power relationships.

\subsection{Food Justice}

A multitude of environmental, social, and economic complexities are intertwined with food and food systems. The concept of food justice, which strives for more equitable food systems and community change, brings together a variety of values and social movements related to food (Gottlieb \& Joshi, 2010). These diverse movements include environmental and social justice, democracy, an ethics of care, community development, engaged citizenry, workers' rights, access to fresh and affordable food, and sustainable land use (Wekerle, 2004; Levkoe, 2006; Gottlieb \& Joshi, 2010). Since food justice is such a broad term, it is difficult to define succinctly; however, Gottlieb and Joshi (2010) argue that food justice is characterized "as ensuring that the benefits and risks of where, what, and how food is grown and produced, transported and distributed, and accessed and eaten are shared fairly" (p. 6).

In addition to promoting justice for those involved in the food system, from consumers 
and communities to producers and processors, the concept of food justice extends beyond people, to include ecological considerations, intersecting with sustainable agroecology and environmental justice movements. Thus, another key tenet of food justice is "respect for the systems that support how and where the food is grown - an ethic of place regarding the land, the air, the water, the plants, the animals, and the environment" (Gottlieb \& Joshi, 2010, p. 223).

At the heart of the food justice movement is a belief that the dominant industrial food system promotes injustice and inequality, as evidenced by the large proportion of the global population that suffers from a range of food-related issues, including undernourishment, difficulty accessing nutritious and affordable food, obesity, and other health problems. These health problems often result from the dominant market-driven food system, which prioritizes the maximization of profits, rather than social and ecological considerations. Other injustices associated with the industrial food system include the poor treatment and exploitation of workers (particularly farm labourers), and environmental degradation associated with the input and transportation demands of large-scale agriculture. These issues have led proponents within the food justice movement to struggle towards a more just and equitable food system. In part, the food justice movement strives to do this by recapturing a connection with the land (Gottlieb \& Joshi, 2010), and by identifying eaters, producers, and others involved in the food system "primarily as citizens as opposed to consumers" (Levkoe, 2006, p. 90).

Food justice originated with emergency food responses to the economic recession of the 1980s, and resulting support for the concept of food security (Wekerle, 2004). Food security is the recognition that all people, at all times, have a right to access culturally 
acceptable and nutritionally adequate food that has been produced in a way that is environmentally and socially sustainable (Levkoe, 2006). Community food security, a closely-related concept, relies on principles of community self-reliance and empowerment, a focus on meeting the needs of low-income people, support for local agriculture, and a systems approach to food issues that includes attention to social justice and ecological concerns (Allen, 2004). The more recent food justice discourse can be seen as an extension of the concept of food security.

An important component of the food justice movement is the recognition of the necessity of addressing the underlying causes of food insecurity, predominantly poverty. As a result, food justice advocates realize the importance of engaging with policy-makers to work towards a more just food system, and to form connections and partnerships between the state, non-governmental organizations, and individuals.

\subsubsection{Food Justice and Scale}

Food justice is closely linked to considerations of scale. As a result of the problems associated with the industrial food system, local alternatives have emerged as a form of resistance that lessen the dependence of local economies on the global food system. These alternatives are often positioned as being inherently more environmentally sustainable, democratic, and socially just. However, as food studies scholars have argued, 'localism' does not produce the changes that food justice advocates hope to see in the food system by virtue of it being local alone (Allen, 2010; Born \& Purcell, 2006; DuPuis \& Goodman, 2005). Drawing on the theory that scale is socially constructed by social actors, Born and Purcell (2006) caution against falling victim to the 'local trap' and argue that outcomes are 
realized not by the scale of initiatives, but rather by the content of the agenda. That is, if a program pursues a goal of social justice, that agenda is more important than the scale at which the initiative operates. Similarly, DuPuis and Goodman (2005) warn that since local initiatives can be driven by the interests of a narrow, elite group, local food initiatives are just as likely to be affected by politics and power relationships as initiatives that operate at other scales. Although localism can "be problematic and contradictory" (p. 362), they contend that it can still be a powerful force against globalization and capitalism, and encourage food scholars to question what they refer to as 'unreflexive localism', or the assumption that local is inherently good.

Levkoe (2011) builds on the idea of 'reflexive localization', and argues that solidarities in food systems must be established not only within a locale, but also between localities. This argument points to another intersection of food justice and scale - that of solidarity and an obligation to work towards justice for all those in the food system, regardless of geographical proximity. As Hinrichs and Allen (2008) have argued, selective patronage campaigns such as 'Buy Local' campaigns have the potential to exclude disadvantaged groups in other localities. While these campaigns may be beneficial to local food workers, they ignore the vulnerabilities of workers elsewhere in the world (Hinrichs \& Allen, 2008). This belief in an ethics of care that spans across geographical distances leads Allen (2004) to the conclusion that "working at the local level is important, but insufficient to developing environmentally sound and socially just agrifood systems" (p. 179). Andrée et al. (2014) found that many people working in the local food movement in eastern Ontario were in fact motivated by care for others - not only for their families, but also their communities and future generations. This finding led them to postulate that "care 
may even be the platform from which to cultivate a radical politics of food justice that challenges neoliberalisation" by placing emphasis on cooperation rather than individualism (Andrée et al., 2014, p. 14).

The notion of an ethics of care is productive when considering food justice and scale. Reflexive localization, with a concern for the well-being of local communities, also concerns itself with the well-being of those elsewhere, thereby contributing to environmentally and socially just food systems at a broader scale. In her call for a "global sense of place" Massey (1994) argues that the local cannot be understood without consideration of global forces that helped to shape that place. DuPuis and Goodman (2005) agree that the local and the global should not be considered in isolation; local food initiatives are not merely a form of resistance against globalizing forces, but rather, are "a mutually constitutive, imperfect, political process in which the local and the global make each other on an everyday basis" (p. 369).

\subsubsection{Food Justice and Urban Agriculture}

As mentioned in the previous section, food justice often manifests as small-scale, local alternatives to the dominant food system. In urban areas, these alternative practices often take the form of practices such as farmers' markets, community gardens, and CSAs. The spatial distribution of these practices reveals interesting patterns when considered through the lens of food justice. A number of studies argue that farmers' markets and CSAs are supported by those with a higher socio-economic status, while community gardens are more frequently located in neighbourhoods with a lower socio-economic status (Hinrichs \& Kremer, 2008; Kremer \& DeLiberty, 2011). In their study of a CSA project in the Midwestern United States, Hinrichs and Kremer (2008) found that CSA participants tended 
to be educated, professional, higher-income citizens. Conversely, a study of urban agriculture in Philadelphia found that $50 \%$ of community gardens in the city were located in the lowest-income neighbourhoods (Kremer \& DeLiberty, 2011). A review of food studies literature revealed no similar studies regarding the socio-spatial distribution of alternative food practices in Canadian cities; however, a report by Agriculture and AgriFood Canada states that recent immigrants make up a significant proportion of community gardeners in Canada (Agriculture and Agri-Food Canada, 2007).

The cultivation of food in the city has materialized as a form of food justice and an alternative to inequities in the dominant food system (Gottlieb \& Joshi, 2010). Enabling citizens to grow food in urban areas provides a means for people to reconnect with their food, which can contribute to the food justice principles of empowerment, self-sufficiency, and the realization of citizens as producers of food. However, in order for food justice to be realized, alternatives for growing and producing food must be available across the spectrum of the population, since access to food is "at the heart of food justice advocacy" (Gottlieb \& Joshi, 2010, p. 176). Growing food in public spaces is also closely related to the second analytical framework that this research draws on: the 'right to the city'.

\subsection{The Right to the City}

Henri Lefebvre's concept of the 'right to the city' refers to the rights of urban inhabitants to make decisions about the places they live, based on the social use value of property. In the view of David Harvey, "the right to the city is far more than the individual liberty to access urban resources: it is a right to change ourselves by changing the city" (2008, p. 23). This discourse can be best understood as a common right, since it depends on collective action and negotiation to reshape what are perceived as acceptable activities within the 
urban environment (Harvey, 2008). It also conceives of identity and place as iterative, performative and mutually constituted.

In the view of Lefebvre, the right to the city is a struggle for a radically democratized city; a struggle that is inherently spatial, since it deals with the re-appropriation of urban space - space that is perceived as private property by the elite groups who manage and control it (Purcell \& Tyman, 2014). Within the dominant economic and political systems, the use of urban space is determined primarily by market values. A right to the city framework would enable citizens to produce and manage urban space according, instead, to its social use value. In this way, the right to the city is about a society where citizens are active participants in the production of urban space, rather than simply consumers or bystanders (Purcell \& Tyman, 2014). Harvey (2008) argues that this "right to make and remake our cities is one of the most precious yet most neglected of human rights" (p. 23), and one that is increasingly falling into the hands of a narrow group of economic and political élites.

In considering the right to the city, various scholars have posed the questions: Whose right is it? And to what city (Harvey, 2003; Marcuse, 2009)? Lefebvre defined the right to the city as both "a cry and a demand" (as cited in Marcuse, 2009, p. 189). Marcuse (2009) contends that the call for the right to the city arises from different segments of the population; the demand comes from those whose immediate needs are unfulfilled, while the cry comes from those whose hopes or aspirations are unfulfilled.

While the right to the city involves citizens remaking space according to their own needs and values, it should not be perceived as an idyllic vision of a utopian city. Due to contesting visions of how space should be used, it necessarily involves negotiation of 
differences, a process that is inevitably subject to the exercise of power. As Marx remarked, "between equal rights, force decides" (as cited in Harvey, 2003, p. 939). These negotiations of difference have potential to be productive, however, and can be seen as a way of renewing urban democracy, resulting in "heterogeneous urban geographies...all of which nevertheless share in common a city produced to meet the complex and multiple needs of urban inhabitants" (Purcell, 2002, p. 106).

\subsubsection{The Right to the City and Urban Agriculture}

The right to the city offers a productive lens for understanding the use of urban space in general, and the potential of urban agriculture in particular. Urban agriculture can be viewed as a form of resistance to the dominant political and economic systems that define how urban land is used (Purcell \& Tyman, 2014). When decisions are made based solely on market value, it is difficult for urban agriculture to compete with other forms of land use, since "the priorities of the state have been greatly reoriented away from the needs of citizens, inhabitants, and users and toward the needs of the market" (Purcell \& Tyman, 2014). Producing food in public urban spaces raises questions "about who has the right of access to space... and what price society is willing to pay to maintain the spaces" (Schmelzkopf, 1995, p. 380). As McClintock (2014) argues:

Ultimately, new forms of value must be ascribed to urban agriculture at the policy level in order for it to join other urban land use priorities... Only if the production of fresh and healthy food is viewed as a public good - and access to it a right - rather than simply a commodity made available via the logic of the market, will cities set aside spaces for agriculture in dense urban areas. In short, use value must be privileged over exchange value if urban agriculture is to scale up in any significant way. (p. 166)

This discussion of use value versus exchange value speaks to the core of urban agriculture as an expression of the right to the city. While the use of urban space is often determined 
based on a property's exchange value on the market, privileging use value would consider non-economic benefits of urban agriculture, such as opportunities for food production, social interaction, and community development (McClintock, 2014). The demand to grow food in urban areas arises from a desire to use and produce space in ways that contribute to urban life socially and environmentally, rather than based on the market value of that space. Producing food and reclaiming space within urban areas can provide urban residents with a greater degree of self-sufficiency, by allowing citizens to break "dependencies on systems of charity and the market economy" (Levkoe, 2006, p. 90). In addition to providing sustenance, it can also fulfill social needs, allowing urban residents opportunities to develop and nurture relationships with fellow community members and to partake in an activity that provides recreational and health benefits. If, as Marcuse (2009) argues, the right to the city is a demand and a cry arising from those whose needs and hopes are unfulfilled, urban agriculture can be perceived of as a use of urban space that aligns with the needs of those whose food requirements are unmet, as well as the hopes of those whose desire for a more tangible connection to either their food or their community remain unfulfilled.

The struggle to create and maintain spaces for urban agriculture also highlights the need to negotiate different visions of how urban space should be used. Since shared open spaces are highly valued among residents, the way that space is used in these areas is subject to contestation. As Howard noted in the late $19^{\text {th }}$ century, "there are few objects which people guard so jealously as their parks and open spaces" (Howard, 1898/1965, p. 140). It is not only questions of how shared spaces should be used that must be navigated, but also broader questions of what sorts of activities are appropriate in a city. As Colasanti et al. 
(2012) argue, varied perceptions of urban agriculture exist among urban residents; while some see the activity as an acceptable and beneficial land use for vacant or idle land, others see it as out of place or even regressive in an urban environment. These multiple perspectives provide a reminder of the need to negotiate complex differences.

While urban agriculture tends to be associated with the realm of civil society, since it is characteristically citizen-led and community-organized (factors that can lead to selfdetermination and community empowerment (Hodgson, Campbell, \& Bailkey, 2011)), it should be noted that the right to the city as embodied through urban agriculture is not entirely beyond the realm of the state. Governments at various levels have the ability to either facilitate or hinder urban agriculture through policy measures; however, although government support is important, ultimately, communities should produce and manage gardens for themselves in the long term, eventually minimizing the role of the state (Purcell \& Tyman, 2014).

\subsection{Social Capital}

The third analytical thread that I will draw on is that of social capital. Social capital can be defined as "features of social organization such as networks, norms, and social trust that facilitate coordination and cooperation for mutual benefit" (Putnam, 1995, p. 67). Social capital does not refer to the information and resources possessed by an individual, but rather, "is located within the social structures, the space between people" (Onyx, 2005, p. 3). While the definition of social capital is difficult to capture concisely, it can be thought of as encompassing a variety of social norms such as trust, reciprocity, solidarity, social relationships, a sense of place, and civic engagement. 
The formation and mobilization of social capital is argued to be imperative to reconciling the natural, social, and economic aspects of sustainable development (Dale, 2005). Indeed, Dale (2005) argues that due to the magnitude of the changes needed to move toward sustainability, social capital is critical to the collective mobilization of communities worldwide. For this reason, it is important that governments determine what actions they can take to foster the development of social capital (Dale, 2005).

While social capital has the potential to facilitate positive social change, it is not inherently beneficial. Depending on their position in society, different groups or individuals may have access to different amounts of social capital (Onyx, 2005). Further, it is important to consider the distinction between two types of social capital: 'bonding' and 'bridging'. Bonding social capital arises from long-term personal connections, and while it has the potential to build positive relationships based on feelings of reciprocity and trust, it may also reinforce exclusivity and homogeneity, and be resistant to outside ideas (Newman \& Dale, 2005). On the contrary, bridging social capital, which involves weak connections to outside networks, may be critical in accessing outside resources or ideas, thus affecting broader social change (Newman \& Dale, 2005). This distinction between bonding and bridging social capital could also be understood in terms of benefits to the individual or localized community, versus more widespread benefits at a larger scale. In order for sustainable community development to be realized, a combination of bonding and bridging social capital is desirable (Newman \& Dale, 2005).

A key concept of social capital involves its potential for collective action (Onyx, 2005). While individuals may gain access to resources and information as a result of the social capital they possess, the power of social capital lies in its broader potential to contribute to 
the common good. How the common good is defined depends on the values and needs of the community in question (Dale, 2005). Social capital is a fruitful concept when applied to urban agriculture, since coordination, cooperation, and collective action are often both a necessary precondition and an outcome of the practice.

\subsubsection{Social Capital and Urban Agriculture}

The concept of social capital can be a useful framework through which to view urban agriculture, and is particularly applicable to community gardens. As places where social capital is produced, accessed and used, community gardens provide a "promising context in which to explore the theoretical nature of social capital" (Glover, 2004, p. 144). Community gardens can help to develop a sense of place (Hynes \& Howe, 2002), while also creating physical "spaces of encounter" (Purcell \& Tyman, 2014, p. 13) where people can meet, socialize, form social networks, and begin to discuss and act on other community concerns (Kingsley \& Townsend, 2006). Indeed, while food is a uniting factor that helps to bring people together, community gardens are often less about gardening and the production of food, and more about building community (Glover, 2004).

Firth et al. (2011) identify four ways by which community gardens contribute to social capital: bringing people together with a common purpose; creating a physical place where members can meet and interact; creating an inclusive space due to the unifying effect of food; and helping to bridge links between communities and institutions. Through a social capital lens, public urban agriculture can be seen as a way of promoting sustainable communities, through its capacity to build community, provide opportunities for social interaction, and utilize public space for the collective good. 
Social capital is produced not only through the everyday functioning of existing community gardens, but also through the act of initiating and establishing community gardens. In order to organize as a group, navigate government departments, and access funding sources, community members build skills, develop an understanding of local social and political systems, and strengthen civic virtues (Levkoe, 2006). While social capital may well be produced and enhanced in community gardens, some level of social capital is also necessary in order for community gardens to become established in the first place.

\subsection{Food Justice, the Right to the City, and Social Capital}

While the concepts of food justice, the right to the city, and social capital are productive lenses in their own right, there are also interesting points of connection between the three. These concepts can be linked along several lines, including a commitment to the common good, heterogeneous visions of space, citizens as participants in the production of food and urban space, and recognition of power inequalities.

The idea of collective action to improve the common good is central to both social capital and the right to the city. The impacts of both of these concepts are best understood as contributing to collective rather than individual benefits, and both depend on community negotiation to make decisions. Community decisions "inevitably rely on sustained dialogue and enhanced civic literacy... it is entirely dependent on what a particular community values and defines as its needs (Dale, 2005, p. 17). Harvey (2008) takes the idea of collective action further, arguing that in order for the right to the city to be fully realized and new forms of urbanization to emerge, broad social movements will be required. The ideas of collective action and defining common goals can also be logically 
extended to food justice, since it values solidarity and community action in working towards a food system in which the benefits and risks of the food system are shared equally.

A further link between social capital and the right to the city lies in their inherently heterogeneous or pluralistic quality. In any shared urban space, a diversity of views and perspectives exist regarding needs and values. To accommodate a multiplicity of views requires not only sustained dialogue to decide what kind of a city is desired, but also compromise to negotiate how space should be used, leading to what Purcell (2002) has termed "heterogeneous urban geographies" (p. 106). This can be seen in the establishment of community gardens, which are often carved out on the fringes of public space, such as the peripheries of public parks, so that these spaces can continue to accommodate other land uses.

Food justice, the right to the city, and social capital can each be seen as conceptualizing citizens primarily as participants (active agents within the food system), rather than just consumers. Food justice recognizes that people have become largely separated from the process of producing their own food. Many expressions of food justice, including urban agriculture, provide a way for citizens to reconnect with their food and even, to an extent, to re-appropriate food production (Purcell \& Tyman, 2014). In a similar vein, the right to the city requires that citizens play an active role in deciding how urban space should be used, and to use and reclaim these areas in ways that meet their needs. Both of these concepts recognize that rights have been taken away from citizens under the political and economic systems that are dominant in North America, which prioritize capital accumulation and individual rights, and concentrate power and decision-making in the hands of the élite. These systems limit citizens' rights - whether to use urban space, 
produce food, or access food that has been grown sustainably.

Finally, the acknowledgement of the effects of power is important to each of the three concepts. Power and inequality can undermine social capital (Onyx, 2005), since the position that an individual holds within a community will affect to what extent they have access to its benefits. Further, different groups may have varying degrees of influence in determining how space in their community is used. In the case of urban agriculture, those who are marginalized may face additional barriers and have less capacity to participate in decisions. Considerations regarding who participates in decisions and who has access to resources have implications for food justice, since a food system in which the benefits are not shared equally is by definition unjust. This does, however, raise a question of how benefits can be distributed equally - whether based on need, on participation, or other considerations.

\subsection{Conclusion}

This chapter has described the three conceptual frameworks that this research draws on: food justice, the right to the city, and social capital. By engaging in urban agriculture in public spaces, citizens assert their right to use urban space in a way that meets their needs, whether they wish to increase self-sufficiency, take part in an activity that provides leisure and health benefits, or form relationships with community members. Simultaneously, urban agriculture provides a mechanism for building social capital and contributing to food justice in the community. When urban agriculture is viewed through the lenses of food justice, the right to the city, and social capital, at the core is a desire for social change more sustainable and equitable food systems, the reclamation of food production, and a 
right to use space in a way that contributes to community development and social cohesion. The next chapter describes the methodology and methods this research employs. Building on the concepts described in this chapter, Chapter 3 delineates a methodological framework that draws on feminist theory and critical GIS to better understand the socio-spatial implications of existing and potential urban agriculture practices in Ottawa. 


\section{Chapter: Methodological Approach}

\subsection{Introduction}

This research seeks to contribute to a more in-depth understanding of how existing urban agriculture practices contribute to the local food system in Ottawa, while also considering the potential for increased urban agriculture initiatives. Key to these lines of inquiry will be a consideration of the socio-spatial distribution of these practices. Drawing on a feminist and critical GIS framework, this research will follow a mixed-methods approach combining qualitative and quantitative methods of data analysis. This chapter begins with an overview of the intersections between feminist and critical GIS approaches, before moving on to a methodological discussion and a detailed account of the methods followed.

\subsection{A Feminist Approach to Critical GIS}

Although this research is not specifically focused on gender issues, it will follow feminist principles of engaging in research that is action-oriented and participatory, while acknowledging the situated and partial nature of the knowledge gained in the research process. A secondary framework, critical GIS, will also be drawn on. Critical GIS blends social theory with GIS (Schuurman, 2009), reflexively linking the technology with society. Elements of critical GIS that will be important in this research include using a combination of qualitative and quantitative methods, while engaging with socio-economic and participatory applications of GIS.

When GIS emerged as a tool of geographical inquiry in the 1980s, feminist geographers were initially skeptical. Critics argued that GIS had limited capabilities to represent things of interest to human geographers, was linked with positivist ways of conducting research, 
and was available only to those with the resources and expertise to access data and utilize the technology (Goodchild, 2006). With the emergence of critical GIS in the late 1990s, however, feminist research increasingly utilized geospatial technologies, often in conjunction with qualitative methods of data analysis (Pavlovskaya, 2006). Although GIS is still generally considered a quantitative method, Pavlovskaya (2006) argues that "similar to other research methods, GIS is neither strictly quantitative nor qualitative but may be meaningfully used in different types of research" (p. 2010).

For this research, a mixed-methods approach combining quantitative and qualitative GIS with other qualitative data collection and analysis techniques will be used. The following section describes the methodological approaches that will be employed in this research. I begin with an overview of mixed-methods research, in order to provide justification for this approach.

\subsection{Methodological Approach}

\subsubsection{Mixed-Methods Research}

A relatively recent trend towards mixed-methods research in geographical scholarship illustrates the benefits that can be realized through the practice. In part, this trend reflects a desire to bridge the perceived gulf between qualitative and quantitative research methods (Winchester \& Rofe, 2010). In the view of Flyvberg (2006), "good social science is opposed to an either/or and stands for a both/and on the question of qualitative versus quantitative methods" (p. 242). The approach can be advantageous, particularly since the use of mixed-methods allows for triangulation, or the validation and corroboration of evidence from multiple sources, while adding context, filling gaps, and allowing for 
multiple truths to emerge (Winchester \& Rofe, 2010; Elwood \& Cope, 2009).

A common criticism of mixed-methods research is related to a perceived incompatibility between qualitative and quantitative epistemologies; however, proponents of the approach argue that researchers are free to combine the best tools available to answer the particular research questions being asked (Teddlie \& Tashakkori, 2011). Another criticism arises from the perception that qualitative methods are frequently relegated to a secondary position in mixed-methods research, with qualitative evidence providing a supportive role in studies that are otherwise largely quantitative. However, recent literature, particularly in feminist geography, provides examples of mixed-methods research in which the qualitative aspect is privileged. The method that takes precedence may be simply a reflection of the research question being asked (Teddlie \& Tashakkori, 2011).

In deciding whether a mixed-methods approach is appropriate, researchers should "select methods - quantitative, qualitative, or a combination of the two - that best satisfy the needs of specific research projects" (Philips, 1998, p. 273). Further, when considering mixed-methods research, particularly in the context of graduate studies, time constraints should also be taken into account, since the use of multiple methods generally requires a more significant time commitment (Teddlie \& Tashakkori, 2011).

In the context of studying urban agriculture in Ottawa, a mixed-methods approach combining qualitative and quantitative analysis may help to provide a more nuanced understanding than would be realized by employing a single method. The collection of multiple sources of data may allow for different perspectives on urban agriculture to be represented, while triangulation of evidence may, as noted by Elwood and Cope (2009), 
allow multiple truths to emerge. Combining interviews, policy analysis, and an element of participatory action research with GIS, this research aims to utilize the advantages of each approach, in order to develop a richer view of existing and potential urban agriculture practices in Ottawa. An explanation of these methodological approaches follows.

\subsubsection{Interviewing}

Using interviewing as a data-gathering method may fill gaps in knowledge, while also enabling the collection of a diversity of opinions (Dunn, 2010). By gathering data from urban agriculture practitioners in Ottawa, this research aims to gain a more complete understanding of optimal site characteristics for urban agriculture. The main objectives of the interviews include ascertaining the role that various local organizations play in supporting and promoting urban agriculture, gathering information on existing urban agriculture practices in Ottawa, and determining what criteria are important when assessing the suitability of a location for urban agriculture. This information will inform the creation of a GIS-based land inventory of potentially suitable sites for urban agriculture.

\subsubsection{GIS as Mixed-Methods Approach}

As noted earlier in this chapter, an increasing number of feminist geographers have employed GIS as a research tool in recent years, often in combination with qualitative methods such as focus groups, interviews, and ethnographies. Kwan (2002) advocates that employing mixed-methods may provide a more nuanced understanding than using GIS alone, and argues that "one of the crucial tasks for feminist GIS users/researchers is to break the positivist/masculinist connection that was historically constituted and to engage 
in the development of critical GIS practices that are congenial to feminist epistemologies and politics" (p. 648). Support for GIS in mixed-method research is also advocated by Bell \& Reed (2004), who conclude, in discussing how GIS could enhance feminist, communitybased action research, that "developing research strategies that integrate a mixed-methods approach that includes GIS technology along with detailed qualitative studies may increase the efficacy of both research practices" (p. 63).

An interesting study reflects on the use of GIS as part of a mixed-methods approach to understanding community gardens. In their research on community gardens in Buffalo, New York, Knigge and Cope (2006) used an exploratory, iterative approach they term grounded visualization, a combination of grounded theory based on qualitative analysis and visualization with GIS. To assess how community gardeners think about and use spaces of urban gardens, they mapped data such as census and land ownership, and reflexively linked these visual representations with data gathered through interviews, participant observation, and surveys, discovering that visualization provided context for the ethnographic research and helped to explain why spatial patterns exist (Knigge \& Cope, 2006). They found that the different research methods "constantly informed, contradicted, complemented, and enriched each other, which generated new questions and wove together new answers along the way" (p. 104), concluding that the grounded visualization approach provided a framework for iteratively exploring multiple forms of data.

Following Pavlovskaya's (2006) argument that GIS can be meaningfully used in different types of research, this research will draw on both qualitative and quantitative aspects of GIS. Quantitatively, this research will explore spatial patterns of urban agriculture practices and socio-economic conditions. Qualitatively, GIS-based 
visualizations, iterative exploration of data, and participatory mapping will be utilized. Finally, a GIS-based land inventory of potential urban agriculture locations will be created, based on information gleaned through interviews with urban agriculture practitioners.

\subsubsection{Participatory Action Research \& Participatory GIS}

Participatory action research (PAR) seeks to include participants in determining the questions, methods, and applications of a research project, while allowing for the inclusion of different types and sources of knowledge (Elwood, 2006b). A key element that distinguishes PAR from other types of research lies in its commitment not only to describe reality, but also to help change it (Kindon, 2010). Since participatory research tends to be a lengthy process, there may be logistical difficulties in incorporating it into graduate research. However, it may be possible to incorporate some elements of PAR to make a project more participatory (Kindon, 2010). Researchers partaking in PAR should be careful not to overstate the participatory element of their research. In her research with women living in logging communities on Vancouver Island, Reed (2003) found she felt more comfortable using the term "interactive research" rather than participatory action research, since "it makes a much more modest claim for understanding others' positions and for empowering participants" (p. 247).

PAR has been used in conjunction with GIS in the form of participatory GIS (PGIS) or participatory mapping. These approaches have become popular in geographical research in the past decade, emerging partly in response to criticisms that GIS applications in research were unavailable to many groups due to financial and technical barriers, and privileged certain types of knowledge, while marginalizing knowledge that is not 
quantitative or visual (Elwood, 2006b). PGIS aims to democratize GIS, by making the technology more accessible to those who have traditionally been excluded, incorporating local knowledge, and making the dissemination of information more accessible (Schuurman, 2009).

While participatory GIS aims to be more inclusive, Elwood (2006b) cautions that the inclusion and exclusion of knowledge is greatly influenced by the priorities of individuals or groups that are involved in a participatory GIS project, affecting the extent to which participants are involved and the experiences that are represented. Although the goal of PGIS is to incorporate local knowledge, often through collaborative mapping, researchers should be mindful of how the practice of PGIS can lead to the exclusion of particular knowledge(s) (Elwood, 2006b). This consideration of the partial state of information will be important for this research, which will draw on the knowledge and perspectives of a relatively narrow group of individuals; namely, those who are involved in urban agriculture in a professional capacity.

This research will adopt some elements of PAR, through a focus on applied research. An important consideration in participatory research is ensuring that results are available to a diverse range of potential users (Elwood, 2006b). The results of this research will therefore be shared with those who may find it useful, including urban agriculture practitioners in the government, community development, and non-profit spheres. Specifically, either this document or a summary of key findings will be shared with interview participants, and the spatial database of lands identified through the land inventory, along with associated metadata, will be provided to interested participants.

This research also incorporates an element of participatory mapping, by asking 
interview participants to sketch responses to some questions on maps. Following Reed's rationale, I have elected to use the term "interactive mapping" to describe this approach, rather than participatory mapping. The rationale behind this exercise is to facilitate the collection of richer data, while providing participants with an alternate way of presenting their views.

\subsubsection{Policy Analysis}

In his call for more public policy in geographic research, Martin (2001) argues that there is a need for "more interesting ways of combining qualitative and quantitative analysis" ( $p$. 203), and that policy analysis may be best suited to a combination of rigorous qualitative

and quantitative methods, with each informing and complementing the other. Several feminist geographers are also of the opinion that a mixed-methods approach including GIS can be effective in influencing policy, since "GIS offers a pithy and effective means to summarize large data sets in ways that are relevant to policy" (Bell \& Reed, 2004, p. 62). Further, Pavlovskaya contends that mapping phenomena or relationships that had previously been unmapped makes them "visible and, therefore, theoretically and politically significant” (p. 2016).

In the formulation of urban agriculture policy, there is a need to recognize different visions of how urban space should be used to ensure a democratic approach to the governance of this space (Colasanti et al., 2012). By employing a mixed-method approach in this research, multiple visions for urban agriculture may emerge, and these pluralisms will be included in policy recommendations. Based on primary and secondary research findings, including evaluation of existing policy documents, identification of effective 
policy measures, and an assessment of the biases and limitations of existing policy, policy recommendations will be formulated. Policies from other municipalities will also be evaluated, in an effort to identify examples of effective policy measures that could be implemented in Ottawa.

\subsection{Methods}

The remainder of this chapter will provide details on the interview process, and GIS-related data preparation, mapping, and analyses. For all mapping and GIS analyses, ArcGIS v. 10.2.2 (Esri, 2014) was used, while Focus (version 2014-08-01; PCI Geomatics, 2014) was used for image classification.

\subsubsection{Interviews}

Initial interview participants were identified by conducting background research on urban agriculture in Ottawa. As the interviews progressed, snowballing was used to identify additional participants, with interviewees suggesting, and in some cases, facilitating, the participation of others. In total, twelve interviews were conducted with urban agriculture practitioners, representing employees of food justice organizations, community health centres, social housing organizations, and the municipal government. Since urban agriculture falls under the purview of several City of Ottawa departments, employees of various branches within the departments of Public Health, Community and Social Services, and Parks, Recreation and Cultural Services were interviewed.

Interviews were semi-structured, a technique that allows for flexibility while still following a degree of predetermined order (Dunn, 2010). An interview guide was used to 
provide guidance (see Appendix 1), but issues or ideas that arose during the interview were explored. Interviews lasted approximately one hour each, and in most cases, notes were taken during the interview process and a written account was recorded shortly after the interview took place. In two instances, interviews were recorded and later transcribed. At the request of one participant, the transcribed notes were sent to the participant to review prior to being finalized.

Interviews also incorporated an interactive mapping exercise in which participants sketched locations they felt would be suitable for urban agriculture or where they felt these activities would be particularly beneficial, based on their familiarity with the area. Participants were provided with a base map of the study area, and as they sketched their responses, notes were recorded regarding their rationale for selecting each location. The areas indicated on the paper maps were later digitized in a GIS.

\subsubsection{Assessing Demand for Urban Agriculture}

Demand for urban agriculture was assessed in two ways: collecting waiting list information and through the interactive mapping exercise. Twenty-eight community garden organizers were contacted by e-mail to request whether their respective gardens had waiting lists, and if so, the number of people on the list. Only gardens with plots allocated to individual members were contacted (i.e. those gardens with only communal plots, and therefore no need of a waiting list, were not contacted). A second method of assessing demand for urban agriculture involved the interactive mapping exercise. Frequently, participants identified communities on the maps where they were aware of an existing demand for community gardens. 


\subsubsection{Mapping Existing Urban Agriculture Practices}

A list of community gardens in the Community Gardening Network (CGN) was obtained from Just Food's website. The website is updated periodically as new gardens are added to the network. The locations of all community gardens in the CGN were initially verified through visual assessment in Google Earth, and later through field visits to confirm that they were in fact places of food production. In most cases, the locations of gardens could easily be verified in Google Earth by the presence of raised beds; in other cases, rectangular in-ground garden plots or regular rows were visible on the surface (see Figure 2). In several cases, gardens in the CGN could not be verified through either Google Earth or site visits. Through the interview process, it was determined that these gardens had ceased to exist due to a loss of organizational support or a loss of land access, and they were removed from the database accordingly.

The interview process also revealed that a number of community gardens exist outside of the CGN. Specifically, Ottawa Community Housing (OCH), the largest social housing provider in the city, has community gardens on several of its properties, some of which are not associated with the network (as will be discussed in Chapter 4). With the cooperation of $\mathrm{OCH}$ staff, a list of gardens on $\mathrm{OCH}$ properties was acquired. As this information was obtained in the winter, field visits to $\mathrm{OCH}$ gardens were not conducted; rather, locations were verified through visual assessment in Google Earth. All gardens (both those in the CGN and those on $\mathrm{OCH}$ properties) were then georeferenced using GIS software. 

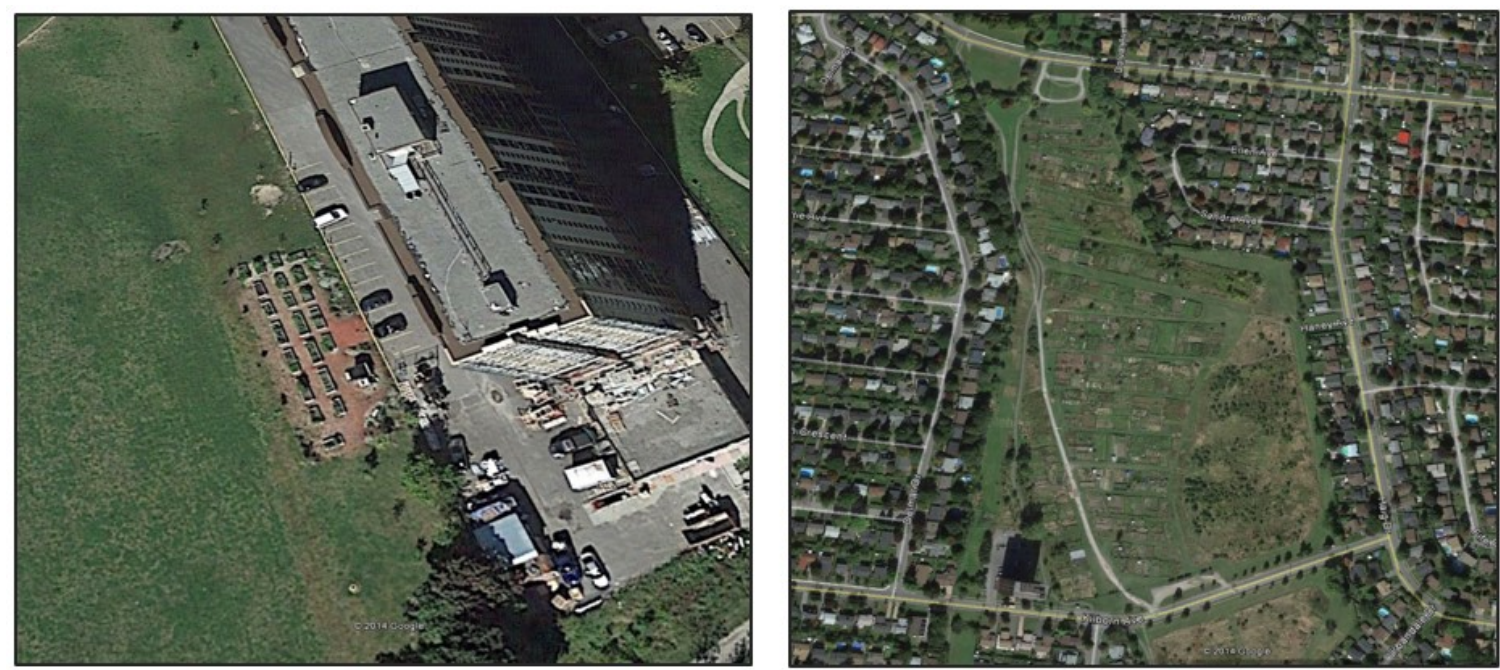

Figure 2 - Google Earth images showing raised garden beds (left) and the in-ground plots of an allotment garden (right).

Since the size of community and allotment gardens can vary considerably, from less than ten plots to several hundred plots, information regarding the number of plots per garden was collected and attributed to the community garden database. While plot size can also vary among gardens, the number of plots was used as an indicator of the number of households participating in a garden. The number of plots per garden was obtained through either Just Food's website or Internet searches, and verified through site visits. If the number of plots could not be verified through site visits (i.e. in the case of OCH gardens) Google Earth was used to visually estimate the number of plots.

Locations of school gardens were also mapped. Canadian Organic Growers (COG) publishes a map of schools participating in their school garden program on their website ${ }^{6}$. This data was downloaded in KML format, and converted to a shapefile for use in a GIS. An interview with a COG staff member confirmed that this list of gardens was up-to-date.

${ }^{6}$ http://cog.ca/ottawa/growing-up-organic/our-schools/ 
The locations of food-bearing trees on public property were also considered. Discussions with Hidden Harvest Ottawa staff revealed they use a tree inventory maintained by the City of Ottawa to identify trees that may produce fruit or nuts. This dataset contains information for city-owned trees on public spaces including road allowances and parks (although not all parks have been surveyed), and is updated on a regular basis. The tree inventory was obtained through the City of Ottawa's Open Data Catalog, and fruit- or nut-bearing tree species were extracted based on a list of edible species provided by Hidden Harvest Ottawa (see Table 1), using the same methodology that the organization uses to identify potentially food-bearing trees. It should be noted that the trees identified through this process represent potential, rather than actual, food production (since, for example, some trees may be too young to produce fruit). Further, since the database is limited to trees located on city-owned land, it does not represent trees in private spaces, such as backyards.

Table 1 - List of potentially fruit- and nut-bearing tree species.

\begin{tabular}{|l|l|}
\hline Fruit-bearing Trees & Nut-bearing Trees \\
\hline Apple species (including crab apples) & Butternut \\
\hline Cherry species (black cherry, chokecherry, pin cherry) & Black Walnut \\
\hline Pear & Ginkgo \\
\hline Serviceberry & Hazel (Turkish, American) \\
\hline High Bush Cranberry & Kentucky Coffeetree \\
\hline Elderberry & Shagbark Hickory \\
\hline Mulberry & \\
\hline Hackberry & \\
\hline Russian Olive & \\
\hline
\end{tabular}

\subsubsection{Spatial Analysis of Urban Agriculture Data}

As a key question of this research is related to the spatial distribution of existing urban agriculture practices, a spatial analysis approach was employed to investigate patterns of urban agriculture locations in relation to socio-economic and other potentially explanatory factors. Directional distribution, hot spot, and regression analyses were used as techniques 
of exploratory data analysis to identify spatial patterns and relationships.

The first step in the exploratory data analysis involved identifying potential explanatory factors for urban agriculture locations. When choosing explanatory factors for a model, there should be some rationale behind the decision, based on theory, previous research, or sound reasoning (Rosenshein, Scott \& Pratt, 2011). Based on Tornaghi's (2014) argument that socio-economic exclusions and injustices are often embedded in urban agriculture, factors often associated with differences in socio-economic status were selected as potential explanatory variables. These included median household income, median dwelling value, highest level of education attained, percentage of visible minorities, and percentage of residents in poverty. Several variables were also selected based on the rationale that a lack of residential yard space could be a determining factor contributing to the presence of some urban agriculture activities. These included average residential parcel size, distance to the urban centre, percentage of population living in apartments, and percentage living in rented dwellings.

Census tracts were used as the geographical unit of analysis for this study. Census tracts are small, relatively stable census geographic units that usually have a population between 2,500 and 8,000, and are as homogeneous as possible in terms of socio-economic characteristics (Statistics Canada, 2012a). Due to their relatively small size and homogeneity, census tracts are often considered an appropriate scale for studying neighbourhood-level processes, and were thus selected as the geographical unit for analysis. 


\section{Data Preparation}

Data representing existing urban agriculture practices (community gardens, school gardens, and food-bearing trees) were aggregated by summing the number of locations of each of the three practices per census tract. In order to normalize these counts, they were calculated as rates per 1,000 people, based on 2011 population counts.

Census data from 2011 were accessed from Statistics Canada. It is important to note changes between the 2011 census and previous years of data collection. As of the 2011 census, Statistics Canada substantially changed their data collection methodology, shifting from a legally enforced long-form census to a voluntary National Household Survey (NHS). While the NHS was sent to more households in order to compensate for a lower response rate, fewer households responded to the voluntary survey in 2011 than the previous 2006 survey (Statistics Canada, 2012b). This has raised concerns related to the uncertainty of the 2011 census data, and the concern that some segments of the population, such as immigrants, or those with low-income, low education levels, or a first language other than English or French, may be less likely to respond (Veall, 2010). However, since the global non-response rate (which is used as an indicator of data quality) is generally lower in urban areas than in rural areas (Bell \& Wei, 2014), the 2011 census data were used for this study, as the alternative would have been to use data that are nearly a decade old.

Each of the census variables being considered as an explanatory factor was standardized by converting the raw variable counts to a percentage, based on the parent variable. For example, the percentage of rented dwellings was calculated by dividing the total number of rented dwellings by the total number of private households by tenure for each census tract. 
Several non-demographic variables were also included as potential explanatory variables. It was hypothesized that average residential parcel size and distance from the urban centre may exert an influence on the number of urban agriculture practices, as there may be more demand for urban agriculture in neighbourhoods with less residential space available for gardening. The average residential parcel size per census tract was based on the average size of single-family lots (other types of residential lots, such as apartments and townhouses were not included in the calculation). Distance from the urban centre was calculated as the distance from the geographical centre of Centretown (the local name for a residential neighbourhood in the downtown core). The percentage of vacant land per census tract (by area) was included as an additional potentially explanatory variable. All demographic and non-demographic variables were standardized by converting them to zscores, in order to allow relative comparisons. Table 2 presents a full list of all demographic and non-demographic variables considered as potential explanatory factors.

\section{Table 2 - Factors considered as potential explanatory variables.}

\begin{tabular}{|l|l|}
\hline Demographic Variables & Non-demographic Variables \\
\hline Percentage of owned dwellings & Average residential parcel size \\
\hline Percentage of rented dwellings & Percentage of vacant land \\
\hline Median household income & Distance from urban centre \\
\hline Average household income & \\
\hline $\begin{array}{l}\text { Percentage of population aged 25-64 with Bachelor } \\
\text { degree or higher }\end{array}$ & \\
\hline Unemployment rate & \\
\hline Percentage Aboriginal identity & \\
\hline Percentage visible minority & \\
\hline Percentage immigrant population & \\
\hline Median commuting duration & \\
\hline Percentage who commute without a vehicle & \\
\hline Percentage low-income after tax & \\
\hline Median dwelling value & \\
\hline Average dwelling value & \\
\hline Population density & \\
\hline Percentage of households with children & \\
\hline Percentage of female lone-parent families & \\
\hline Percentage aged 65 years and older & \\
\hline Percentage of apartment dwellings & \\
\hline
\end{tabular}




\section{Spatial Statistical Analysis}

As mentioned in the beginning of this section, directional distribution, hot spot, and regression analyses were utilized to aid in identifying and visualizing spatial patterns. Each of the three types of urban agriculture practices (community gardens, school gardens, and food-bearing trees) were analyzed separately, based on the rationale that the social dynamics influencing each of these processes may not be the same. This decision was further justified based on initial mapping of each practice, which will be further discussed in the following chapter.

A directional distribution creates a standard deviational ellipse that helps to visualize the spatial distribution of data. A directional distribution analysis (based on one standard deviation) was performed separately on points representing locations of community gardens, school gardens, and food-bearing trees, in order to initially assess the spatial pattern of these activities. For community gardens, a second directional distribution was created, weighted on the number of plots per location.

A hot spot analysis (Getis-Ord $\mathrm{G}_{\mathrm{i}}^{*}$ ) can identify where statistically significant high and low values cluster spatially by assessing each feature in relation to neighbouring features (Chang, 2010). In order to be statistically significant, a feature must have a high (or low) value, and be surrounded by high (or low) values. A hot spot analysis returns a zscore for each feature being analyzed, with a positive score indicating a clustering of high values (a hot spot), and a negative score indicating a cluster of low values (a low spot). A stronger score is representative of stronger clustering. For each of the urban agriculture practices, a hot spot analysis was conducted using the data aggregated at the census tract 
and represented as the number of locations per population of 1,000 . In the case of community gardens, analyses were conducted using both the number of community garden locations, and the number of community garden plots. A hot spot analysis is based on how spatial relationships with other features are conceptualized. With polygon input features of varying sizes (such as census tracts), a fixed distance conceptualization is recommended. For each set of urban agriculture practices, a fixed distance was specified, with the distance value selected based on the distance at which spatial autocorrelation was most pronounced (based on the Morans I value). The fixed distance band used for each variable is shown in Table 3.

Table 3 - Fixed distance band used for each of the hot spot analyses.

\begin{tabular}{|l|l|}
\hline Variable & Fixed Distance Band $(\mathbf{m})$ \\
\hline Community garden plots per population of 1,000 & 2,000 \\
\hline Community garden locations per population of 1,000 & 2,500 \\
\hline School gardens per population of 1,000 & 1,500 \\
\hline Edible trees per population of 1,000 & 1,500 \\
\hline
\end{tabular}

The third spatial analysis technique utilized to explore the urban agriculture data was regression. Regression analysis aims to explain a dependent variable by virtue of a selection of explanatory variables. In standard regression models, a single global equation is used to explain the dependent variable for the entire area under consideration. However, localized forms of regression also exist.

Geographically weighted regression (GWR) is one form of local spatial analysis, offering an alternative to global forms of regression modeling that may mask interesting spatial variations and differences at the local scale (Fotheringham, Brunsdon \& Charlton, 2002). GWR takes into account that relationships between a dependent variable and explanatory variables may not be constant over space (a concept referred to as spatial nonstationarity). That is, GWR adjusts a model based on the idea that neighbouring features 
are more likely to be similar than not (Lafary, Gatrell \& Jensen, 2007). Further, GWR recognizes that spatial data are unique in that they have both attribute information and locational information; this characteristic is important, since it means that statistical techniques developed for aspatial data may not be appropriate for spatial data (Fotheringham et al., 2002). GWR, although not appropriate in all circumstances, may also represent a shift away from a positivist approach in that it is concerned with local relationships rather than solely on global models and generalizations (Fotheringham et al., 2002).

Whether conducting a global analysis or a local analysis, the first step is to attempt to fit an ordinary linear regression model to the data, to determine whether there are relationships that are worth investigating in more detail (Fotheringham et al., 2002). For each of the three urban agriculture practices, Ordinary Least Squares (OLS) was performed to calculate a global regression model. The dependent variable in each case was the number of urban agriculture locations per population of 1,000 (in the case of community gardens, the number of plots was also tested). Following the procedure outlined by Megler, Banis, \& Chang (2014) in their study of graffiti locations in San Francisco, selecting the best model was highly iterative. In order to maximize the goodness-of-fit of the model, multiple versions were conducted. Explanatory variables were added and removed based on the rationale explained earlier in this section, and different combinations of explanatory variables were experimented with. The results of each test were used to inform subsequent tests, with the quality of each iteration assessed based on model diagnostics. These included the size and direction of the co-efficient (i.e. whether the direction was as expected), significance of the p-value, variance inflation factor, Pearson's correlation $\left(\mathrm{r}^{2}\right)$, 
adjusted $\mathrm{r}^{2}$, and Akaike's Information Criterion (AICc). The variance inflation factor is a measure of variable redundancy; a value greater than 7.5 indicates that a variable should be reassessed due to problems with redundancy. The $r^{2}$ value indicates the proportion of the variation in the dependent variable which is accounted for by the variation in the model, and ranges from 0 to 1 . For example, an $\mathrm{r}^{2}$ value of 0.5 indicates that half of the variation in the dependent variable can be explained by the explanatory variables. The adjusted $\mathrm{r}^{2}$ contains an adjustment for the number of variables in the model, and is therefore a preferable measure to the $\mathrm{r}^{2}$ value (Charlton \& Fotheringham, 2009). The AICc is a relative measure that can be used to compare different models using the same dependent variable, with models with smaller AICc values being preferable (Charlton \& Fotheringham, 2009). The model iterations were refined to optimize these goodness-of-fit measures, and the bestperforming model from each of the three urban agriculture practices was selected to investigate whether geographically weighted regression offered an improvement over the global regression model.

Geographically weighted regression was conducted for each of the three urban agriculture practices, using the same dependent and explanatory variables as those used in the best-performing global model. In geographically weighted regression, the equation for a feature is calculated based on data from the surrounding region, weighted based on proximity. For a given feature, the weight of the data is at a maximum when the location is shared between the feature and the data point; as the data increase in distance from the feature, the weight continuously decreases (Fotheringham et al., 2002). The surrounding region can be calculated based on one of two distance measures: fixed or adaptive spatial kernels. A fixed spatial kernel uses the same distance for calculating each feature, while 
an adaptive spatial kernel adapts the distance based on variations in the density of the data. A secondary parameter is the bandwidth method, which determines how the kernel distance is calculated. Users may specify a particular bandwidth (i.e. a distance value when a fixed spatial kernel is used or a number of units when an adaptive spatial kernel is used), or choose the AICc bandwidth method. The AICc method chooses a bandwidth that minimizes the AICc value of the model. Charlton and Fotheringham (2009) recommend using an adaptive spatial kernel and AICc bandwidth in most cases.

For each of the three urban agriculture practices, GWR was conducted using both a fixed spatial kernel and an adaptive spatial kernel. The AICc bandwidth method was used in all tests. Spatial autocorrelation in the GWR residuals was calculated using Morans I. The results of the GWR analyses were mixed, as will be explained in Chapter 4.

\subsubsection{Creating a Land Inventory}

The remainder of this chapter will explain the process of creating a land inventory to identify potential areas for increased urban agriculture in Ottawa. Through interviews with urban agriculture practitioners, fifteen variables were identified as being important considerations for urban agriculture (see Table 4). This information, along with a review of relevant literature, was used to inform the land inventory procedure. Of the factors identified by interview participants, some were used as criteria to identify potentially suitable sites for urban agriculture, while others were included in the inventory for informational purposes only. Additionally, some criteria, such as community support and aesthetics, cannot be readily represented in a GIS, but are nonetheless important considerations. These difficult-to-represent criteria help to illustrate that the inventory is a 
tool for the preliminary assessment of potentially available land, but that ultimately, sites would need to be considered on a case-by-case basis.

Spatial data were obtained from various data sources, including the City of Ottawa's Open Data Catalog, the National Capital Commission, and Statistics Canada. Additional data layers, including land use, ownership, and city water infrastructure, were provided upon request by the City of Ottawa. High resolution $(20 \mathrm{~cm})$ aerial imagery was obtained from the National Capital Commission (2011).

Table 4 - Variables identified through interviews as important considerations for urban agriculture, with relevant data sources.

\begin{tabular}{|c|c|c|}
\hline Criteria & Explanation & Data Used \\
\hline \multicolumn{3}{|l|}{ Biophysical } \\
\hline \multirow[t]{2}{*}{ Land Use } & $\begin{array}{l}\text { Vacant or underutilized land may be } \\
\text { suitable for urban agriculture }\end{array}$ & $\begin{array}{l}2010 \text { land use layer (source: } \\
\text { City of Ottawa) }\end{array}$ \\
\hline & $\begin{array}{l}\text { Existing incompatible land uses, such as } \\
\text { building footprints, should be excluded } \\
\text { from consideration }\end{array}$ & $\begin{array}{l}\text { Ottawa 1:2000 scale } \\
\text { topographic data (includes } \\
\text { footprints of buildings, roads, } \\
\text { sidewalks, driveways, parking } \\
\text { lots, forest, etc.). Some, but not } \\
\text { all, regions of the study area, } \\
\text { updated as recently as } 2013 \text {. }\end{array}$ \\
\hline Slope & $\begin{array}{l}\text { A small degree of slope is manageable } \\
\text { (e.g. through raised beds or terracing), but } \\
\text { greater than } 10 \% \text { slope could be difficult }\end{array}$ & $\begin{array}{l}\text { Slope was derived from a } 10 \mathrm{~m} \\
\text { resolution digital elevation } \\
\text { model (source: Ontario Ministry } \\
\text { of Natural Resources) }\end{array}$ \\
\hline Sunlight & $6+$ hours a day preferable & $\begin{array}{l}\text { Tree canopies extracted from } \\
\text { Ottawa 1:2000 scale } \\
\text { topographic data and buffered } \\
\text { by } 1 \mathrm{~m} \text { to represent locations } \\
\text { affected by tree shade }\end{array}$ \\
\hline $\begin{array}{l}\text { Access to } \\
\text { water }\end{array}$ & $\begin{array}{l}\text { Existing access to city water supply is } \\
\text { preferable, as the cost associated with } \\
\text { setting this up can be prohibitively } \\
\text { expensive }\end{array}$ & $\begin{array}{l}\text { Water infrastructure layer } \\
\text { identifies location of water } \\
\text { mains (source: City of Ottawa), } \\
\text { but not individual connections. }\end{array}$ \\
\hline Soil & $\begin{array}{l}\text { Most soil in urban areas is contaminated } \\
\text { due to past land use. New community } \\
\text { gardens are required to undergo soil } \\
\text { testing. If the soil is contaminated, raised } \\
\text { beds must be used instead. }\end{array}$ & $\begin{array}{l}\text { Soil data is not available for } \\
\text { urban Ottawa; however, soil } \\
\text { contamination can be mitigated } \\
\text { in most cases through the use } \\
\text { of raised beds rather than in- } \\
\text { ground plots. }\end{array}$ \\
\hline
\end{tabular}


Table 4 (continued) - Variables identified through interviews as important considerations for urban agriculture, with relevant data sources.

\begin{tabular}{|c|c|c|}
\hline \multicolumn{3}{|l|}{ Social } \\
\hline $\begin{array}{l}\text { Land } \\
\text { ownership }\end{array}$ & $\begin{array}{l}\text { Gardens on publically owned land can } \\
\text { have more land tenure security than } \\
\text { gardens on privately owned land; however, } \\
\text { the process to obtain permission for } \\
\text { gardens in public spaces can be lengthy }\end{array}$ & $\begin{array}{l}\text { For this study, publicly } \\
\text { accessible land was } \\
\text { considered. Publically owned } \\
\text { land (federal, provincial, or } \\
\text { municipal) was identified from } \\
\text { the } 2010 \text { land use layer } \\
\text { (source: City of Ottawa). } \\
\text { Vacant, privately-owned land } \\
\text { was also considered. }\end{array}$ \\
\hline \multirow[t]{3}{*}{$\begin{array}{l}\text { Site } \\
\text { accessibility }\end{array}$} & Vehicular access & $\begin{array}{l}2011 \text { road data (source: } \\
\text { Statistics Canada) }\end{array}$ \\
\hline & Public transit access & $\begin{array}{l}\text { Public transit stops (source: } \\
\text { City of Ottawa's Open Data } \\
\text { Catalog) }\end{array}$ \\
\hline & Bicycle / pedestrian access & $\begin{array}{l}\text { Cycling and walking paths } \\
\text { (source: City of Ottawa's Open } \\
\text { Data Catalog) }\end{array}$ \\
\hline $\begin{array}{l}\text { Neighbourhood } \\
\text { income }\end{array}$ & $\begin{array}{l}\text { Gardens can be especially beneficial in } \\
\text { low-income areas; several interview } \\
\text { participants expressed a preference for } \\
\text { creating gardens in low-income } \\
\text { neighbourhoods }\end{array}$ & $\begin{array}{l}2011 \text { census (source: Statistics } \\
\text { Canada) }\end{array}$ \\
\hline $\begin{array}{l}\text { Population } \\
\text { density of } \\
\text { surrounding } \\
\text { area }\end{array}$ & $\begin{array}{l}\text { Gardens should be located in close } \\
\text { proximity to where people eat, live, and } \\
\text { cook. High population density of } \\
\text { surrounding area is therefore preferable. }\end{array}$ & $\begin{array}{l}2011 \text { census (source: Statistics } \\
\text { Canada) }\end{array}$ \\
\hline $\begin{array}{l}\text { Proximity to } \\
\text { other } \\
\text { community } \\
\text { facilities }\end{array}$ & $\begin{array}{l}\text { People are more likely to spend time in } \\
\text { areas with multiple attractions }\end{array}$ & $\begin{array}{l}\text { Locations of parks, museums, } \\
\text { community centres, libraries, } \\
\text { and schools (source: City of } \\
\text { Ottawa's Open Data Catalog) }\end{array}$ \\
\hline $\begin{array}{l}\text { Community } \\
\text { support }\end{array}$ & $\begin{array}{l}\text { Committed group of people required to } \\
\text { organize and participate; broader } \\
\text { community support also needed. }\end{array}$ & $\mathrm{N} / \mathrm{A}$ \\
\hline $\begin{array}{l}\text { Percentage of } \\
\text { people living in } \\
\text { apartments / } \\
\text { condominiums }\end{array}$ & $\begin{array}{l}\text { People living in apartments and } \\
\text { condominiums have less access to green } \\
\text { space; therefore, more need for urban } \\
\text { agriculture in public places. }\end{array}$ & $\begin{array}{l}2011 \text { census (source: Statistics } \\
\text { Canada) }\end{array}$ \\
\hline $\begin{array}{l}\text { Neighbourhood } \\
\text { crime rates }\end{array}$ & $\begin{array}{l}\text { Anecdotal evidence suggests gardens can } \\
\text { help reduce crime rates }\end{array}$ & $\begin{array}{l}\text { Crime rates (source: Ottawa } \\
\text { Police Service) }\end{array}$ \\
\hline Aesthetics & $\begin{array}{l}\text { Gardens can be unsightly if not well- } \\
\text { maintained, which can decrease } \\
\text { community support. }\end{array}$ & N/A \\
\hline Site visibility & $\begin{array}{l}\text { Gardens should be visible for safety } \\
\text { reasons, and also to create awareness in } \\
\text { community. However, high visibility may } \\
\text { also lead to increased pilfering of produce. }\end{array}$ & $\mathrm{N} / \mathrm{A}$ \\
\hline
\end{tabular}

There was a general consensus among interview participants of a need to consider

underutilized as well as vacant land when identifying potential locations for urban 
agriculture. As one interview subject remarked, "The challenge is reimagining space as available for gardening" (M. McCallum, personal communication, September 15, 2014). Further, several interview participants remarked that urban land should not be allowed to remain vacant for long periods of time, as it represents a missed opportunity for urban agriculture, even if food production is only an interim use. The first step in creating the land inventory therefore involved identifying vacant or underutilized land. Potentially underutilized land was identified by selecting parcels within the following land use categories: schools, hospitals, other institutions, utilities, offices, open space, idle and shrub land, and passive recreation. Since the goal of the inventory was to identify opportunities on public or semi-public land, only publically owned office land was retained in the dataset. Incompatible land uses were removed from these parcels, by deleting impervious surfaces such as buildings, driveways, parking lots, roads, and sidewalks. Cemeteries were deleted manually based on visual interpretation of aerial imagery. On federally-owned land, designations that were perceived as incompatible with urban agriculture, such as cultural and historical sites, capital parks, and important natural habitat, were removed from the inventory.

Vacant parcels were processed slightly differently. Vacant land was identified from the land use layer, and both privately- and publically-owned vacant parcels were retained in the dataset, based on the rationale that the municipal government could provide incentives for private landowners to allow publically-accessible urban agriculture as an interim use on vacant land, as has been done in other municipalities. Further, existing impervious structures, such as parking lots, were not considered barriers on vacant parcels, since they do not necessarily preclude some forms of urban agriculture (such as container 
gardening), and such surfaces may even promote greater accessibility, by allowing easier access for wheelchairs.

\section{Image Classification}

Visual analysis of the land inventory at this point revealed that the data representing building and road footprints were not as current as the aerial imagery from 2011. This was particularly evident in the case of institutional land (e.g. universities and health care facilities), where building development proceeds relatively rapidly. In the interest of representing the most current data available, the aerial imagery was classified using remote sensing techniques to distinguish pervious from impervious surfaces.

Two techniques commonly used to classify images include unsupervised classification and supervised classification. An unsupervised classification uses algorithms to place pixels into classes based on the natural clusters represented in the image values (Lillesand, Kiefer \& Chipman, 2008). These classes can then be examined to determine the real-world land cover features that they represent, and aggregated accordingly (for example, separate classes representing coniferous trees, deciduous trees, and grass could be aggregated into a single vegetation class). In contrast, a supervised classification is conducted based on a user-specified number of classes. For each class, the user selects a number of sample sites from the imagery that represent that class (referred to as training areas). When the supervised classification is performed, the training areas are used by the algorithm to assign each pixel in the imagery to the defined class that it is most similar to. Initial unsupervised classification attempts proved unsatisfactory, due to confusion caused by heterogeneity of the urban landscape and shadows in the imagery; therefore 
supervised classification was performed. Nine classes were initially defined: trees and shrubs, grass, bare soil, light built-up areas, dark built-up areas, shaded trees and shrubs, shaded grass, shaded bare soil, and shaded light built-up areas. Each class had at least eight training areas, selected from locations distributed throughout the study area. A maximum likelihood classification with a 'null' class was used to perform the classification. The null class picked up pixels that were not represented in the nine defined classes, including relatively isolated urban features (such as swimming pools, green roofs, and red cars). The initial classified image was then aggregated into three broader land cover classifications: built-up, vegetated, and bare soil. A 3 x 3 mode filter was applied to smooth the image and reassign isolated misclassified pixels to the value of the surrounding class.

The areas identified as built-up according to the supervised classification were extracted and converted to polygons. These impervious areas were then removed from land identified as underutilized in the inventory. Impervious areas were not removed from vacant land, for reasons explained in the previous section.

\section{Slope \& Sunlight}

Although it is possible to grow food on steep slopes using techniques such as terracing, interviews revealed that steep slopes are not ideal locations. Based on views expressed during interviews and a review of similar inventory procedures (e.g. Calgary Food Committee, 2012), it was determined that sites with a slope greater than $10 \%$ should be excluded from the inventory. Slope was derived from a $10 \mathrm{~m}$ digital elevation model, and locations with a slope greater than $10 \%$ were removed from the inventory.

In consideration of shade, a $1 \mathrm{~m}$ buffer was created around tree canopies, and these 
areas were excluded from the inventory. Building shade was not taken into consideration, due to a lack of building height data for the entire study area. Removing north-facing slopes was considered; however, since all slopes greater than $10 \%$ were already excluded, this was deemed unnecessary, since an assessment of existing community gardens revealed that some successful gardens were located on north-facing areas with a small degree of slope (i.e. less than 10\%).

\section{Site Access \& Safety}

Site access and safety were also considered. Land within $10 \mathrm{~m}$ of railway lines or Ottawa's bus rapid transit network ${ }^{7}$ was excluded, as access to these areas is limited. In further consideration of access and safety, sites that would only be accessible by pulling off along a highway or highway ramp were excluded through visual assessment of aerial imagery. Sites that had limited access for other reasons (e.g. that could only be accessed by traversing through a forested area, crossing through residential property, or crossing unbridged waterways) were also removed from the inventory.

Some concern has been expressed regarding the human health impacts of consuming food grown in urban areas that has been exposed to contaminants in the air and soil. While soil contamination is a concern in urban areas due to historical land uses, interviews revealed that this can be largely mitigated through the use of raised bed gardens. Regarding air contamination, Saumel et al. (2012) found that vegetables grown in hightraffic areas with no barriers from traffic showed an increased presence of trace metals in

\footnotetext{
7 Ottawa's bus rapid transit network (the Transitway) has limited access for regular vehicular
} traffic. 
their biomass; however, crops grown at a distance of at least $10 \mathrm{~m}$ from high-traffic streets presented significantly less trace metals. In light of this study, a $10 \mathrm{~m}$ buffer was created along major roadways (identified as highways, freeways, or arterial roads), and these areas were removed from the inventory.

\section{Ecological Considerations}

Due to their importance in providing wildlife habitat and contributing to ecological and social well-being, forested areas were removed from the inventory. In further consideration of protection of important natural features and functions, a $30 \mathrm{~m}$ buffer was created along natural water bodies (e.g. rivers, streams, and wetlands), and these areas were removed from the dataset ${ }^{8}$. This distance is likely a conservative estimate, given the small scale of many urban agriculture activities.

\section{Size}

Several interview participants noted the importance of utilizing small fragments of land for urban agriculture, and particularly of integrating the practice with existing land uses. Based on this rationale, and Napawan's (2014) call for policy to "accommodate a fuller range of urban agriculture projects," (p. 1) by recognizing a greater complexity of urban agriculture typologies, it was important that the land inventory identify small sites that could potentially be used for urban agriculture. However, due to spatial datasets not aligning perfectly with one another, there were some 'slivers' in the inventory resulting from

\footnotetext{
${ }^{8} \mathrm{~A}$ width of $30 \mathrm{~m}$ was selected since ecological buffers greater than $30 \mathrm{~m}$ represent a low-tomoderate risk of disturbing natural features and functions (Beacon Environmental Ltd., 2012).
} 
overlaying different datasets. In an effort to remove these slivers, only sites with an area greater than $50 \mathrm{~m}^{2}$ were retained in the inventory. While this approach had the drawback of removing very small sites from the inventory, it helped to create a cleaner dataset. Finally, the features in the inventory were dissolved based on the property identification number (PIN) and the land use classification. This had the effect of merging any features that were located on the same property and had the same land use type into a single site.

\section{Additional Information}

In addition to the factors used as criteria to identify potentially suitable sites, several factors were included in the inventory for informational purposes only. These included demographic information, such as population density, household income, and neighbourhood crime rates. Also included were attributes related to site accessibility and proximity to other community facilities or services, such as libraries, parks, schools, and community centres.

Proximity to water mains was also included for informational purposes. While interviews revealed that proximity to existing water connections was very important due to the prohibitively high costs of setting up access, the water infrastructure data available depicted only the locations of water mains, not locations of existing connections. Proximity to existing water connections could therefore not be determined with certainty.

\section{Validation of the Inventory}

The final step in the land inventory process was to remove any existing community gardens from the dataset. This process also served as a means of validating the inventory. Of the 
24 existing community gardens on public or semi-public land within the study area, 19 were identified as potentially suitable sites in the land inventory. The five existing community gardens that were not identified were located in public parks and had been classified in the 'active recreation' land use category (a designation generally intended for active organized sports and games) and therefore did not meet the criteria of the inventory.

A second means of validation involved comparing the inventory results with the locations of proposed community gardens. Each year, the Community Gardening Network accepts applications for funding for new and existing community gardens. A list of new gardens that had applied for funding in 2015 was acquired through the cooperation of Just Food. Within the study area, fourteen new gardens were proposed. Six of these sites were located on properties owned by Ottawa Community Housing; since these properties were classified as a residential land use, they were not identified in the land inventory. Of the remaining eight proposed gardens, seven were identified as potentially suitable in the inventory. The remaining site was a proposal for planter boxes on the sidewalk outside of a drop-in centre.

\subsection{Chapter Summary}

This chapter provided an overview of the research methodology, beginning with a discussion of feminist and critical GIS approaches, and moving on to a methodological discussion of mixed-methods research, GIS, interviewing, participatory action research, and policy analysis. A detailed methods section followed, explaining the interview process and the procedures followed to conduct the spatial modeling and create the land inventory. A significant component of the methods section focused on the data collection and 
preparation process.

Chapter 4 will present the results of the interviews, spatial modeling, and land inventory, with an analysis of research findings. In Chapter 5, the policy implications of these findings will be discussed. 


\section{Chapter: Results and Discussion}

\subsection{Introduction}

This chapter presents the results and discussion of the interviews, GIS analysis, and interactive mapping exercise described in the previous chapter. The first half of the chapter focuses on a qualitative analysis of urban agriculture in Ottawa, while the second half of the chapter presents a discussion of the GIS analysis. In some cases, both qualitative and quantitative evidence are combined to glean additional insight into the state of urban agriculture in Ottawa. The chapter begins with a discussion of organizations supporting urban agriculture in Ottawa, followed by a discussion of sites of urban agriculture as spaces where community development and food justice are experienced. Demand for space for food production in the city is then assessed, based on data obtained from community garden coordinators and interviews with urban agriculture practitioners. Finally, the spatial analysis and land inventory results are presented and discussed.

\subsection{Descriptive Account of Urban Agriculture in Ottawa}

\subsubsection{Organizational Network of Urban Agriculture}

Broadly, the major groups that support urban agriculture in Ottawa include the municipal government, food-related organizations, and community development organizations. In many ways, Just Food, particularly through the Community Gardening Network, serves as an umbrella organization linking urban agriculture to other food security initiatives. Through information gained during interviews, it was clear that there is a high level of interconnection and cooperation among governmental and non-governmental organizations working to support and promote urban agriculture in Ottawa (see Figure 3). 


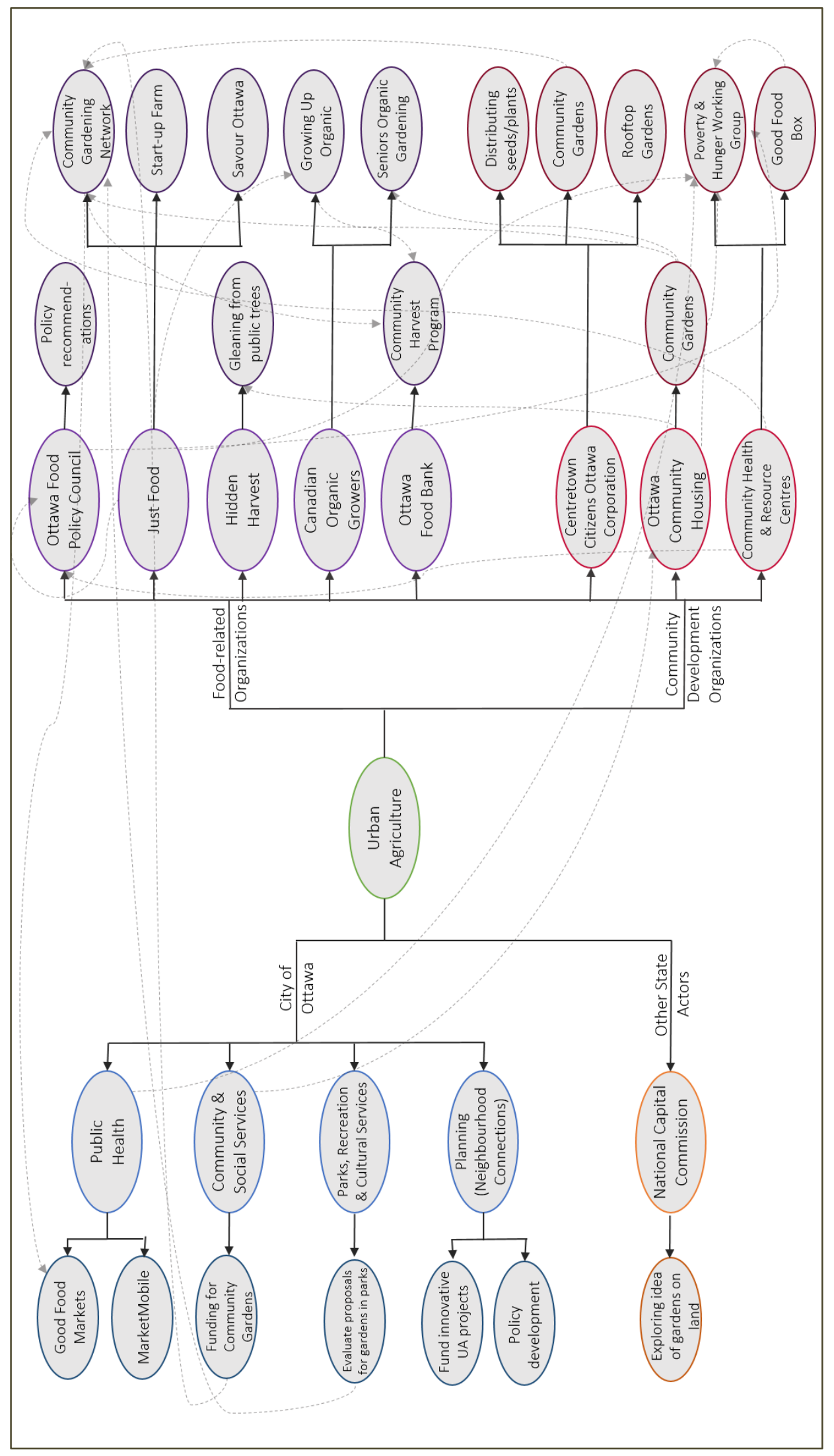

Figure 3 - Organizational network of urban agriculture related initiatives in Ottawa. 
Through the city's commitment to the Community Garden Action Plan (CGAP), the Community \& Social Services Department works closely with Just Food to support existing community gardens and establish new ones. The idea of the CGAP was community-driven. In 2004, the CGN, a community-based organization, approached city council to request more comprehensive support from the city. In response, the City dedicated a staff member to work closely with the CGN in supporting their goals. The CGAP was passed in 2004, and a Community Garden Action Plan Evaluation was subsequently released in 2009, based on consultation feedback from city staff and community stakeholders. The evaluation recommended the establishment of a Community Garden Development Fund (CGDF). This was created in 2009, as a collaboration between Just Food, the City of Ottawa, and the Community Gardening Network, and distributes nearly $\$ 80,000$ per year towards the development of new gardens and expansion of existing gardens.

Several other municipal departments also work to support urban agriculture. Ottawa Public Health (OPH) and Just Food are both members of the Poverty and Hunger Working Group, a community-based coalition dedicated to improving food security. Not only does the Poverty and Hunger Working Group support Good Food Markets and the MarketMobile, but they also support community gardens and the work of Hidden Harvest. The Planning Department, through the Neighbourhood Connection Office, works with residents on small-scale projects to make communities more livable. They support urban agriculture in two main ways: by funding innovative urban agriculture projects (such as a biodome located in Brewer Park Community Garden), and through developing policies 
related to new urban agriculture initiatives, such as investigating the feasibility of community gardens in hydro corridors. Finally, the Parks, Recreation \& Cultural Services Department plays a key role in evaluating proposals for community gardens in public parks.

Food-related civil society organizations, including the Ottawa Food Policy Council (OFPC) and Canadian Organic Growers (COG), are also closely linked with Just Food. The OFPC emerged through a community-based food research project led by Just Food. Among other activities, they are currently working on policy recommendations and advocacy to increase urban agriculture in Ottawa, by encouraging the City to adopt a broader definition of the practice, beyond community gardens. Canadian Organic Growers works in collaboration with Just Food to conduct workshops related to sustainable growing techniques. COG's Growing Up Organic program also receives funding support from the CGN towards the establishment of new school gardens. The Ottawa chapter of COG is the only chapter of the organization engaged in this kind of programming. Since 2007, they have worked with primary and secondary schools in Ottawa and surrounding counties, to develop school gardens and integrate gardening material into school curricula.

Since community gardens are recognized as an important tool in the promotion of community development, organizations with a community development mandate are often very involved with supporting urban agriculture. Thirteen Community Health and Resource Centres (CHRCs) are located throughout the city, providing a range of community-based services, with a particular focus on services for residents who are considered vulnerable or at-risk. Community developers at these organizations always have an "ear to the ground" (G. Blinick, personal communication, August 28, 2014) when 
it comes to the establishment of community gardens in their service area. Their support often includes helping to provide logistical and capacity-building support, and hosting gardening workshops delivered by Just Food.

Community gardens are not the only food-producing initiatives supported by the CHRCs. The Sandy Hill Community Health Centre hopes to work with Hidden Harvest Ottawa and community residents to harvest food from fruit-bearing trees in public parks in their neighbourhood. As one community developer remarked, "food-bearing trees at the park are a perfect opportunity" (G. Blinick, personal communication, August 28, 2014) for increasing awareness of food that is already being grown in publically accessible spaces.

Two non-profit housing providers in Ottawa are also very active in promoting urban agriculture: Ottawa Community Housing $(\mathrm{OCH})$ and Centretown Citizens Ottawa Corporation (CCOC). As landlords, housing providers often have the ability to establish gardens relatively easily, since access to land is a less significant barrier. $\mathrm{OCH}$ is the largest social housing provider in Ottawa, providing homes for over 30,000 residents, many of whom are immigrants, students, people on social assistance, and people with disabilities. $\mathrm{OCH}$ currently has over twenty gardens on their properties, although the number fluctuates. While OCH works closely with Just Food, not all gardens on OCH properties are part of the CGN. Fulfilling the criteria to qualify for the Community Garden Development Fund (such as attendance at annual meetings and periodic reports) can be difficult for some $\mathrm{OCH}$ residents, many of whom face barriers such as mental health issues. The city also supports gardens on $\mathrm{OCH}$ properties, by providing funds towards common spaces in community housing complexes, which often establish and maintain community gardens. As a landlord, $\mathrm{OCH}$ is very supportive of residents who want to garden, and recently released a guide to 
explain how tenants can set up community gardens. In some communities, tenants are responsible for the organization and maintenance of gardens; however, in communities with limited capacity, an $\mathrm{OCH}$ staff person will take on the lead role. $\mathrm{OCH}$ also works closely with CHRCs, and has partnered with Hidden Harvest to identify and plant foodbearing trees on $\mathrm{OCH}$ properties.

$\mathrm{CCOC}$ is another non-profit, community-based housing provider, whose mission involves providing affordable housing for low- and moderate-income people. The CCOC has a long history of involvement with urban agriculture. In 1979, when CCOC built their first building, incentives were available for developers to include amenity space in their buildings. To take advantage of these incentives, CCOC included planting boxes on the roof of the building, and due to the positive outcomes of the rooftop garden, the CCOC has included them on most of the eighteen buildings they have subsequently built. In addition to rooftop gardens, the CCOC also distributes seeds and plants to residents. Originally, the intent behind this initiative was to help improve community aesthetics through the distribution of flowers; however, in recent years, in response to resident demand, the CCOC has expanded this program to include vegetables and herbs.

CCOC's urban agriculture activities extend to community gardens on and off CCOC properties. CCOC provided support for the establishment of two gardens that are currently part of the CGN, and continues to provide maintenance and support for these gardens. Recently, they included a community garden in the courtyard of a new property development; however, since this garden is open to residents only (not the general public), it is not part of the CGN. 


\subsubsection{Spaces of Interaction, Community Development, and Food Justice}

Urban agriculture practitioners tend to look at the practice through two interconnected lenses: food security and community development. Interviewees were divided on whether urban agriculture can contribute significantly to food security, due to its relatively small scale. However, they were united in their belief of the benefits urban agriculture can bring to community development.

Interview participants echoed many of the social capital and community development benefits noted in the urban agriculture and community garden literature, remarking on the ability of urban agriculture to strengthen relationships, break social isolation, make communities safer from crime, provide therapeutic benefits, and create a sense of place and neighbourhood pride. While cognizant of food security benefits, Ottawa Community Housing feels that community development is the most valuable aspect of community gardening. Their tenants are often socially isolated, due to challenges and stigma associated with mental health, and gardens can create a common space where tenants can socialize in a low-pressure environment.

Several interviewees remarked on the potential of urban agriculture to provide citizens with an opportunity to give back to the community. If a gardener has extra produce, they can distribute it to the food bank or to others in the community. Similarly, taking part in gleaning produce from trees on public property can create opportunities for people to work together and contribute to food banks. This sense of working together towards a common goal can help build more resilient communities.

While the support of urban agriculture involves the interaction and cooperation of many 
organizations and individuals, sites of urban agriculture are also places of interaction themselves, where everyday acts of community development and food justice take place. Site visits and interviews revealed that a wide array of activities take place within the spaces of community gardens, aside from the cultivation of plots for individual food production. Many gardens participate in community food security initiatives, either by contributing to food banks, or by making food directly available to community members. Many gardens take place in Just Food's "Plant a Row, Grow a Row, Donate a Row" program, which encourages gardeners (both private and community gardeners) to plant extra vegetables for donation to local food banks. Frequently, community gardens have entire plots that are maintained by garden members and specifically dedicated for donation.

In other cases, garden members will coordinate the collection of produce from individual plots for donation. One community garden, Partage Vanier, is located on the grounds of a food bank, and all ten raised bed plots support the work of the organization. At the Kilborn Allotment Gardens, Shepherds of Good Hope, a non-profit organization dedicated to helping the homeless and impoverished, maintains a large plot that helps to support their mission.

Many gardens also help make fresh produce available to community residents directly from the garden. It is common for gardens to have a "community plot", which is collectively maintained, and from which community members can help themselves. The Debra Dynes Community Garden (Figure 4), located in a social housing complex, is a "giving garden" that follows a different model to help with community food security. Community volunteers maintain all twenty-six raised beds plots in the garden, and the produce is available for anyone in the community to take as they need it. While demand 
from the community may exceed supply, this approach can help to engage people who are not garden members and contribute to community food security, while also reducing the likelihood of theft and vandalism. Several community gardens also host Good Food Markets, where community members can purchase fresh produce for wholesale prices. These activities that take place in community gardens help to demonstrate that an ethics of care is prevalent in many urban agriculture initiatives, and extends beyond immediate connections to a broader concern for the well-being of others in the community.

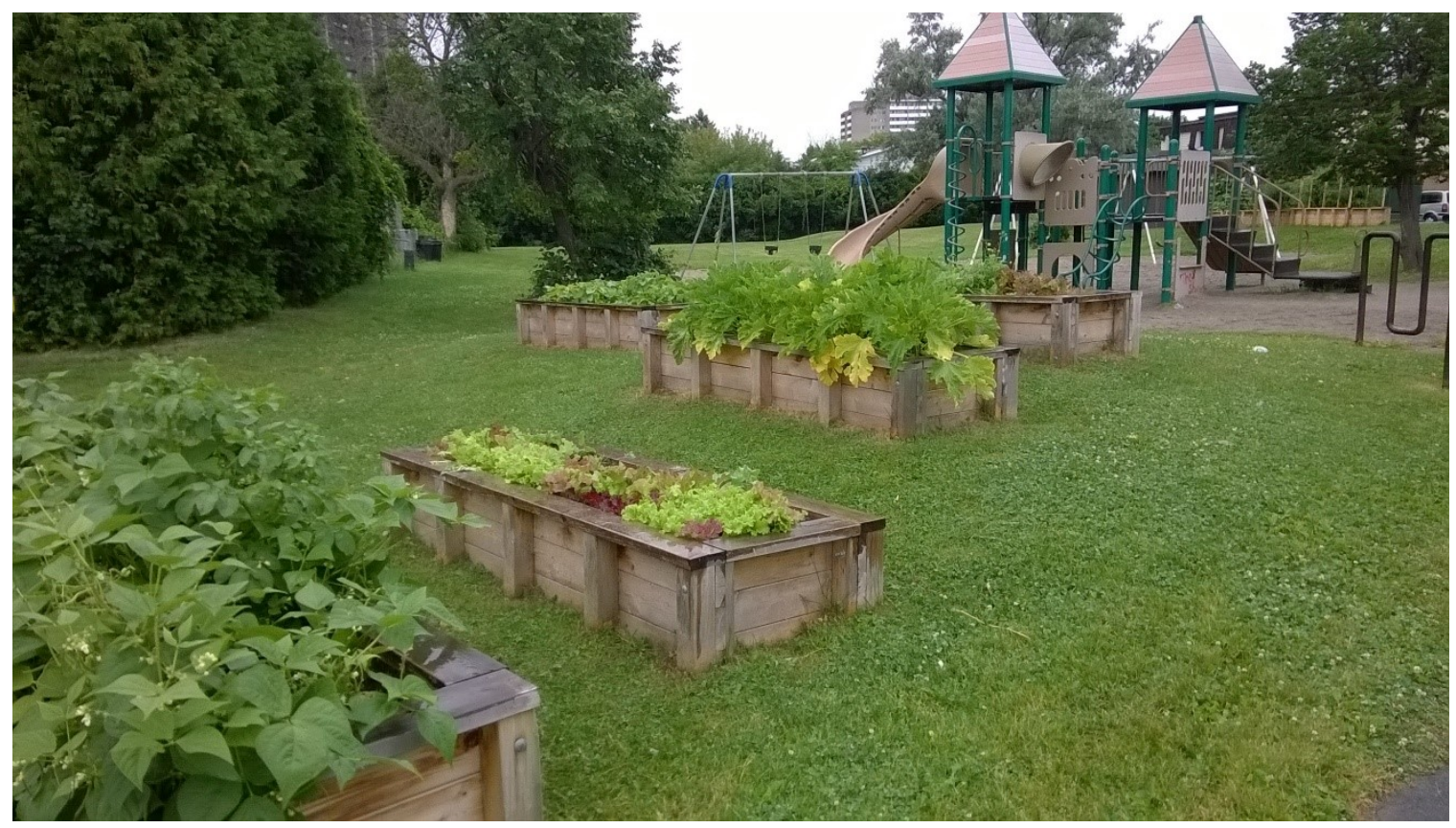

Figure 4 - The Debra Dynes “Giving Garden”.

Gardens in social housing complexes frequently follow a communal model, in which produce is available as needed by community members. In cases where plots are allocated to members, it is not uncommon for residents to share a plot, particularly when people have mobility or mental health issues that make it challenging to maintain a plot individually. Several interview participants working in community development noted that communal gardens, from which everyone contributes and everyone benefits, may be a better model in areas where people are faced with barriers, such as low-income, mental 
health, and mobility issues. Communal gardens can help ease the time and financial obligations of maintaining a plot individually, thereby encouraging broader participation.

Interviewees noted that food is unique in the way it can bring people together, regardless of background, knowledge, skills, or experience; community gardening "wouldn't be so unifying if not about food" (S. Bramley, personal communication, September 10, 2014). As another participant remarked:

One of the key things about food, and I've been a food activist for a long time, is that food is essentially a social activity. Anything that has to do with food will contribute to the development of more robust community relationships (C. Kneen, personal communication, July 24, 2014).

The strengthening of community relationships and care extended to others through urban agriculture activities points towards the production of social capital in these spaces.

Some interviewees felt that publically-accessible forms of urban agriculture are an important component in the development of a more sustainable local food system. As one participant noted: "the issue of [food] access is huge, and the issue of access to fresh fruits and vegetables even bigger. There are several different strategies which are being used to try and address that. One of them [...] is the creation of community gardens, where people in neighbourhoods have access to land where, if they don't have land where they live, where they can actually do some growing" (C. Kneen, personal communication, July 24, 2014). In this way, places of food production in public areas can contribute to food justice, by helping to increase access to fresh and wholesome foods.

Urban food production can increase access not only to fresh food, but also more specifically to fresh food that is local, organic, and culturally important. This can be especially important in low-income areas, where the higher prices often commanded by local and organic can make these types of food inaccessible across the socio-economic 
spectrum of the population. Several interviewees noted that growing some of one's own food can decrease the amount that families spend on food, at least throughout the growing season, but potentially throughout the year, if enough is produced to preserve. With larger plot sizes, such as those found in allotment gardens (see Figure 5), the degree of selfsufficiency from growing one's own food can be even more substantial.

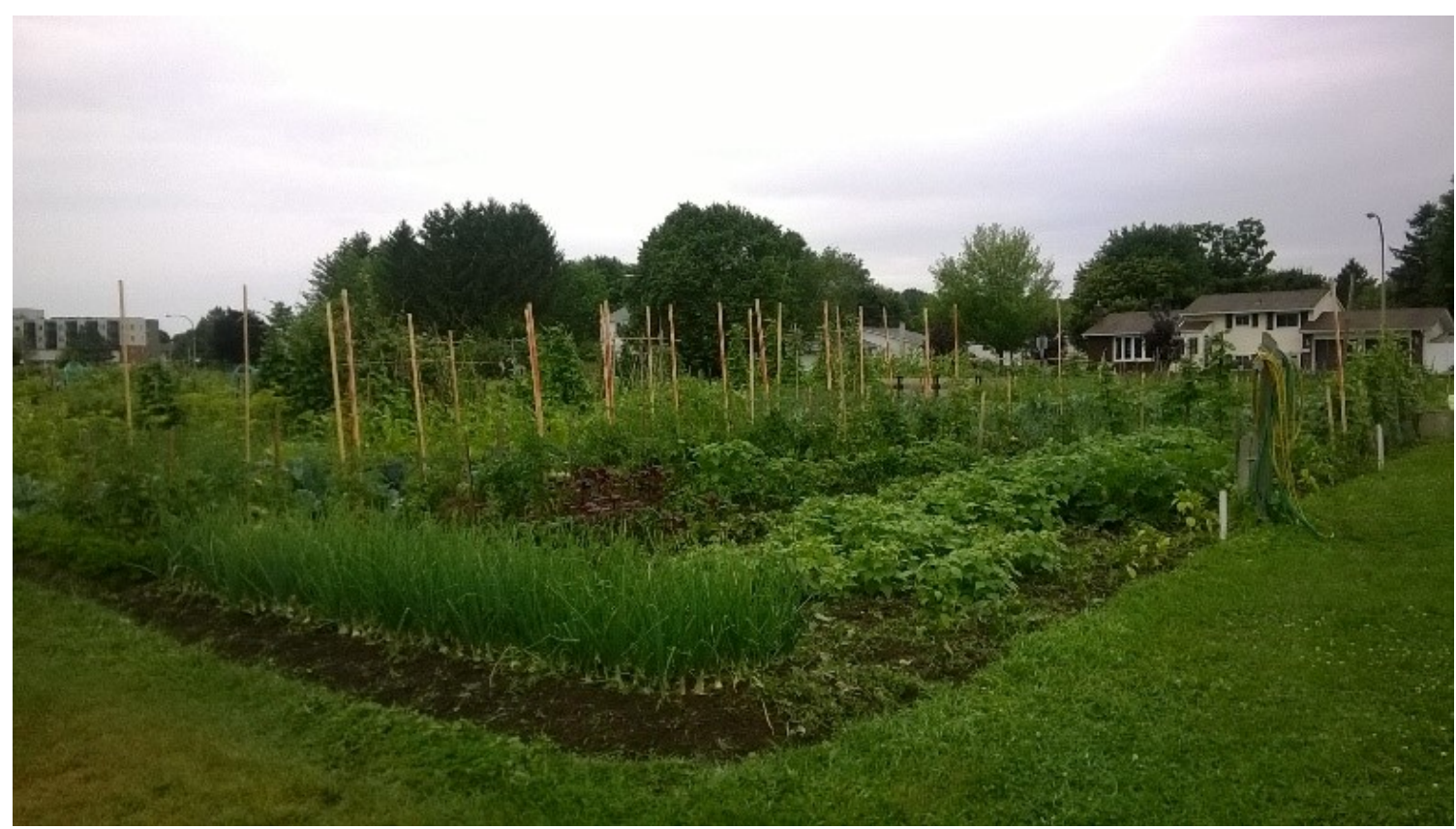

Figure 5 - Example of typical allotment garden plot (at Nepean Allotment Garden).

As the above activities illustrate, urban agriculture can contribute to community food security, in addition to individual food security. In addition, many interviewees noted that urban agriculture could foster a greater appreciation of where food comes from, which can help to strengthen support for other local food initiatives.

\subsubsection{Conceptualizations of Public Access in Community Gardens}

Community gardens are often portrayed as spaces that are accessible to, and provide benefits for, the public, as the community development and food security benefits above 
help to illustrate. However, community gardens have been referred to as a "third space" (Sciarra, 2007), or a space that is neither public nor private. Site visits revealed that gardens have varying degrees of access (real or perceived) for individuals who are not members. Gardens enclosed within locked gates represented the most obvious restriction of access. This was the case with two community gardens, which, incidentally, were located in two of the census tracts with the lowest incomes in the study area. In other cases, enclosures were not physical, but a perception of privacy existed. Several gardens were enclosed by unlocked fences, and one garden had a sign posted indicating the area was under video surveillance (Figure 6). Many gardens had signs reminding passers-by not to pick the vegetables, since the plots were tended by members. While such measures do not necessarily prevent the wider community from enjoying the garden space and reaping the broader benefits of community gardening, they can impart the perception that these are proprietary spaces, and cause non-members to question whether they are welcome in the space.

In some cases, gardens may be enclosed for safety reasons, for example, to prevent children from running out into traffic on adjacent busy streets. Often, however, the decision to enclose gardens is driven by negative experiences related to pilfering, theft, or vandalism. For example, at the Robert Legette Children's Garden (Figure 6), which is maintained communally by residents, an ongoing issue with pilfering has led to police involvement. Pilfering is not an issue that is restricted to in-ground gardens- the CCOC generally deals with one or two complaints of pilfering from their rooftop gardens each year. Despite these cases, according to interviewees, initial concerns regarding pilfering often fail to materialize. Several interviewees noted that, in general, the higher the level of 
community engagement with a garden, the lower the likelihood that issues of pilfering and vandalism emerge.

While some gardens impart a perception of privacy, others have a very open layout, particularly those that are located in public parks. Indeed, one interview participant remarked that one of the benefits of community gardens is that they provide a pleasant space for community residents to spend time, particularly in areas with little green space. Gardens that are communally tended also impart the perception of publicly accessible green space; one such garden that is located on the grounds of a social housing apartment building encourages passers-by to help themselves to herbs. Urban green spaces such as these can contribute not only to improved physical and psychological benefits to residents, but also to strengthening social interactions and a sense of place (Tzoulas et al., 2007).

Both individually and communally tended gardens illustrate an example of residents using urban space in a way that meets their needs, based on the social use value of the land. However, the perceptions of privacy associated with some garden spaces does raise Harvey's (2008) question of "whose rights and whose city" (p. 939) the right to the city confers. However, the movement for increased access to space for food production can also be viewed as a collective struggle, from which collective rights will eventually be realized. 


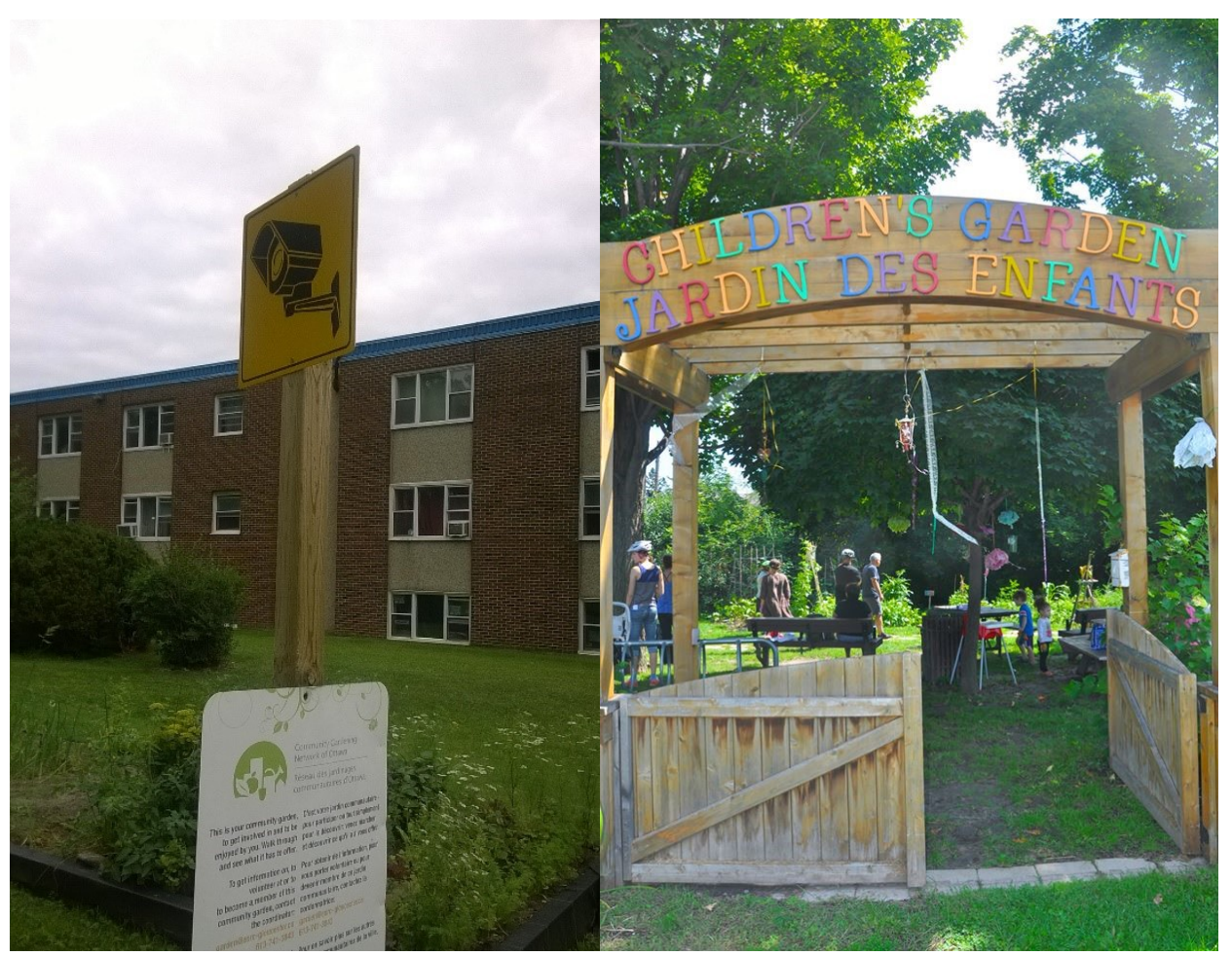

Figure 6 - Community garden with sign indicating video surveillance (left). Robert Legette Children's Garden (right. Photo: P. Ballamingie).

\subsubsection{Competition for Space}

One of the most significant barriers facing urban agriculture is access to land. Particularly in densely populated urban areas, there are many competing demands, from recreation and green space, to buildings and parking lots, and even well-established gardens are not immune to development pressures. Carlington Community Garden, for example, is currently situated adjacent to a community health and resource centre, but a low-income seniors' residence is planned for the property. With 154 plots, the garden is the largest non-allotment garden in the study area, and is located in a low-income neighbourhood. Urban agriculture practitioners are currently exploring relocation options, but are resigned to the fact that moving the entire garden in its current state may not be possible, due to the difficulty of finding space for such a large garden in the urban core, where space is at a 
premium.

The use of public parks for urban agriculture can be particularly contested, and was an issue that divided interviewees. Currently, eleven community gardens in the study area (over 20\%) are located in public parks. Parks are easily identifiable as municipally-owned land, and if residents see park space that appears under-used, it can appear to be a good candidate location for a community garden. Indeed, several interview participants expressed the view that all city parks should have some community garden space. However, as one interview participant noted, creating community gardens on park land is "essentially privatizing a section of the park" (K. Jones, personal communication, September 11, 2014), since once a garden is created, that space cannot be concurrently used for other recreational activities.

In densely populated urban areas, this problem is most pronounced. In the neighbourhood of Hintonburg-Mechanicsville, for example, residents have been trying to start a community garden for years, but are unable to find a location. In this area, the city is already unable to meet their parkland goals. Often, parks are the only form of green space available in a neighbourhood, but the parks themselves face multiple demands, with space allocated to other recreational activities, including playgrounds, sports fields, rinks, and pools. In the space that is left, it becomes difficult to argue that space should be allocated to community gardens, particularly since they can be perceived as a proprietary use from which relatively few residents reap the most benefit.

When gardens are situated in parks, the Parks and Recreation Department prefers that they are located in fringe areas, to help minimize their impact on other activities. An example of a garden located on the periphery of a park is the Sandy Hill Community 
Garden in Dutchie's Hole Park, which is located along the edge of a field, adjacent to a forested strip of land, in a somewhat remote section of the park. From the perspective of maintaining community support, locating gardens in marginal areas can have other benefits. While many residents enjoy the appearance of community gardens, others prefer a more manicured look, and find gardens to be unsightly, particularly if they are not wellmaintained. For aesthetic reasons, the Parks and Recreation Department also prefers raised beds rather than in-ground plots, since the beds help to minimize visual impacts. Raised beds are also seen as preferable for several other reasons: they can be used even when soil in the park is contaminated; they can be removed and used elsewhere if interest in a garden fades (which has not happened, to date); and, as a form of political technology, they help contain the size of gardens, by reducing the likelihood that gardeners will appropriate more land over time without permission.

The debate about whether and how to incorporate community gardens in public parks illustrates the negotiation of differences that often characterize struggles for the right to the city. While community gardens in parks are likely to remain contested, edible trees may represent another option for urban agriculture in these spaces. Several interviewees expressed that a potential partnership opportunity may exist between the Parks and Recreation Department and Hidden Harvest. While this concept would not be without challenges, since fruit-bearing trees can also cause an unsightly appearance if not harvested in time, it could also be an opportunity for more accessible food in public places. As a form of edible landscaping, trees are more easily integrated into multi-use spaces than community gardens, a factor which could help to balance multiple demands and create "heterogeneous and hybrid urban geographies" (Purcell, 2002, p. 106). 


\subsection{Demand for Urban Agriculture}

Since the establishment of the Community Garden Development Fund in 2009, the number of community gardens in Ottawa has doubled. Clearly, space for urban food production is in high demand, whether driven by a desire to increase food self-sufficiency, strengthen social networks, or some other motivation. Of the 28 community garden coordinators contacted, 21 replied, representing a response rate of 75\%. Over 90\% (19) of these gardens maintain a waiting list. The two gardens that do not have a waiting list are currently full; one has expanded in size to meet demand, but has reached the limit of space available, and expects to have a waiting list for the 2015 growing season.

The length of waiting lists varied from three individuals to 75, and several gardens, particularly those in the urban core, reported that it could take 2-5 years to receive a plot. One garden in the downtown area, Nanny Goat Hill, was so overwhelmed by demand that they abandoned waiting lists in favour of a lottery system. Other gardens, knowing they will be unable to accommodate everybody, limit the number of people they will add to their waiting lists, so the number of people on their lists does not necessarily reflect the true extent of demand.

Figure 7 depicts the 2011 population density of the study area by census tract, overlaid with locations of community gardens symbolized by waiting list length. This helps to illustrate the demand for community gardens in the urban core, where population density is highest. The high demand among the public for space to grow food was echoed by interview participants, several of whom noted that demand for community garden plots is virtually insatiable. A common theme identified by urban agriculture practitioners involved reconciling the demand for urban agriculture in the densely populated urban core 
with the challenge of finding available space in these areas.

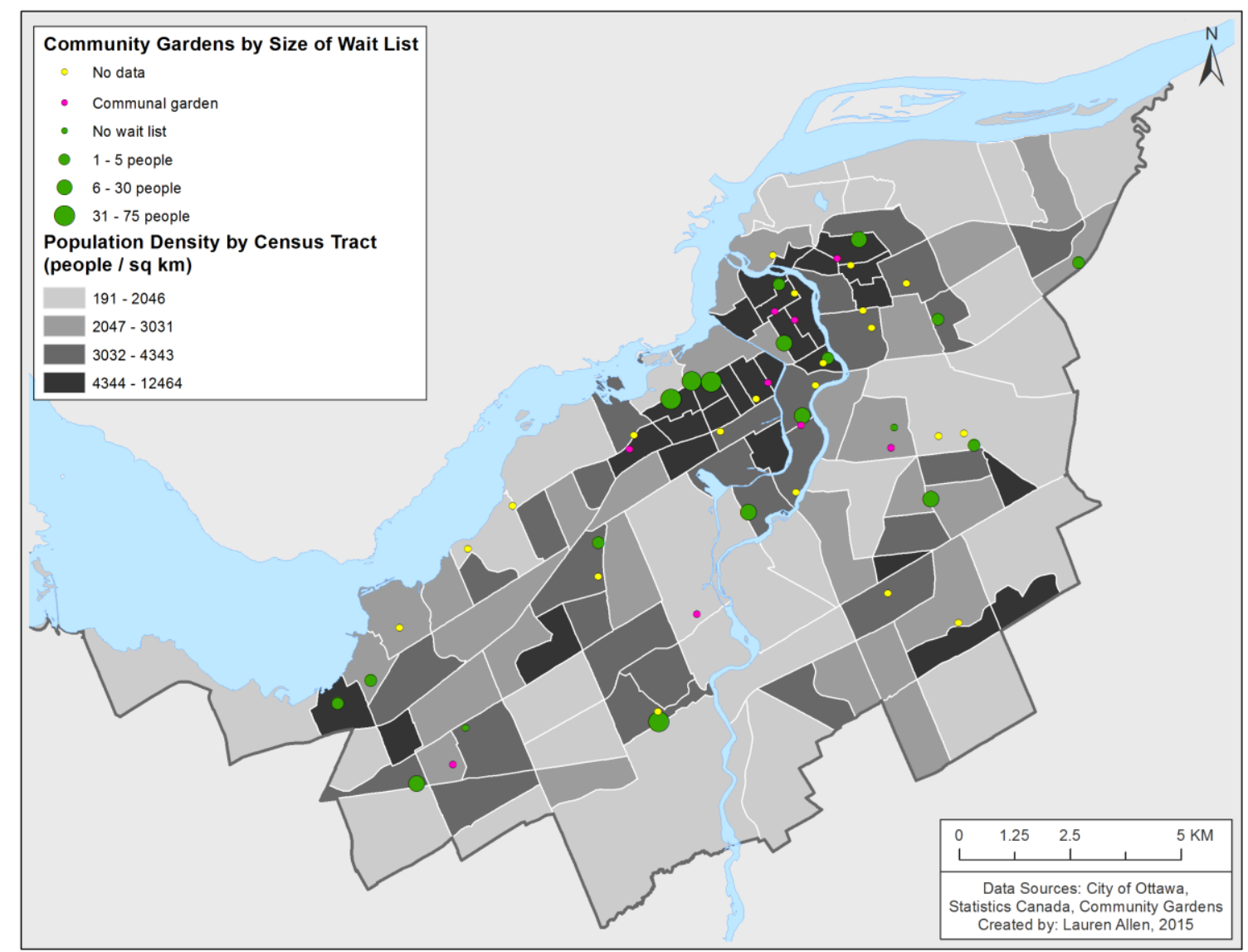

Figure 7 - Community garden locations, symbolized based on length of waiting list. Population density by census tract is symbolized using a quartile classification scheme.

Since the waiting list data represents only existing gardens, it does not reveal information regarding demand in areas where community gardens are lacking. However, the fact that there were over twenty applicants for funding for new community gardens in 2015 indicate that demand is widespread. The interactive mapping exercise also helped to inform unfulfilled demand (see Figure 8). During the exercise, interviewees frequently indicated areas where they were aware of existing struggles to establish a community garden. Many interviewees identified the Hintonburg-Mechanicsville neighbourhood of Ottawa, where community residents have been trying for years to establish a community 
garden. Residents have tried to access land from various sources, including the NCC, schools, and churches; at one point, residents were informally using a vacant lot as a garden. As one interviewee noted, "if we had space in Hintonburg-Mechanicsville, we would have had a garden ten years ago" (E. Hayes, personal communication, September $22,2014)$. The struggle for a community garden in this area has been long, and has involved different community members over time, indicating a widespread desire for space to grow food.

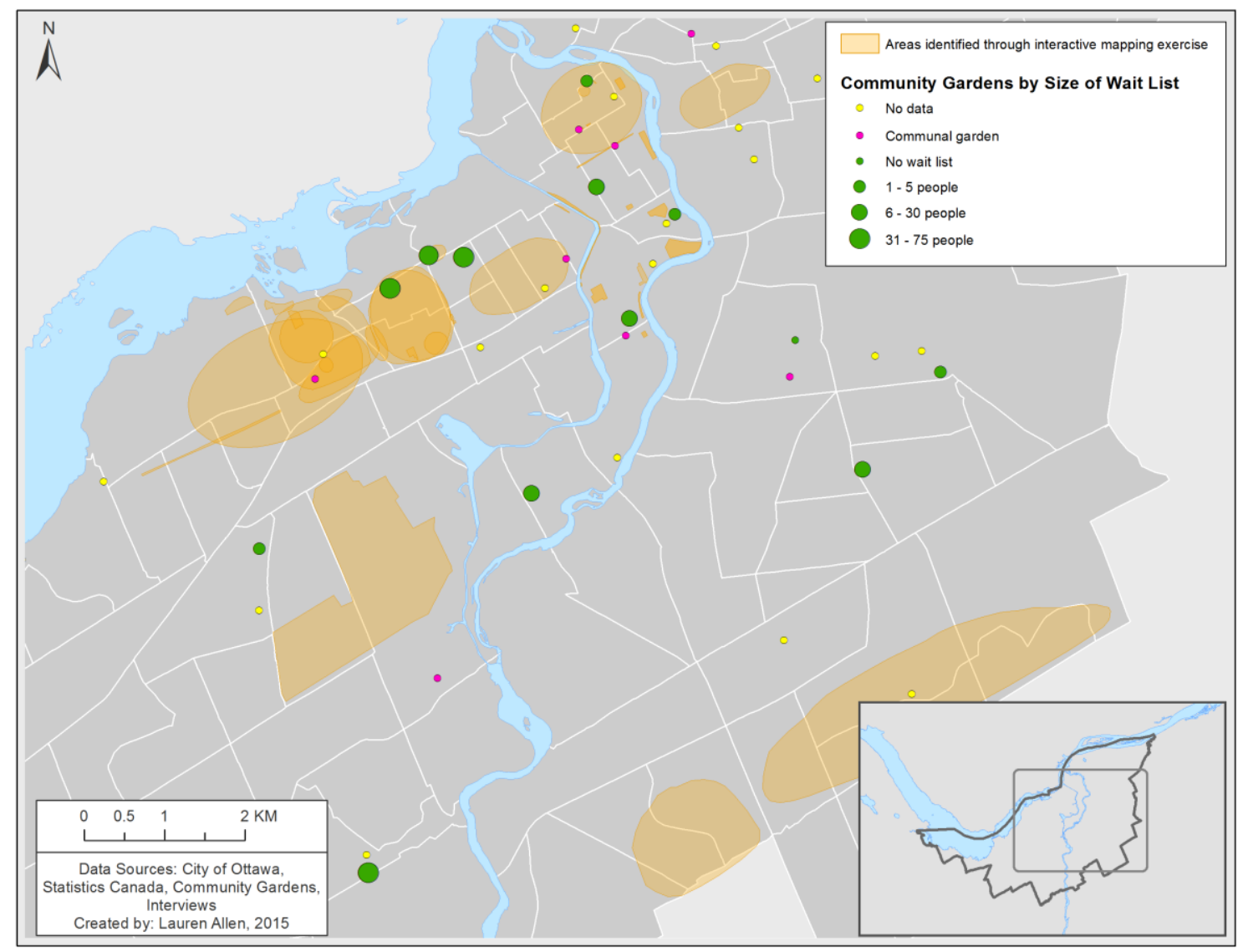

Figure 8 - Locations identified by interviewees as places where increased urban agriculture would be particularly beneficial (represented by orange polygons). Darker shades of orange indicate areas identified by multiple interviewees.

Waiting list information was not collected directly from non-CGN gardens (a category that includes many gardens on non-profit housing properties). However, interviews 
revealed that the dynamics in these gardens might be somewhat different. At the CCOC, there is either very little interest in rooftop garden plots, or, more frequently, there is a high level of interest necessitating a waiting list. Interest in one rooftop garden at a CCOC building in downtown Ottawa had been low, until two elderly residents (immigrants from Africa and Asia who had grown food in their home countries) started gardening on the rooftop, sparking the interest of other residents. This anecdote speaks to the idea of community gardens as places where social capital is both necessary and produced, in that it can connect people across cultural backgrounds, but also depends on social interaction and, in this case, learning by observing in order to be successful. Gardens on $\mathrm{OCH}$ properties tend not to have waiting lists, although this may be partially a reflection of the fact that many of these gardens follow a communal model, where gardening is done by members of a group and harvest is shared among the gardeners.

The concept of food justice promotes the idea that everyone has a right to food, and also a right to the ability to grow food, if desired. For justice to be realized, therefore, alternatives for growing and producing food must be available to all (Gottlieb \& Joshi, 2010). The unfulfilled demand for space to grow food in Ottawa is therefore problematic when studied through this lens. The next section of this chapter will consider how urban agriculture locations are distributed throughout the study area, to begin to assess whether there is "distributional justice" (Tornaghi, 2014) of food-growing opportunities in Ottawa.

\subsection{Spatial Analysis of Urban Agriculture Locations}

\subsubsection{Initial Mapping of Urban Agriculture Activities}

Overlaying community and school gardens with demographic data (Figure 9) revealed 
initial insights regarding the socio-spatial distribution of these practices. Nearly half the community gardens in the study area $(44.0 \%)$ are located in census tracts representing the highest quartile of low-income individuals (i.e. those with over $21.5 \%$ of individuals classified as low income according to the after-tax low-income (LIM-AT) measure). This finding is perhaps not surprising, given that a number of community gardens are located in social housing communities, and that several urban agriculture practitioners indicated a preference for supporting gardens in lower-income neighbourhoods. This finding is also in accordance with Kremer \& DeLiberty (2011) who found that over 50\% of community gardens in Philadelphia were located in the lowest-income neighbourhoods, supporting their conclusion that "personal food production in community gardens is filling the [local food] gap in low-income, inner city neighbourhoods" (p. 1260). 


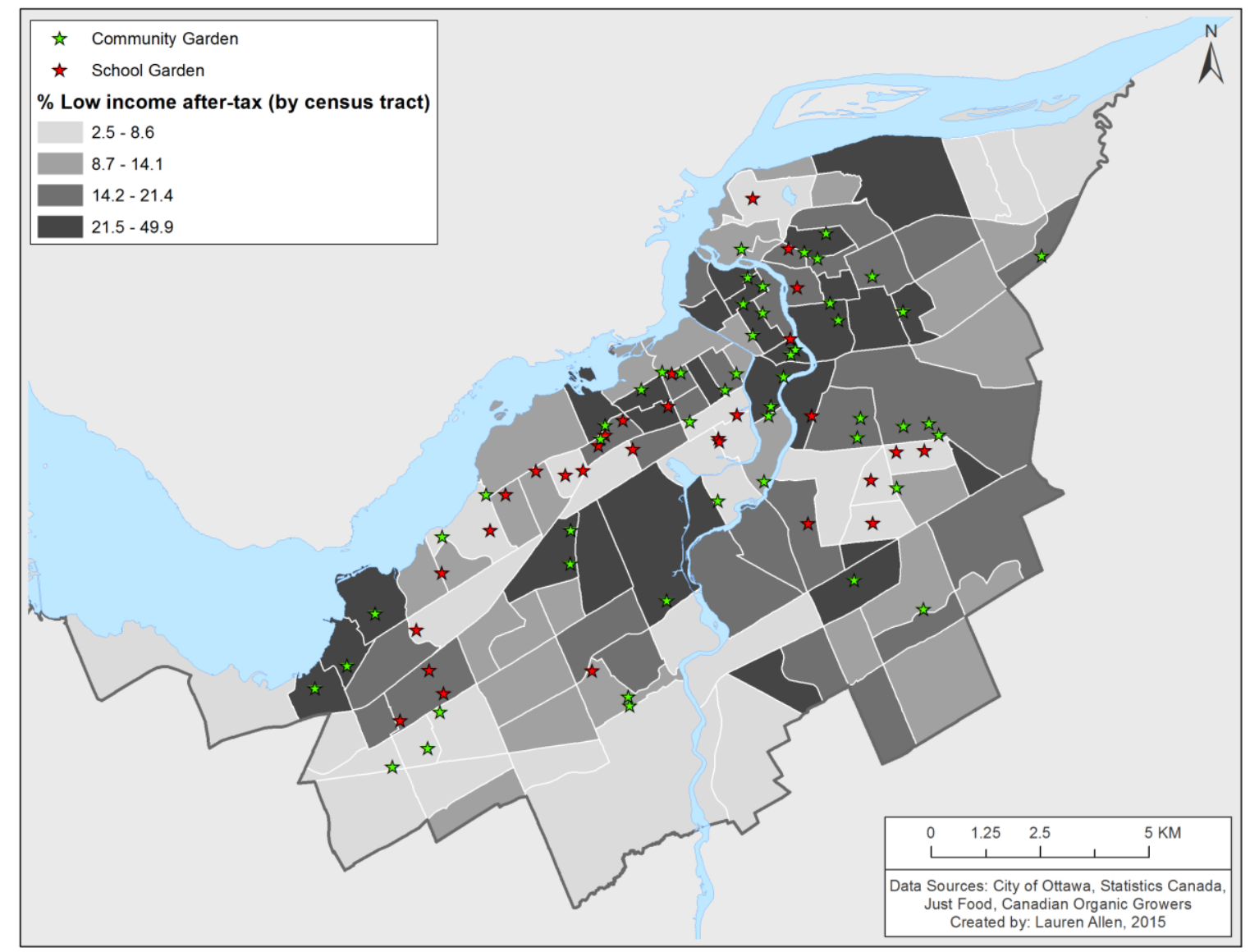

Figure 9 - Percentage low income by census tract according to after-tax low-income measure, overlaid with locations of community and school gardens.

However, given the wide range in size of community gardens (from several raised beds to over 300 plots), considering the number of community garden plots instead of the number of garden locations may be a better indicator of how access to public space for gardens is distributed. In fact, this comparison reveals that the initial observation of a higher prevalence of community gardens in low-income areas may not be quite so straightforward. While $44.0 \%$ of community gardens are located in the lowest-income census tracts, this represents only $33.9 \%$ of community garden plots in the study area. The highest percentage of community garden plots (43.6\%) are actually found in the census tracts with the second-lowest prevalence of low-income individuals. 
Locations of school gardens in relation to prevalence of low income is also interesting. Forty percent $(40.0 \%)$ of school gardens are located in the census tracts that have the lowest percentages of low-income individuals, while only $10.0 \%$ are located in census tracts in the highest low-income quartile. Visual analysis of the map in Figure 9 reveals a cluster of school gardens in the Westboro and Hintonburg-Mechanicsville neighbourhoods, and a smaller cluster in the eastern part of the study area, near the neighbourhood of Alta Vista. This distribution was noted by the Project Manager of Growing Up Organic, who explained that schools generally approach COG to participate in the program, rather than vice versa. The program began in the Westboro and Hintonburg-Mechanicsville neighbourhoods, and spread to nearby schools through word of mouth, and then gained a second foothold in the Alta Vista area. However, the higher incidence of school gardens in higher income neighbourhoods may also reflect greater capacity and support in these areas.

The initial exploratory mapping of community and school gardens revealed different distributional patterns, with community garden locations more prevalent in lowincome areas, and school gardens more common in high-income areas. This may indicate that the social processes influencing each of these practices are not the same, providing support for the decision to consider each separately in the remainder of the spatial analyses.

\subsubsection{Directional Distribution Analyses}

A directional distribution analysis (based on one standard deviation) was performed separately for community gardens, school gardens, and edible trees, in order to assess initial spatial patterns (Figure 10). Each of the resulting ellipses show a northeast- 
southwest orientation, centred over the core of the study area, indicating that these practices are concentrated in more urban areas. Two distributional analyses were conducted for community gardens, one using unweighted locations, and the other weighted based on the number of plots per location. Unsurprisingly, the weighted ellipse displays a shift away from the urban core, likely reflecting the fact that there is more space available for larger community gardens in less densely populated areas.

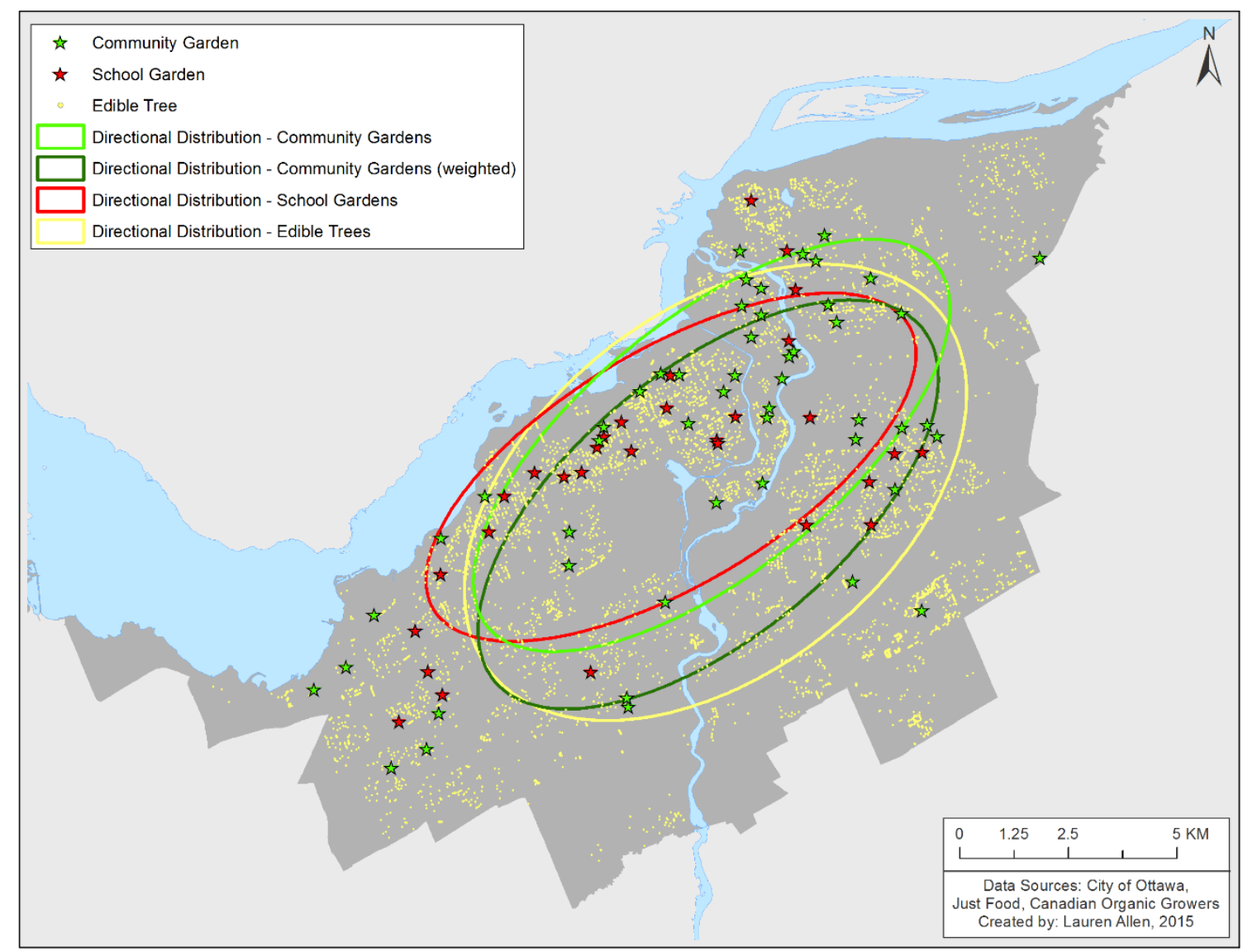

Figure 10 - Directional distribution analysis (based on one standard deviation) for community gardens, school gardens, and edible trees.

\subsubsection{Hot Spot Analyses}

Figures 11-14 show the hot spot analyses for each of the urban agriculture practices. The analysis of community garden locations per population of 1,000 (Figure 11) revealed a relatively large hot spot in the urban core, encompassing census tracts in the 
neighbourhoods of Sandy Hill, Ottawa East, and Lowertown, as well as portions of Centretown, the Glebe, Ottawa South, Overbrook, and Vanier. One cold spot was identified, consisting of two census tracts in the Hunt Club neighbourhood. This area has no community gardens, and is surrounded by census tracts with few or no gardens. In contrast, the analysis of the number of community garden plots per population of 1,000 (Figure 12) revealed two hot spots; unsurprisingly, these correspond with the two large allotment gardens that are within the study area, Kilborn Allotment Gardens (which has 355 plots) and Nepean Allotment Gardens (which has 252 plots). No cold spots were identified; this may be a reflection of the fact that there are many census tracts with few or no community garden plots, so no areas stand out as being statistically low.

The analysis of the number of school gardens per population of 1,000 (Figure 13) also revealed two distinct hot spots. The more statistically significant of these covers the neighbourhoods of Westboro, Hintonburg-Mechanicsville, and West Centretown. As mentioned in the previous section, this region represents the location where the school garden program started, and spread to nearby schools through word of mouth. The second hot spot, which is less statistically significant, corresponds with a smaller cluster of school gardens near the neighbourhood of Alta Vista.

Finally, the analysis for fruit and nut-bearing trees (Figure 14) shows one highly significant hot spot, in the neighbourhoods of Rockcliffe-Manor Park and Lindenlea-New Edinburgh. Rockcliffe-Manor Park has the highest median household income in the study area (roughly \$213,000) while Lindenlea-New Edinburgh also has a high median household income, at approximately $\$ 90,000$. Several smaller, less significant hotspots are also present corresponding with two average-income census tracts, and one low-income 
census tract. One cold spot is also identified, encompassing four census tracts in the neighbourhood of Sandy Hill and one census tract in Vanier. One of these has the lowest median household income in the study area $(\$ 28,000)$, while the others have average or low household income levels. The Sandy Hill census tracts also have a high percentage of rented dwellings, ranging from $72-90 \%$, due to a highly mobile student population in the vicinity of the University of Ottawa.

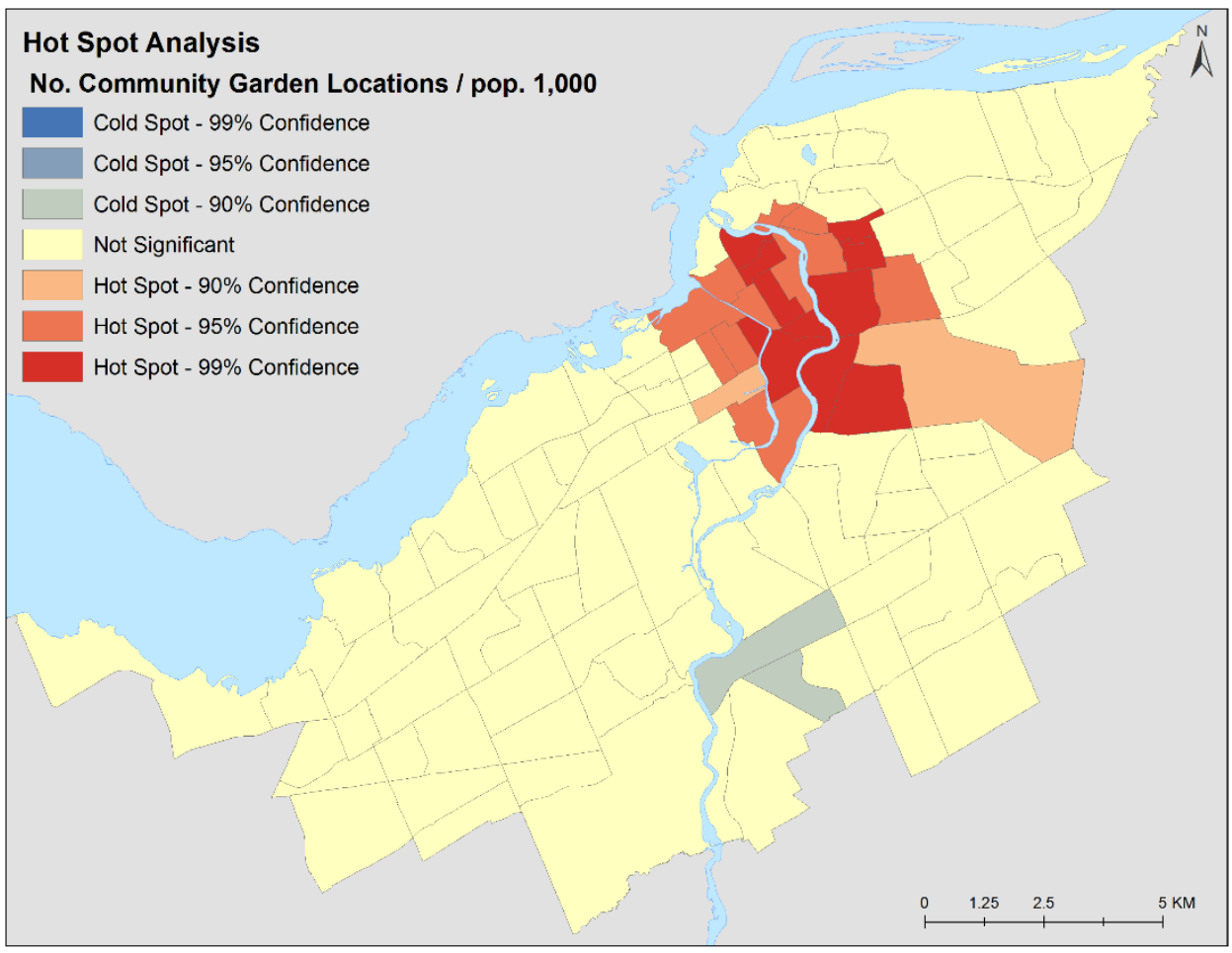

Figure 11 - Hot spot analysis for number of community garden locations per population of 1,000 . 


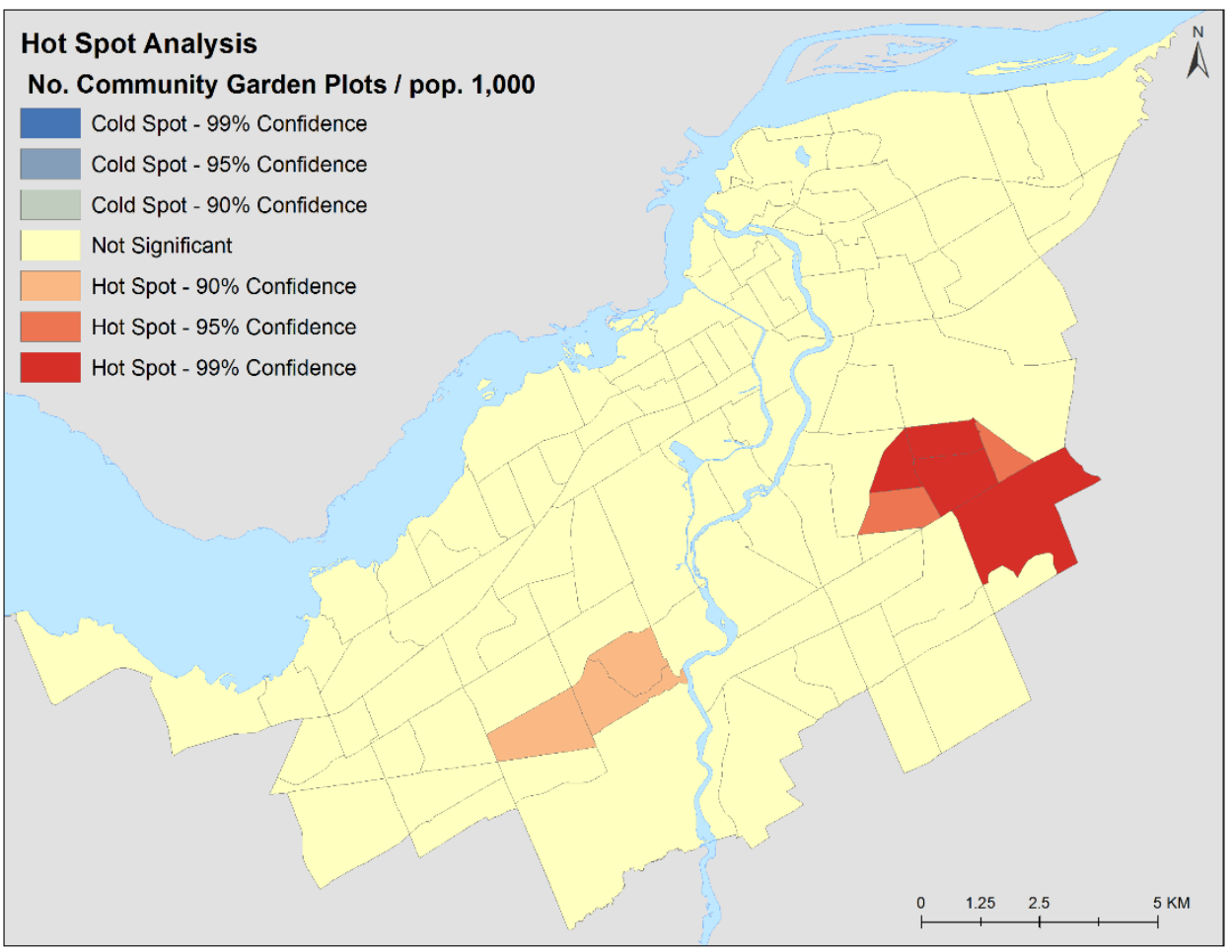

Figure 12 - Hot spot analysis for number of community garden plots per population of 1,000 .

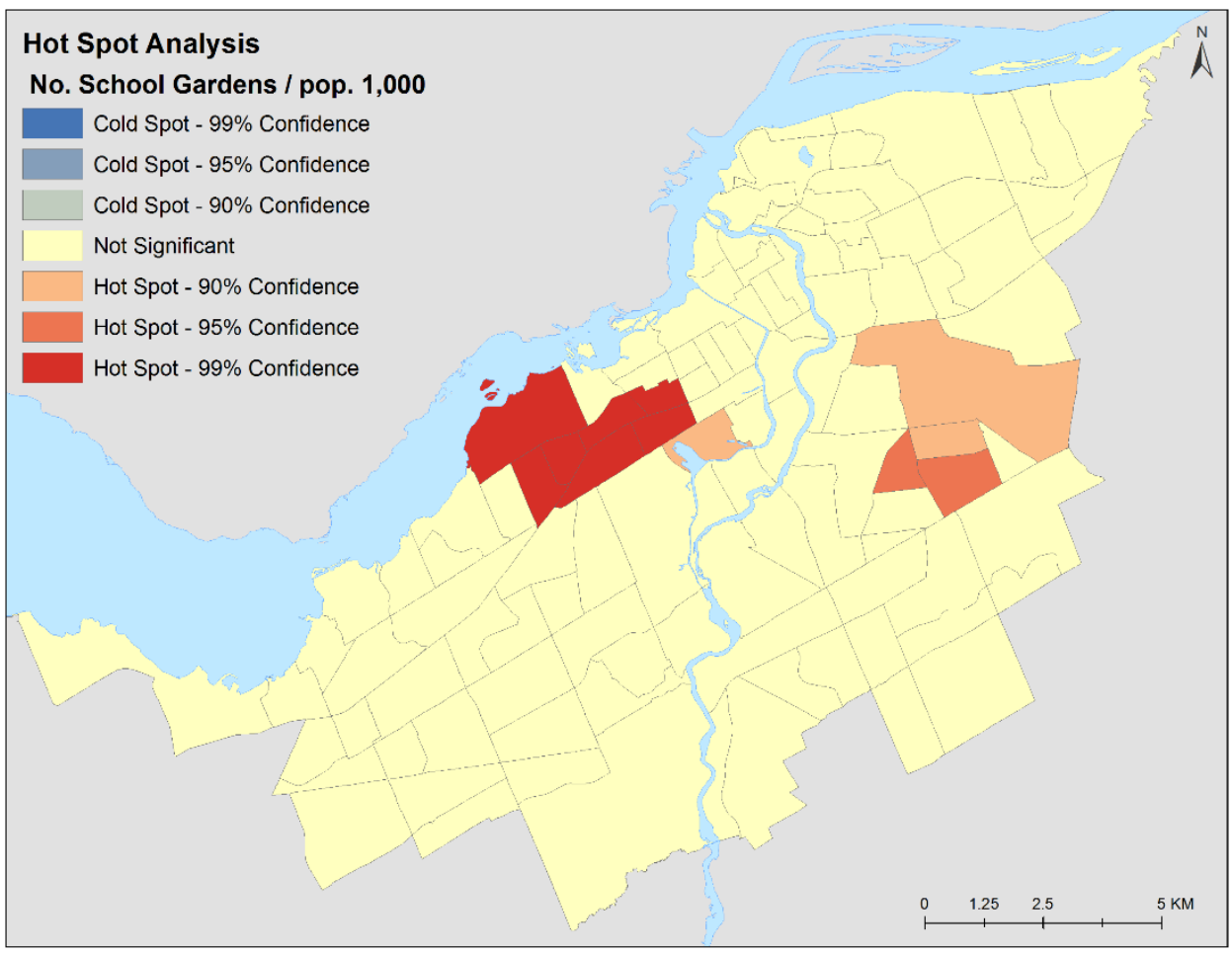

Figure 13 - Hot spot analysis for number of school garden locations per population of 1,000 . 


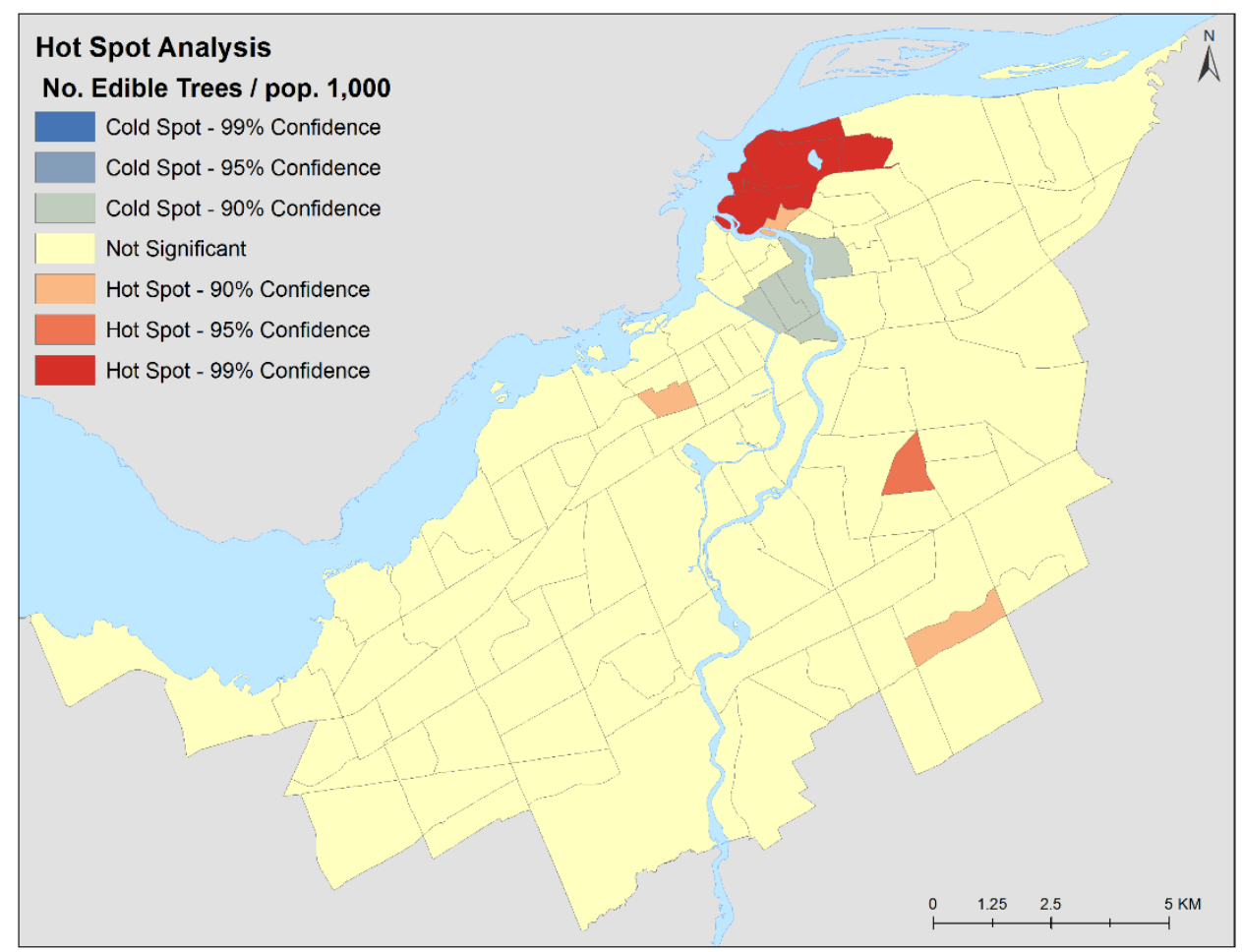

Figure 14 - Hot spot analysis for number of fruit- or nut-bearing trees per population of 1,000 .

\subsubsection{Regression Modelling}

This section will present the results of the regression modelling. Results for the ordinary least squares modelling will be presented first, followed by geographically weighted regression.

\section{Ordinary Least Squares}

Ordinary least squares modelling using the number of community garden plots per population of 1,000 as the dependent variable did not yield meaningful results. Various combinations of explanatory variables were experimented with, but only one explanatory variable was consistently identified as significant, and adjusted $r^{2}$ values remained low (below 0.1) for all iterations. Using the other urban agriculture practices as dependent variables (number of community garden locations, number of school gardens, and number 
of edible trees per population of 1,000$)$ produced more significant results. A summary of the best-performing model for each dependent variable is provided in Table 5.

Table 5 - Summary of best-performing OLS model for each dependent variable.

\begin{tabular}{|c|c|c|c|c|c|c|}
\hline $\begin{array}{l}\text { Dependent } \\
\text { Variable }\end{array}$ & $\begin{array}{l}\text { Explanatory } \\
\text { Variables }\end{array}$ & $\begin{array}{l}\text { Variable } \\
\text { Co- } \\
\text { efficient }\end{array}$ & $\begin{array}{l}\text { Variable } \\
\text { Prob- } \\
\text { ability }\end{array}$ & $\begin{array}{l}\text { Variance } \\
\text { Inflation } \\
\text { Factor } \\
\text { (VIF) }\end{array}$ & $\begin{array}{l}\text { Adjust- } \\
\text { ed } r^{2}\end{array}$ & $\begin{array}{l}\text { Akaike's } \\
\text { Information } \\
\text { Criterion } \\
\text { (AICc) }\end{array}$ \\
\hline \multirow{7}{*}{$\begin{array}{l}\text { Number of } \\
\text { community } \\
\text { gardens } \\
\text { per } 1,000 \\
\text { population }\end{array}$} & Intercept & 0.109764 & $0.000000^{*}$ & - & \multirow[t]{7}{*}{0.241} & \multirow[t]{7}{*}{-76.755} \\
\hline & $\begin{array}{l}\text { \% Rented } \\
\text { dwellings }\end{array}$ & -0.052286 & 0.162310 & 5.594 & & \\
\hline & $\begin{array}{l}\text { Median } \\
\text { household } \\
\text { income }\end{array}$ & -0.073301 & 0.074816 & 6.931 & & \\
\hline & $\begin{array}{l}\text { \% Population } \\
\text { aged 25-64 } \\
\text { with } \\
\text { Bachelor's } \\
\text { degree or } \\
\text { higher }\end{array}$ & 0.119344 & $0.000240^{*}$ & 3.957 & & \\
\hline & $\begin{array}{l}\text { Unemploy- } \\
\text { ment rate }\end{array}$ & 0.033816 & 0.137336 & 2.115 & & \\
\hline & $\begin{array}{l}\text { \% Population } \\
\text { who are } \\
\text { immigrants }\end{array}$ & -0.055390 & $0.005519^{*}$ & 1.591 & & \\
\hline & $\begin{array}{l}\% \text { of Female } \\
\text { lone-parent } \\
\text { families }\end{array}$ & 0.135039 & $0.000009^{*}$ & 3.409 & & \\
\hline \multirow{7}{*}{$\begin{array}{l}\text { Number of } \\
\text { school } \\
\text { gardens } \\
\text { per } 1,000 \\
\text { population }\end{array}$} & Intercept & 0.076586 & $0.000001^{*}$ & - & \multirow[t]{7}{*}{0.239} & \multirow[t]{7}{*}{-98.405} \\
\hline & $\begin{array}{l}\text { \% Population } \\
\text { aged 25-64 } \\
\text { with } \\
\text { Bachelor's } \\
\text { degree or } \\
\text { higher }\end{array}$ & -0.052129 & 0.078227 & 4.215 & & \\
\hline & $\begin{array}{l}\text { \% Population } \\
\text { who are } \\
\text { immigrants }\end{array}$ & -0.031040 & 0.110410 & 1.881 & & \\
\hline & $\begin{array}{l}\text { \% Low } \\
\text { income } \\
\text { based on low } \\
\text { income after- } \\
\text { tax measure }\end{array}$ & -0.079672 & $0.006676^{*}$ & 4.214 & & \\
\hline & $\begin{array}{l}\text { Median } \\
\text { dwelling } \\
\text { value }\end{array}$ & 0.091494 & $0.000405^{*}$ & 3.171 & & \\
\hline & $\begin{array}{l}\text { \% Apartment } \\
\text { dwellings }\end{array}$ & 0.121421 & $0.000094^{*}$ & 4.471 & & \\
\hline & $\begin{array}{l}\% \text { Families } \\
\text { with children }\end{array}$ & 0.087821 & $0.001188^{*}$ & 3.498 & & \\
\hline
\end{tabular}




\begin{tabular}{|c|c|c|c|c|c|c|}
\hline \multirow{7}{*}{$\begin{array}{l}\text { Number of } \\
\text { edible trees } \\
\text { per } 1,000 \\
\text { population }\end{array}$} & Intercept & 16.716214 & $0.000000^{*}$ & - & \multirow[t]{7}{*}{0.612} & \multirow[t]{7}{*}{824.90} \\
\hline & $\begin{array}{l}\text { Median } \\
\text { household } \\
\text { income }\end{array}$ & 13.682689 & $0.000000^{*}$ & 3.897 & & \\
\hline & $\begin{array}{l}\text { \% Population } \\
\text { aged 25-64 } \\
\text { with } \\
\text { Bachelor's } \\
\text { degree or } \\
\text { higher }\end{array}$ & -8.477475 & $0.000007^{*}$ & 3.538 & & \\
\hline & $\begin{array}{l}\text { \% Population } \\
\text { who are } \\
\text { visible } \\
\text { minority }\end{array}$ & 1.868876 & 0.097209 & 1.443 & & \\
\hline & $\begin{array}{l}\text { Median } \\
\text { dwelling } \\
\text { value }\end{array}$ & 6.526632 & $0.000860^{*}$ & 4.187 & & \\
\hline & $\begin{array}{l}\text { Average } \\
\text { residential } \\
\text { parcel size }\end{array}$ & -1.563960 & 0.235237 & 1.958 & & \\
\hline & $\begin{array}{l}\text { Distance to } \\
\text { urban centre }\end{array}$ & -5.041702 & $0.000462^{*}$ & 2.196 & & \\
\hline
\end{tabular}

An asterisk (*) beside the variable probability indicates a statistically significant p-value $(p<$ 0.01).

Using the number of community garden locations as the dependent variable, the best-performing model included six explanatory variables: percentage of rented dwellings, median household income, percentage of the population with a Bachelor's degree or higher, unemployment rate, percentage of the population who are immigrants, and percentage of female lone-parent families. While only three of these variables (education, immigrant population, and female lone-parent families) had statistically significant probabilities, removing the non-significant variables had detrimental effects on the adjusted $r^{2}$ and AICc values of the model. The adjusted $r^{2}$ value for the model was 0.24 , indicating that approximately a quarter of the variance in the dependent variable can be explained by the model. In some aspects, the model supports the concept that community gardens are more likely to be located in areas with lower socio-economic indicators. As unemployment rates and the percentage of female lone-parent families increase, and 
household income decreases, the number of community garden locations increases. The percentage of rented dwellings had a negative relationship with the dependent variable, which was unexpected, since it was hypothesized that higher rates of renting would be associated with a higher need for community gardens. It may be the case that while demand is higher, population density in areas with a high proportion of renters is also higher, and access to public space where gardening could occur is therefore more limited. Further, areas with a high percentage of itinerant renters may lack the long-term community support required to support community gardens.

Two variables diverge from the expectation that community gardens are more likely to be located in areas with lower socio-economic indicators: a higher level of education had a positive relationship with the dependent variable, while a higher rate of immigrants had a negative relationship. Mapping the percentage of immigrants shows that while there are some isolated census tracts in the urban core with high levels of immigrants, many of the areas with high percentages of immigrants are located outside of the urban core, with high concentrations in the neighbourhoods of Hunt Club and Heron Gate. Most of the community gardens in Ottawa are located closer to the urban core, and only two are in the neighbourhoods of Hunt Club and Heron Gate, both of which are located on $\mathrm{OCH}$ properties. A potential explanation for the performance of the education variable will be explored in the discussion of the geographically weighted regression results.

Using the number of school garden locations as the dependent variable, six variables were also included in the best-performing model: percentage of the population with a Bachelor's degree or higher, percentage of the population who are immigrants, percentage of low-income individuals, median dwelling value, percentage of apartment 
dwellings, and percentage of families with children. All except for the education and immigrant variables were identified as statistically significant. Unsurprisingly, as the percentage of families with children increased, the number of school gardens increased. Higher rates of apartment living were also associated with an increase in the dependent variable, which may be indicative of a greater desire for school gardens in urban areas. An increase in median dwelling value and decreases in low-income and immigrant populations were also associated with an increase in the dependent variable, indicating that school gardens may be more highly associated with factors indicative of higher socio-economic status. However, higher education rates had a negative relationship with the dependent variable. The adjusted $\mathrm{r}^{2}$ value for the model was 0.24 , indicating that almost a quarter of the variance in the number of school gardens can be explained by the model.

The final OLS model used the number of edible trees as the dependent variable. Again, six variables were included in the best-performing model: median household income, percentage of the population with a Bachelor's degree or higher, percentage of the population who are a visible minority, median dwelling value, average residential parcel size, and distance to the urban centre. All variables except for the percentage visible minority variable were identified as significant to the model. An increasing number of edible trees was strongly associated with higher household incomes and higher median dwelling values, indicating that this form of urban agriculture may be associated with higher socio-economic levels. However, decreasing levels of education, and to a lesser extent, increasing levels of visible minorities, were also associated with an increasing number of edible trees. Increasing distance to the city centre, and to a lesser extent residential parcel size had a negative relationship with the dependent variable, indicating 
that edible trees on public property may be more likely to be located near the urban core (although not directly in the urban core, as the cold spot in Sandy Hill illustrates). The adjusted $\mathrm{r}^{2}$ value for the model was 0.61 , indicating that almost two-thirds of the variance in the number of edible trees can be explained by the model.

\section{Geographically Weighted Regression}

In order to assess whether a local model could perform better than the global ordinary least squares model, geographically weighted regression was conducted for each urban agriculture practice, using the same variables that were identified in the best OLS model. For community and school gardens, the GWR analysis yielded a slightly lower adjusted $\mathrm{r}^{2}$ value and a slightly higher AICc value than the corresponding OLS model, indicating no improvement of the local model over the global model. However, for edible trees, the GWR model showed improvements over the global model. The GWR analysis was conducted using both an adaptive kernel and a fixed kernel, and while both showed an improvement over the local model, the fixed kernel performed better according to the goodness-of-fit measures of the model. The adjusted $\mathrm{r}^{2}$ increased from a value of 0.61 for the global model to 0.72 for the local model, while the AICc decreased from 824.90 to 805.28. The increase in $\mathrm{r}^{2}$ from the global model to the local model indicates an improvement in the performance of the model, while the decrease in the AICc value provides further evidence that the local model is a better fit for the data (Charlton \& Fotheringham, 2009).

Table 6 presents the characteristics of the GWR coefficients, as well as the OLS coefficients. The GWR coefficient means are quite similar to the OLS coefficients, but the difference between the minimum and maximum values displays quite a range for several 
of the explanatory variables. Additionally, several of the variables display a change in sign from negative to positive. The range and direction change support the idea that the relationships between the explanatory variables and the dependent variable are nonstationary. Spatial autocorrelation of the global model residuals, with a Morans I value of 0.006 , showed a very slight tendency towards clustering. The local Morans I value of 0.025 showed a slight tendency for dispersion, which may indicate that spatial relationships that were present in the global model were smoothed out in the local model, through the use of spatially varying parameter estimates (Fotheringham et al., 2002).

Table 6 - GWR and OLS coefficients for the local and global regression models.

\begin{tabular}{|l|l|l|l|l|}
\hline \multirow{2}{*}{} & \multicolumn{2}{l}{ GWR } & \multirow{2}{*}{ OLS } \\
\cline { 2 - 4 } & Minimum & Mean & Maximum & \\
\hline Intercept & 11.926549 & 15.681243 & 18.038809 & 16.716214 \\
\hline Median household income & 3.391791 & 13.185358 & 22.796137 & 13.682689 \\
\hline $\begin{array}{l}\text { \% Population aged 25-64 with } \\
\text { Bachelor's degree or higher }\end{array}$ & -12.668669 & -6.952931 & -1.264547 & -8.477475 \\
\hline $\begin{array}{l}\text { \% Population who are visible } \\
\text { minority }\end{array}$ & -1.924501 & 1.439223 & 3.639013 & \\
\hline Median dwelling value & -4.842562 & 3.826255 & 11.862613 & 6.526632 \\
\hline Average residential parcel size & -5.793337 & -0.201618 & 3.710225 & -1.563960 \\
\hline Distance to urban centre & -17.738613 & -7.53926 & 0.174084 & -5.041702 \\
\hline
\end{tabular}

Mapping the standardized differences between observed and predicted values (Figure 15) reveals three census tracts with high under-prediction. One of these census tracts, located in Rockcliffe-Manor Park, has the highest rate of edible trees in the study area, which, at 143 per population of 1,000 , is over three times higher than the value of the next highest census tract. The model did predict a high value for this census tract (128 locations per population of 1,000$)$, but the very high observation may explain the failure of the model to accurately predict this area. The other two census tracts with high underprediction also had among the highest observed values in the study area, indicating that the 
model may not perform as well in areas with very high rates of edible trees. One census tract, in the neighbourhood of Rothwell Heights in the northeastern corner of the study area, shows high over-prediction. This census tract has the highest residential parcel size in the study area, and inspection of aerial imagery revealed a relatively low street density among large, heavily forested residential properties. Since edible trees on public property are usually found along roadways, the low street density could explain the low observed levels of edible trees on public land, and the resulting over-prediction.

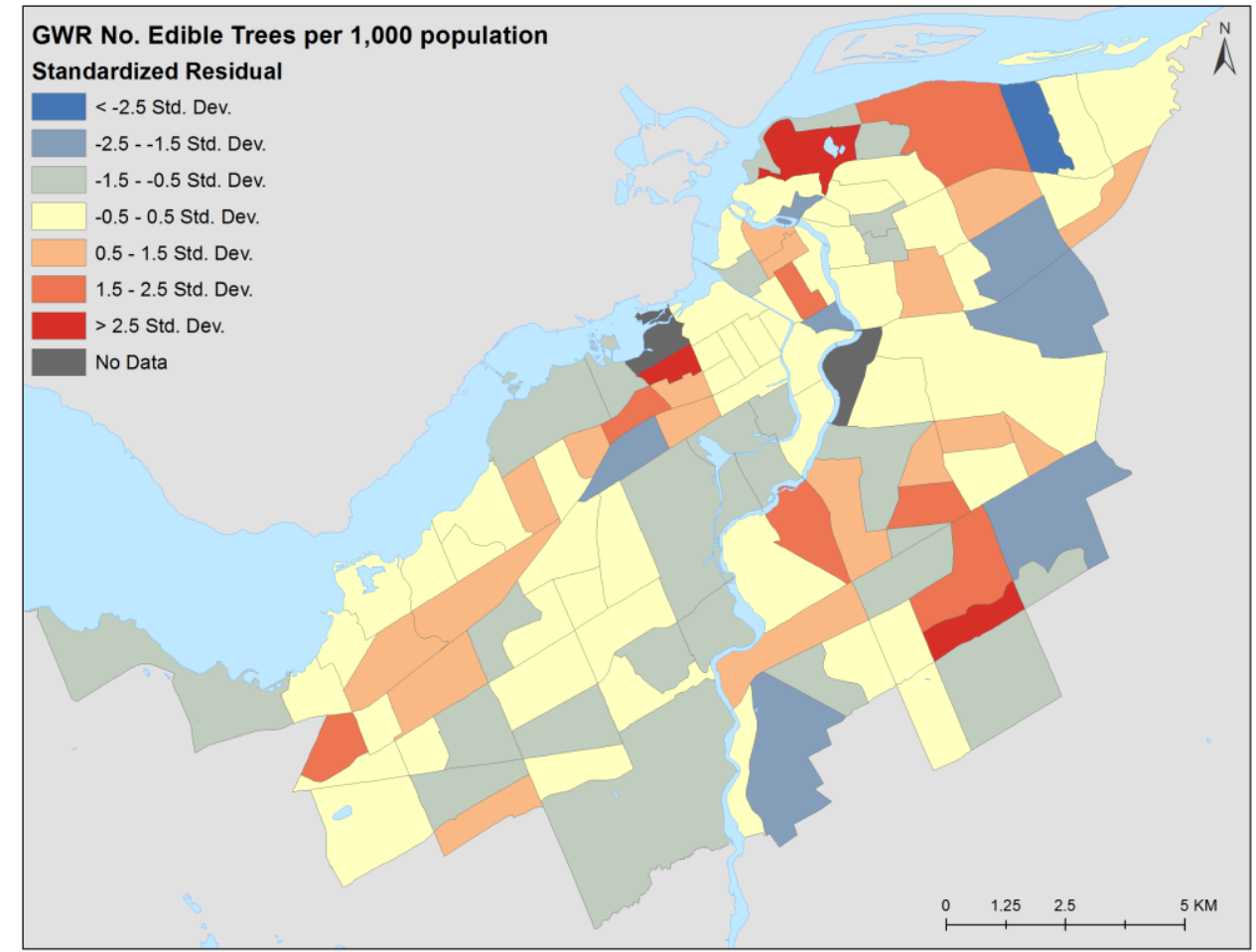

Figure 15 - Standardized residuals of the GWR model.

Maps of the local coefficient estimates for each variable are shown in Figure 16 21. The percentage of the population that is a visible minority shows relatively little variation in terms of the range of local coefficient values (see Table 6). The relatively large range in coefficient values of the other variables provides further evidence for nonstationary relationships. 


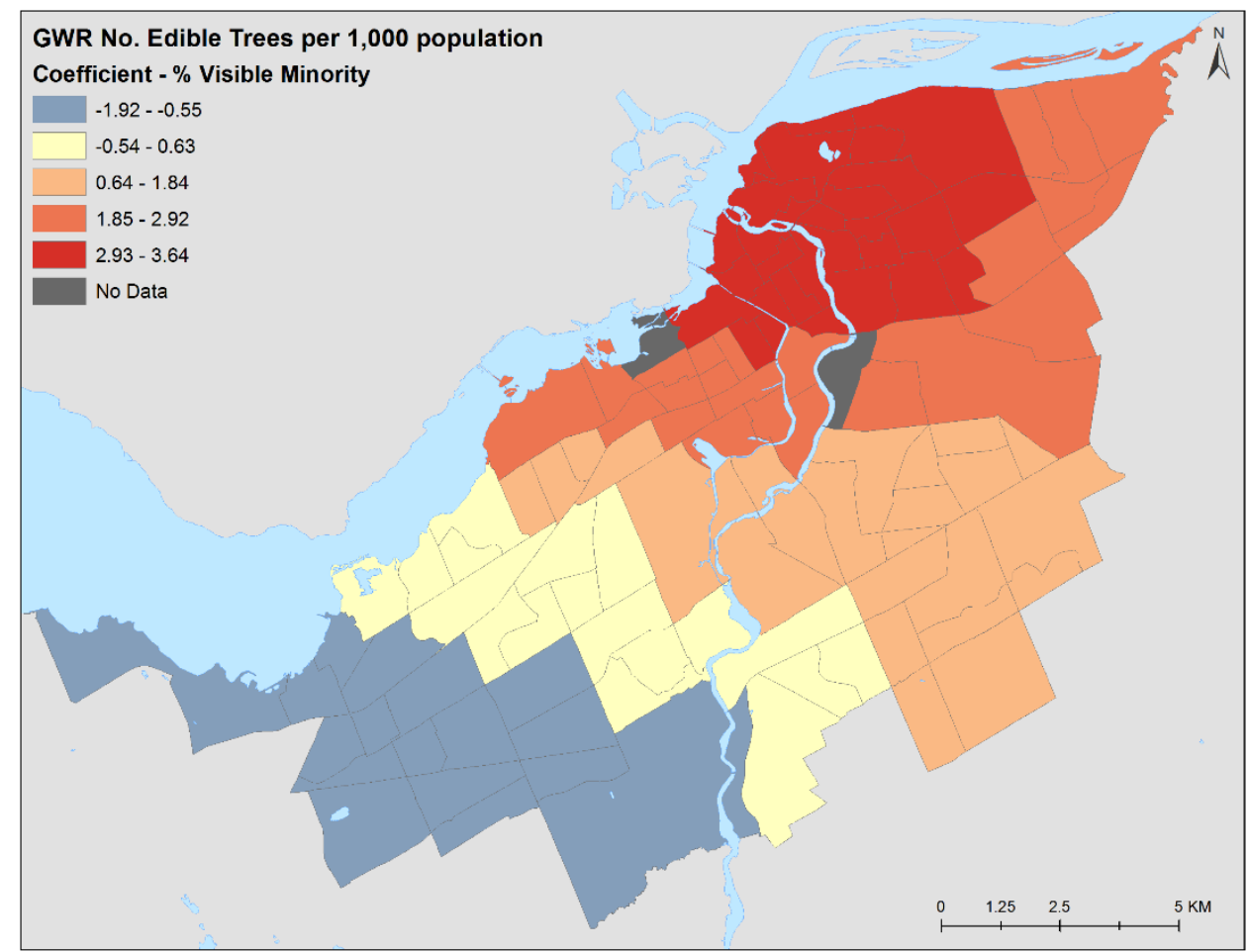

Figure 16 - Coefficient map of the percentage of the population that is a visible minority variable.

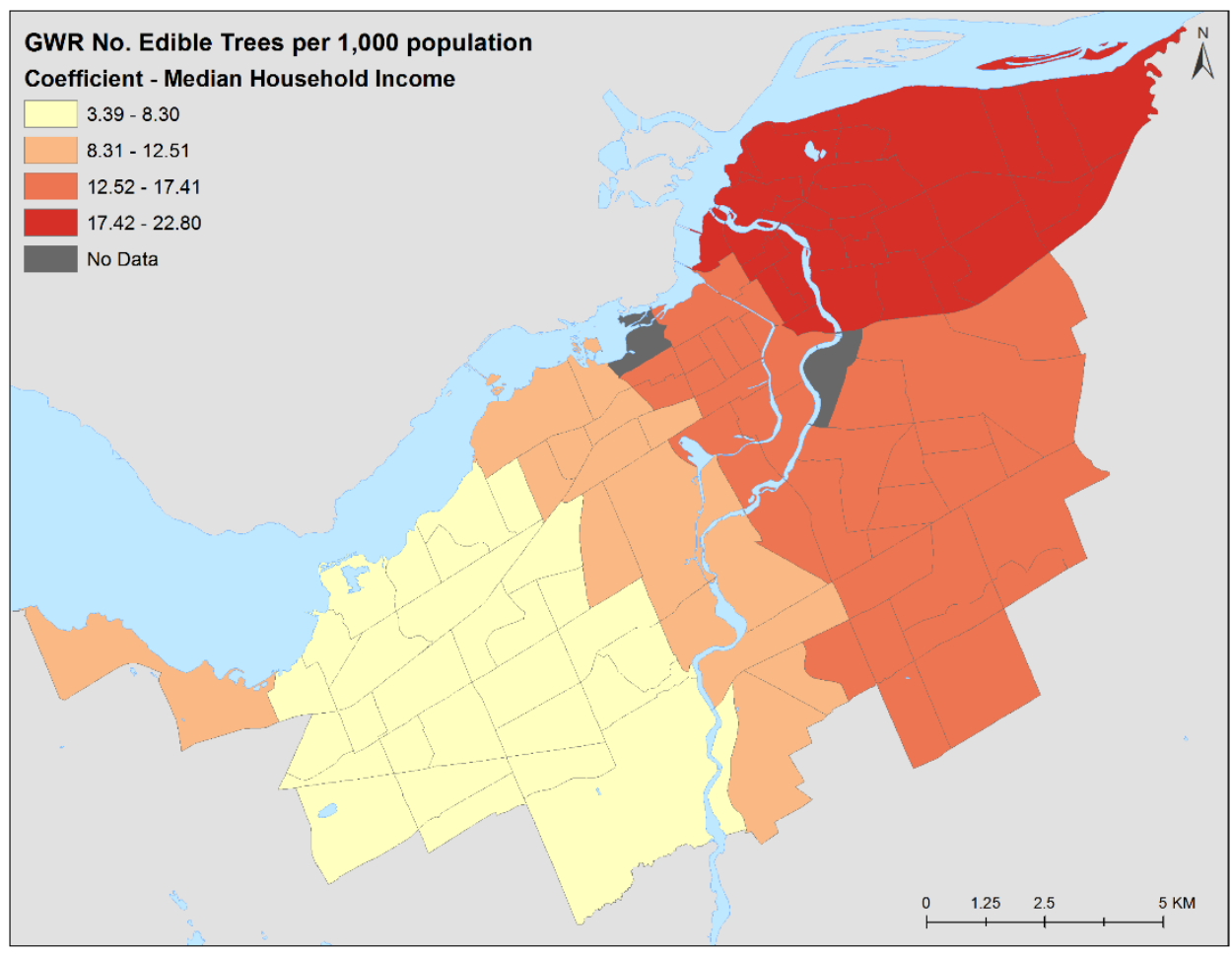

Figure 17 - Coefficient map of the median household income variable. 


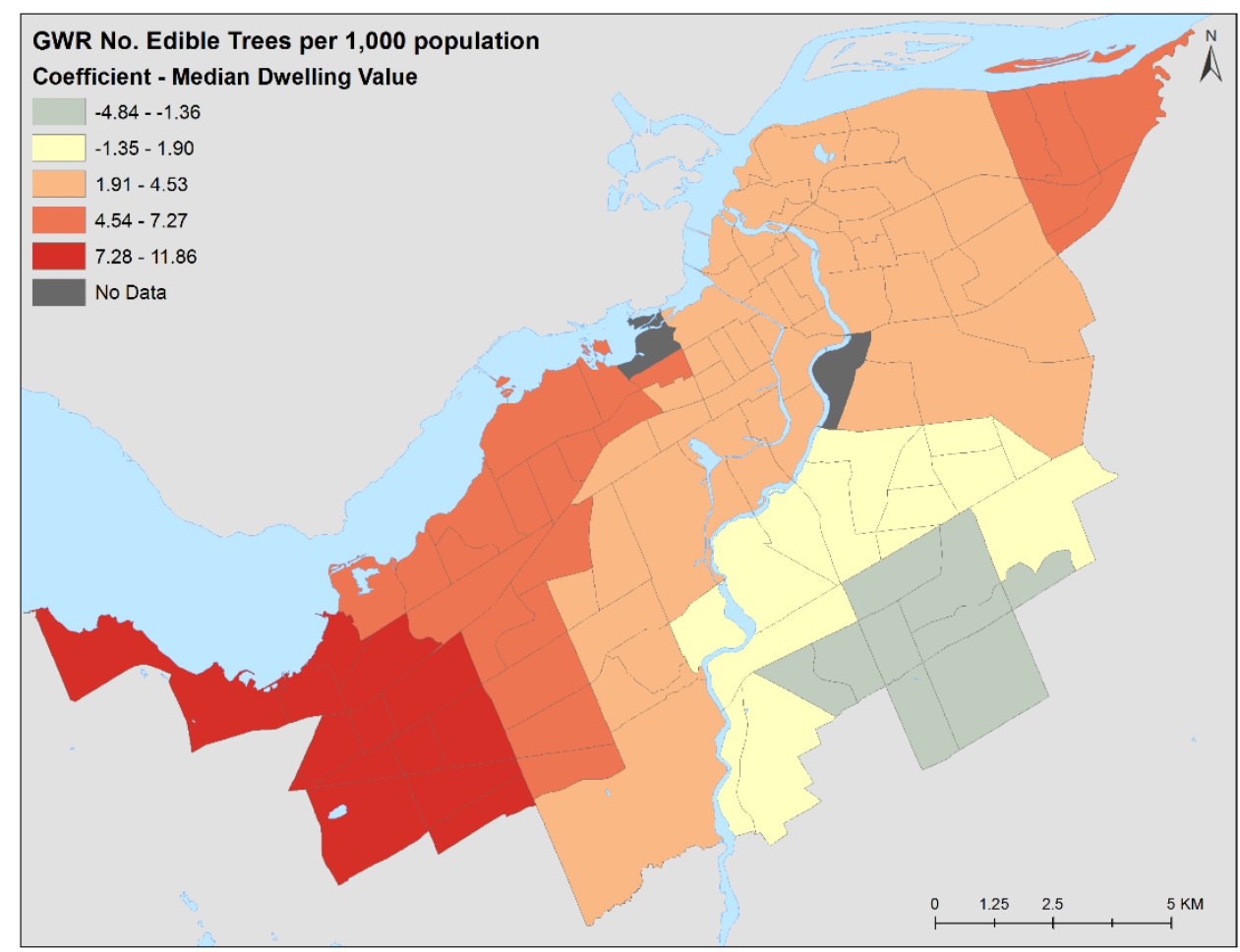

Figure 18 - Coefficient map of the median dwelling value variable.

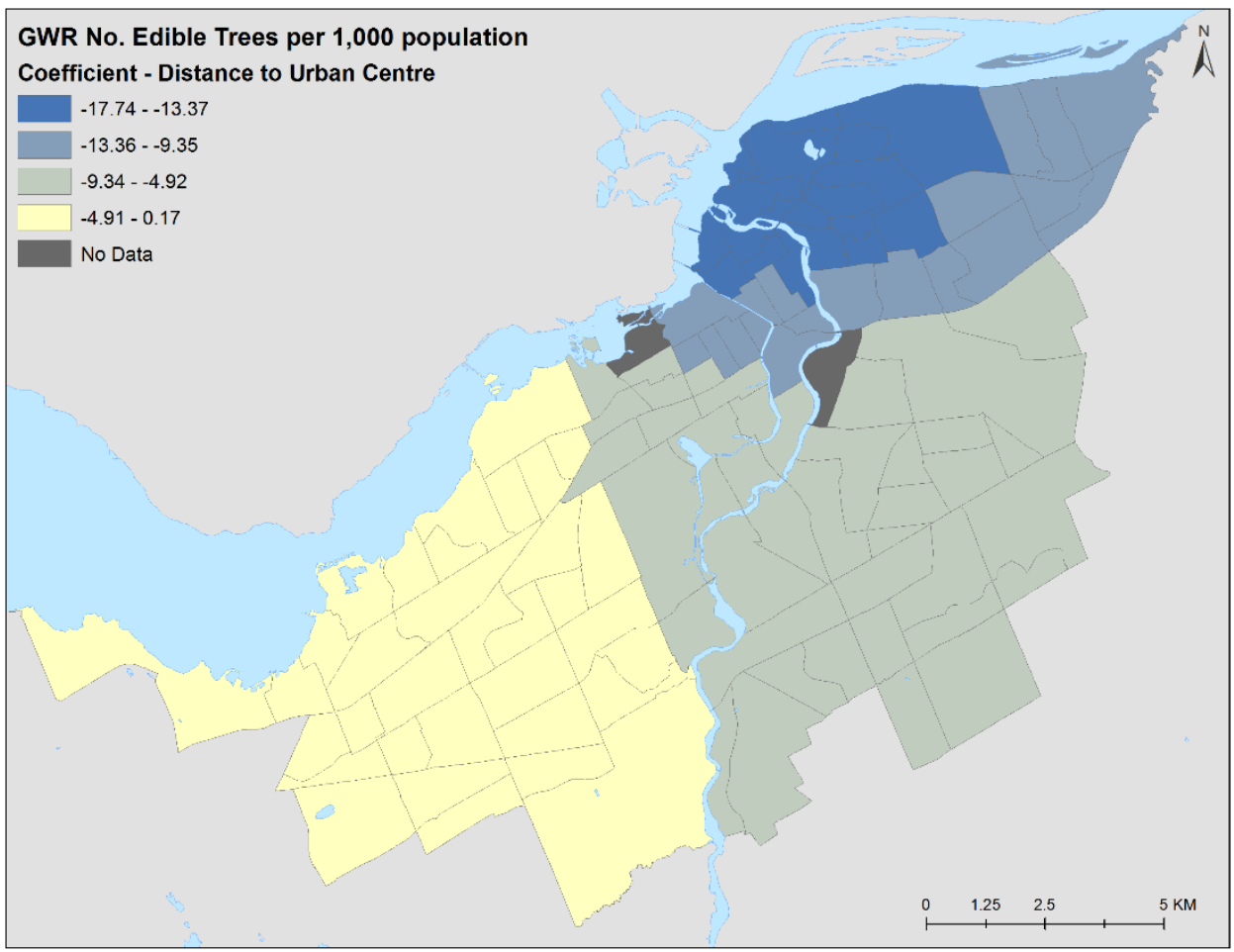

Figure 19 - Coefficient map of the distance to urban centre variable. 


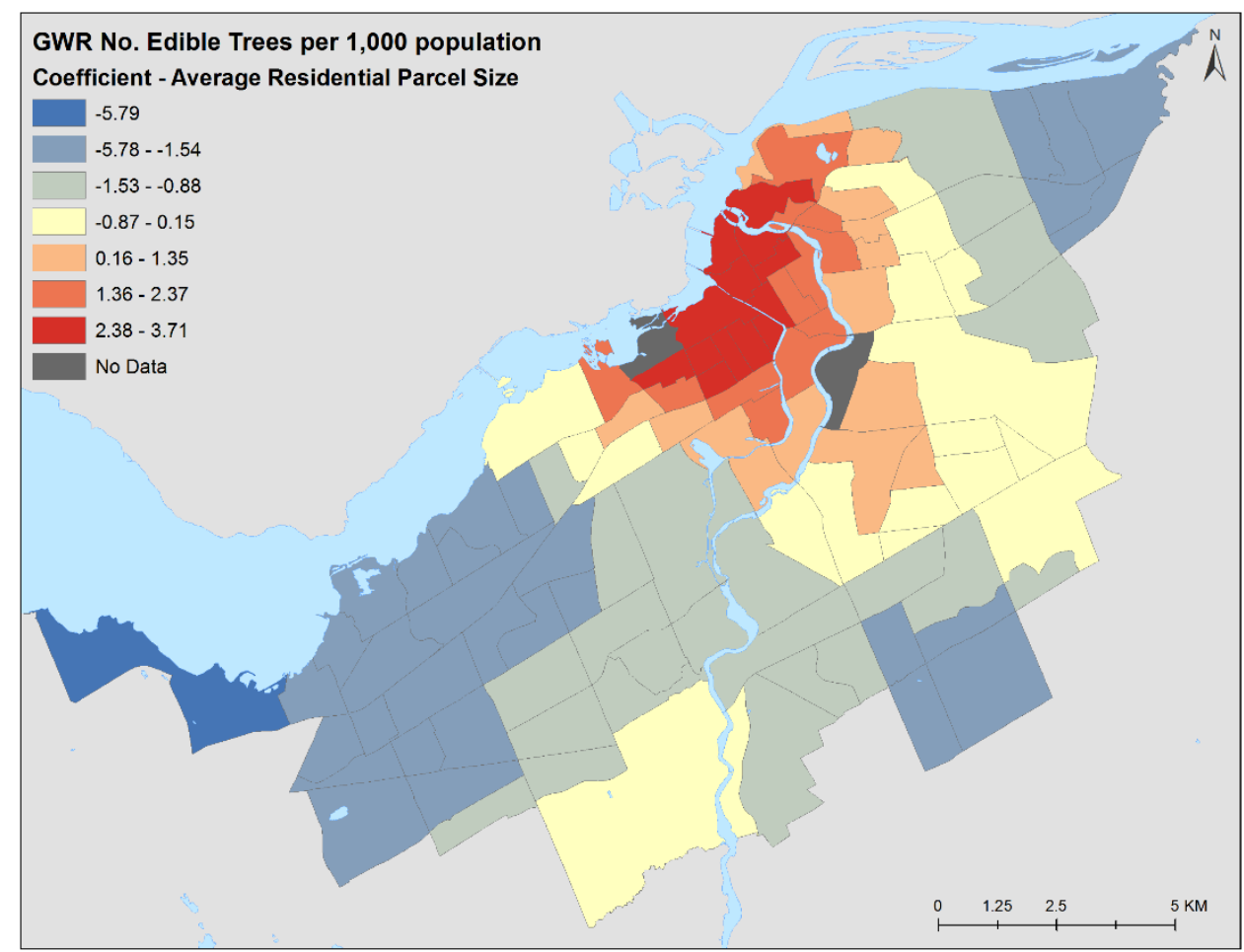

Figure 20 - Coefficient map of the average residential parcel size variable.

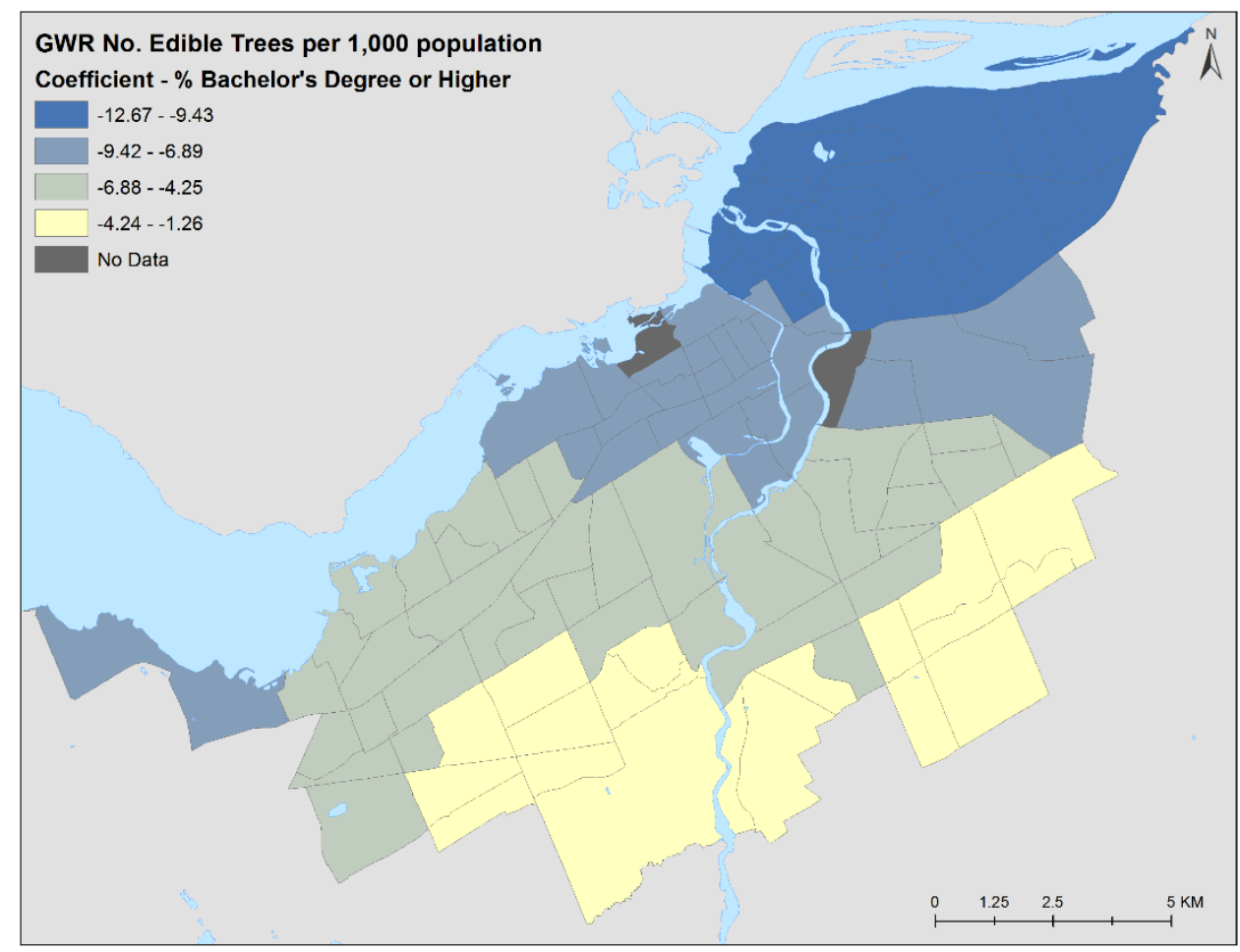

Figure 21 - Coefficient map of the percentage of the population that holds a Bachelor's degree or higher variable. 
Throughout the study area, median household income and median dwelling value display a positive relationship with the number of edible trees (aside from several census tracts in the southeast, which show a slight negative relationship between median dwelling value and the dependent variable). However, the relative strength of each of these variables varies across the study area. Distance to the urban centre also exhibits a consistent negative relationship throughout the study area, although the effect is strongest in the northeast, and becomes less pronounced in the southwest.

Average parcel size shows the strongest positive influence in the centre of the study area, where parcel sizes are the smallest, but begins to exert a negative influence farther away from the centre. In downtown areas, there are likely to be more edible trees in neighbourhoods with larger parcel sizes; however, in areas that are less dense, this relationship is reversed.

The coefficients of the visible minority variable reveal that a northeast-southwest pattern also exists in the influence of this variable; although the variation in the range of this variable is relatively small, it exhibits a positive influence in the northeast, and a negative influence in the southwest.

The education variable displayed a negative relationship with the number of edible trees, which was unexpected. For all census tracts, the relationship was negative; however, this relationship had the strongest impact in the northeast part of the study area, and a less significant impact moving southwest. The performance of the education variables in the global models for community gardens and school gardens was also unexpected; higher levels of education were positively associated with number of community gardens, and negatively associated with the number of school gardens. The sociological process 
underlying this relationship is not immediately clear, however, comparing maps of income levels with those of education levels may provide some insight (see Figures 22 and 23). Although high levels of education tend to be associated with higher socio-economic levels in general, this pattern is not consistently exhibited in Ottawa. While high household incomes and high levels of education do align in some neighbourhoods, many of the neighbourhoods that are in close proximity to the two major universities in Ottawa, including Sandy Hill and Centretown, exhibit high levels of education but low household income levels. This could be attributed to the high numbers of university students residing in these areas. It may be that the education variable is overshadowed by the household income variable, leading to the unexpected associations between education and urban agriculture displayed in the regression modeling. 


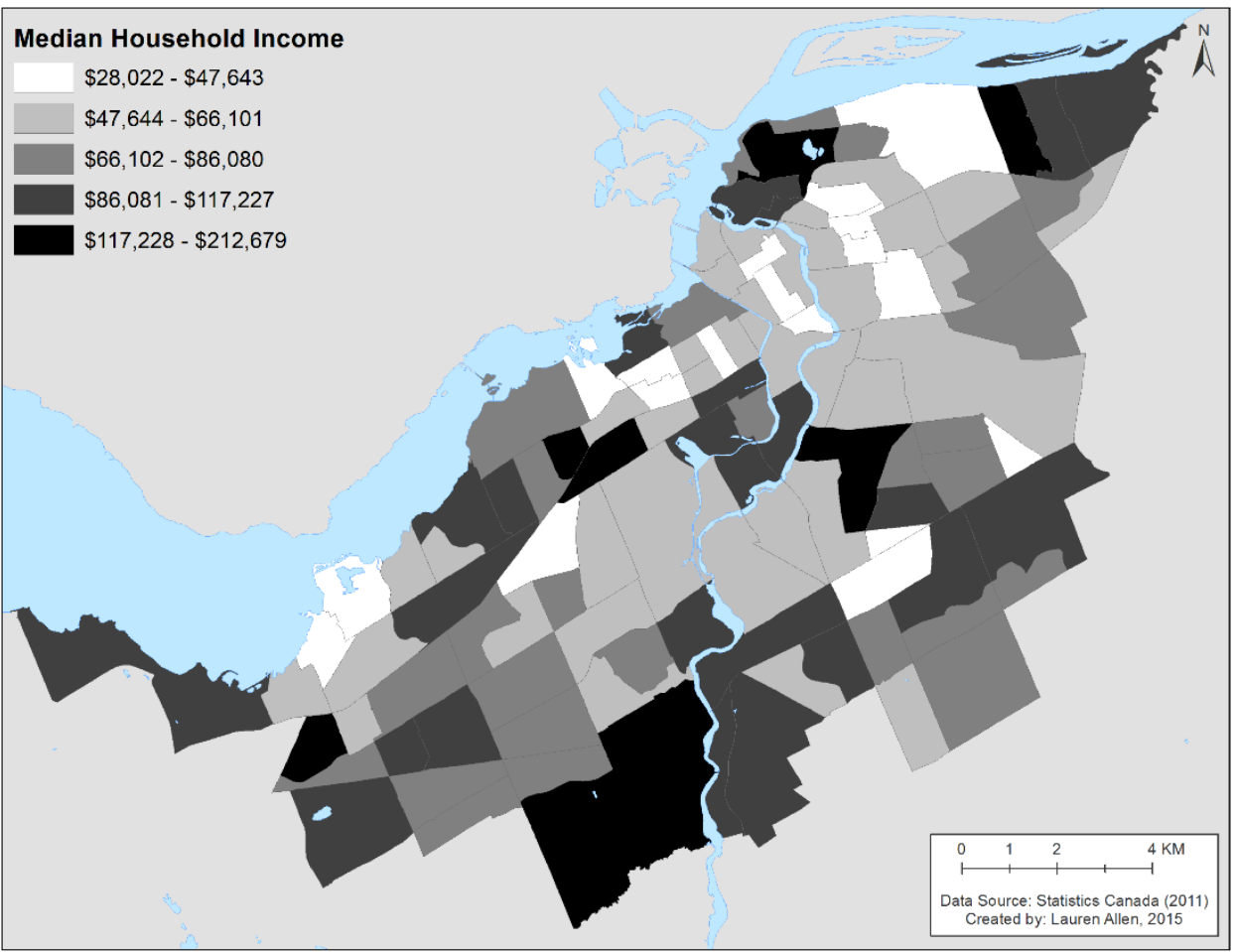

Figure 22 - Median household income of study area (by census tract).

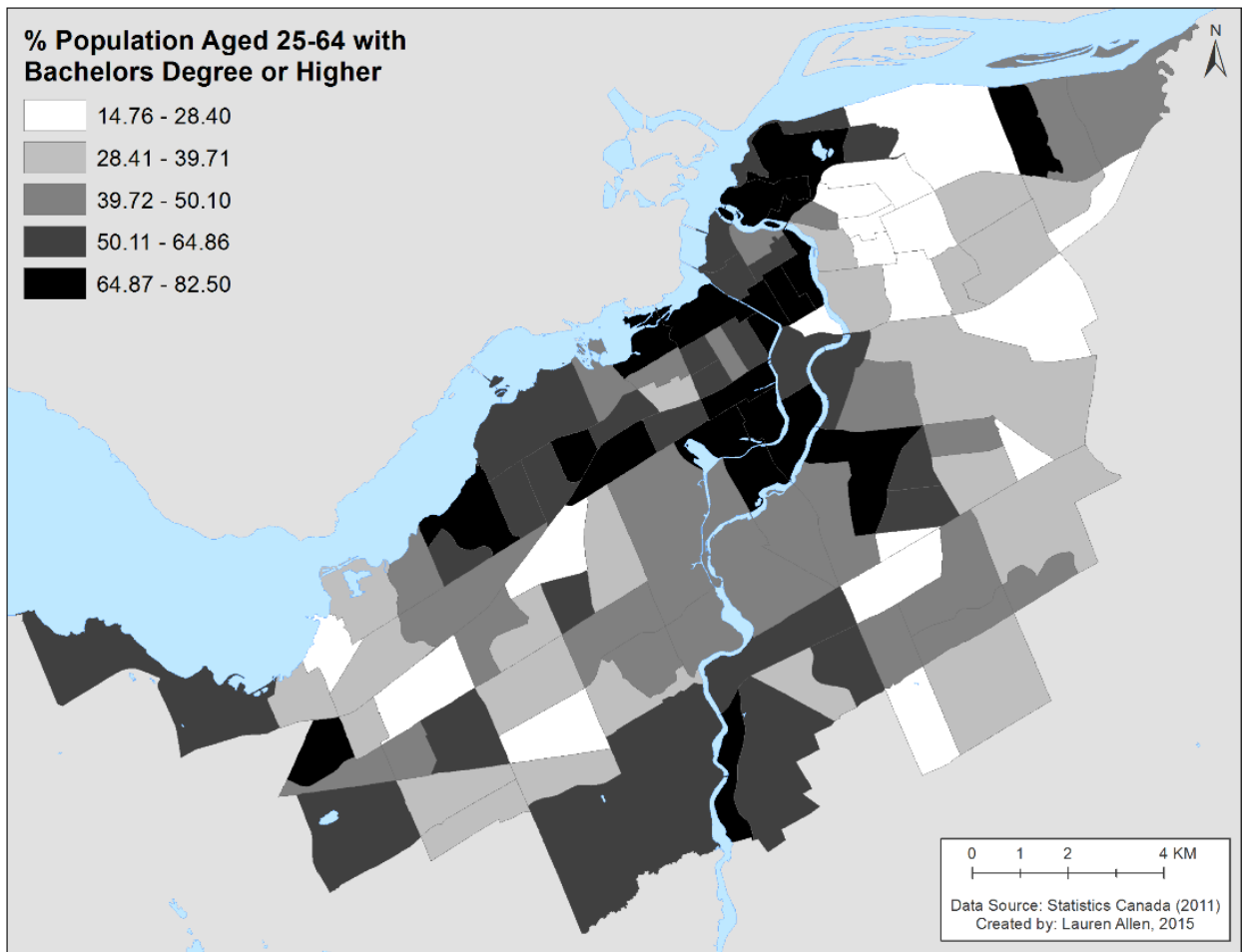

Figure 23 - Percentage of population with a Bachelors degree or higher (by census tract). 


\subsection{Limitations of Regression Modelling of Social Processes}

The adjusted $\mathrm{r}^{2}$ values for the global regression models for community and school gardens were 0.241 and 0.239 respectively, indicating that roughly $75 \%$ of the variance in these phenomena is unexplained by the model. In these cases, a local model showed no improvement over the global model. As Megler et al. (2014) noted in their study using regression to model graffiti locations in San Francisco, while regression analysis cannot hope to fully explain complex social processes, it can contribute to a greater understanding of the process. This may also be the case with gardens; while $75 \%$ of the variance is unexplained, regression modeling did help to highlight which socio-economic variables play a role in the distribution of gardens in a way that aligned with expectations about these phenomena. Information gained during interviews may provide insight on other important factors.

During interviews, participants consistently emphasized that the importance of community support could not be understated when it comes to the creation and management of community gardens. As one interviewee remarked, "the first thing you need if you're going to start a community garden is a bunch of people who want to do it" (C. Kneen, personal communication, July 24, 2014). A core group of community members is needed to plan, develop, maintain, and garden. Further, since the process of starting a garden can be lengthy, due to the identification of suitable land, negotiations with landowners, and required soil tests, tenacity and commitment are required on the part of community members. While "some communities can do anything" (S. Bramley, personal communication, September 10, 2014), not all have the same capacity to dedicate time and energy to the process. While community capacity may be linked to socio-economic factors, 
community support itself is difficult to represent in a GIS, and may account for some of the variance not explained through regression modelling. Nonetheless, the modelling did provide some useful insights regarding the social processes that may play a role in the distribution of community and school gardens.

\subsection{Inventory of Land Potentially Available for Urban Agriculture}

The final section of this chapter will report on the results of the land inventory. The inventory revealed 1,380 hectares $(3,410$ acres $)$ of vacant or underutilized land that could potentially be used for food production in urban Ottawa. These sites were located on 2,752 sites, comprised of 2,573 distinct property parcels. By area, 1,048 hectares (76.0\%) of the land identified was located on land classified as underutilized, while 332 hectares (24.0\%) was located on vacant land.

Table 7 provides an overview of the area of land identified within each land use category. Over one third of the land was located on sites classified as 'passive recreation', a category used by the City of Ottawa to classify lands and parks used for informal or unorganized activities. A further $11.4 \%$ occurred on lands categorized as 'open space', a classification for lands that are maintained, but that are not intended to serve the public as recreational lands. Lands in the open space category may be public right of ways, or be intended for some future public use. Ten percent of the land identified was located on utilities land, which includes land adjacent to the municipal water treatment facility and below hydro lines. Nearly seventeen percent of the land identified was located on office or institutional lands (including educational facilities, healthcare facilities, and other institutions). 
Table 7 - Sites potentially suitable for urban agriculture by land use category.

\begin{tabular}{|l|l|l|}
\hline Land Use Category & $\begin{array}{l}\text { Area } \\
\text { (hectares) }\end{array}$ & $\begin{array}{l}\text { Percentage } \\
\text { of total } \\
\text { area }\end{array}$ \\
\hline Passive recreation & 522 & $37.8 \%$ \\
\hline Vacant & 332 & $24.0 \%$ \\
\hline Open space & 157 & $11.4 \%$ \\
\hline Utilities & 139 & $10.1 \%$ \\
\hline $\begin{array}{l}\text { School property (elementary, secondary, and post- } \\
\text { secondary) }\end{array}$ & 91 & $6.6 \%$ \\
\hline Office (publically owned) & 64 & $4.7 \%$ \\
\hline $\begin{array}{l}\text { Other institutional property (includes churches, } \\
\text { libraries, non-profit museums, and other institutions } \\
\text { not related to educational and health facilities) }\end{array}$ & 51 & $3.7 \%$ \\
\hline Hospital property & 23 & $1.7 \%$ \\
\hline TOTAL & $\mathbf{1 , 3 8 0}$ & $\mathbf{1 0 0 \%}$ \\
\hline
\end{tabular}

By ownership, properties owned by either the federal government or the National Capital Commission account for nearly $40 \%$ of the lands identified. Slightly less than one third of the land is not owned by any level of government, and includes vacant or institutional properties, but a significant portion also represents hydro corridors. A quarter of the land in the inventory is owned by the City of Ottawa, while small percentages are owned by either the Province of Ontario or an unknown public entity (see Table 8).

Table 8 - Sites potentially suitable for urban agriculture by land ownership.

\begin{tabular}{|l|l|l|}
\hline Ownership & $\begin{array}{l}\text { Area } \\
\text { (hectares) }\end{array}$ & $\begin{array}{l}\text { Percentage of } \\
\text { total area }\end{array}$ \\
\hline National Capital Commission or other federal land & $\begin{array}{l}539(342+ \\
197)\end{array}$ & $39.1 \%$ \\
\hline Non-public (mostly institutional or vacant land) & 423 & $30.7 \%$ \\
\hline Municipal & 357 & $25.9 \%$ \\
\hline Unknown public land & 37 & $2.7 \%$ \\
\hline Provincial & 24 & $1.7 \%$ \\
\hline TOTAL & $\mathbf{1 , 3 8 0}$ & $\mathbf{1 0 0 \%}$ \\
\hline
\end{tabular}

Examining the location of land by ownership (Figure 24) reveals that a large tract of federally-owned land is concentrated in the northeastern section of the study area, a region that was formerly the location of the Canadian Forces Base Rockcliffe military base. While this land is currently federally owned, a mixed-use redevelopment plan is expected 
to be submitted to the City of Ottawa sometime in 2015 (Pugliese, 2014). While urban agriculture could be included in the development plan, it is clear that not all of the land is realistically available for that purpose. Other concentrations of federally owned land in the inventory largely represent office complexes, such as the federal government offices at Tunney's Pasture, visible just south of the Ottawa River, near the centre of the study area.

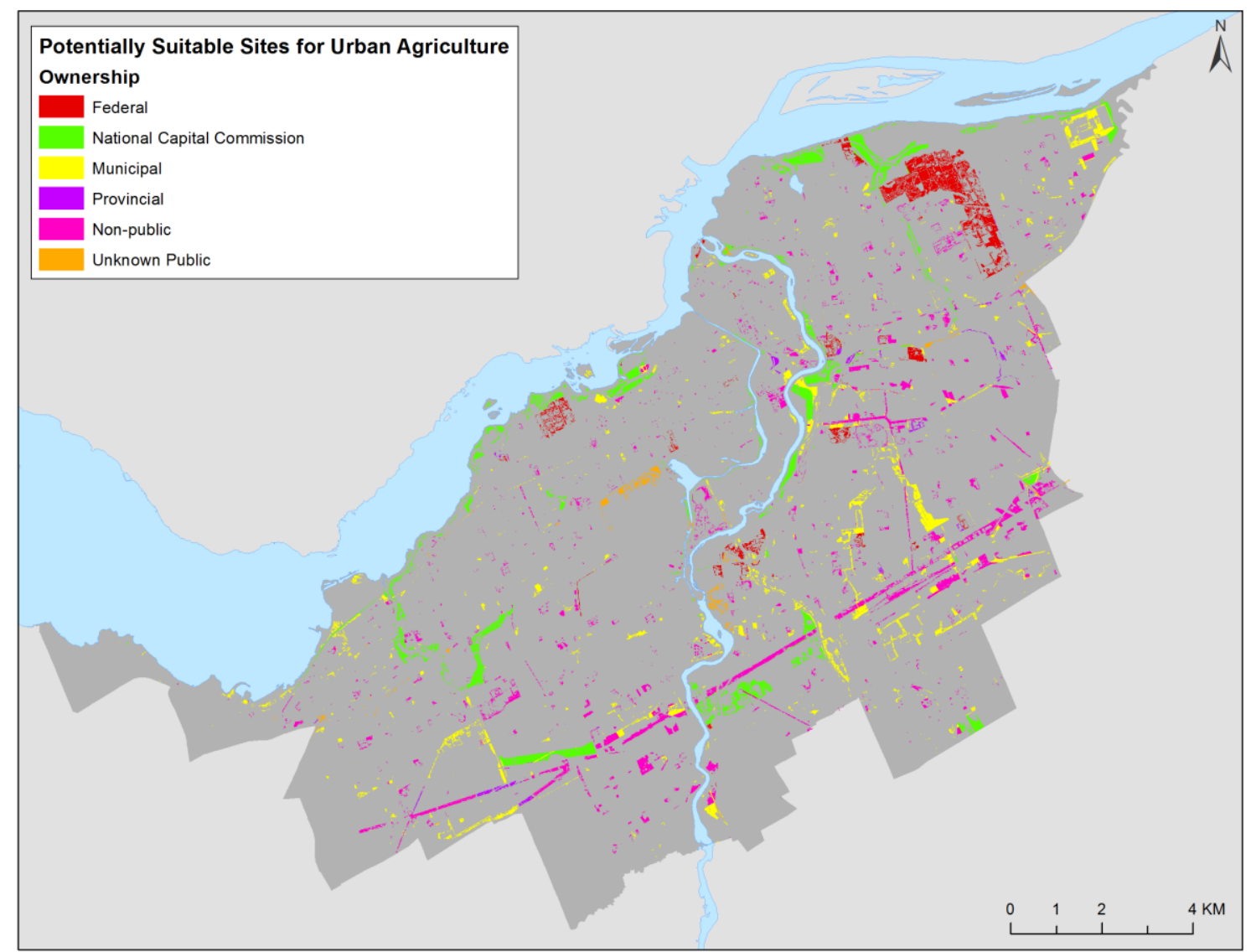

Figure 24 - Sites identified as potentially suitable for urban agriculture through the land inventory.

Much of the land owned by the NCC consists of elongated strips along the Ottawa and Rideau Rivers, the Rideau Canal, and smaller waterways. Much of this land has limited vehicular access, but has excellent access by other modes of transportation, since it aligns with the networks of walking and cycling trails throughout the city. This could be an 
opportunity to combine urban agriculture with sustainable transportation methods. However, since some of these sites are not in close proximity to existing infrastructure, water access would need to be investigated.

As mentioned in the previous paragraph, much of the land that is not publicallyowned is located in hydro corridors. Interviews with city staff revealed that hydro corridor lands are in fact city-owned, but are leased by the province, pointing to a possible error in the land ownership database. Since the use of hydro corridors for urban agriculture has been the subject of some debate, this subject is discussed in further detail below. Smaller non-public sites, mostly vacant and institutional lands, are scattered throughout the study area.

Municipally-owned land identified as potentially suitable for urban agriculture is also scattered throughout the study area. A large, municipally-owned site is located in the extreme northeast corner of the study area, and represents lands surrounding the municipal water treatment facility. Visual analysis of the site reveals a significant amount of available land around the periphery of the facility, and urban agriculture has been successfully integrated in underutilized spaces on land belonging to water treatment plants in other jurisdictions (e.g. CitySoil Farm in Renton, Seattle). However, further research and environmental testing would be prudent to determine whether there are concerns related to negative environmental impacts on land adjacent to water treatment plants.

Table 9 presents the results of the land inventory by site size. Over half of the sites identified are smaller than 1,000 square metres in size; however, by area, these sites make up less than $4 \%$ of the land identified. These sites are distributed relatively evenly throughout the study area. By area, nearly $60 \%$ of the land identified as potentially suitable 
is comprised of sites greater than 2 hectares. This land, which could be suitable for large allotment-style gardens, is located mainly towards the peripheries of the study area.

Table 9 - Sites potentially suitable for urban agriculture by size.

\begin{tabular}{|l|l|l|}
\hline Size of Site & $\begin{array}{l}\text { Number of } \\
\text { Sites }\end{array}$ & $\begin{array}{l}\text { Combined Area of } \\
\text { Sites (hectares) }\end{array}$ \\
\hline $50 \mathrm{~m}^{2}-1,000 \mathrm{~m}^{2}$ & 1,495 & 53 \\
\hline $1,000 \mathrm{~m}^{2}-0.5$ hectares & 770 & 181 \\
\hline 0.5 hectares -2.0 hectares & 355 & 338 \\
\hline$>2.0$ hectares & 132 & 808 \\
\hline TOTAL & $\mathbf{2 , 7 5 2}$ & $\mathbf{1 , 3 8 0}$ \\
\hline
\end{tabular}

\subsubsection{Comparison of land inventory results to lands identified through interactive}

\section{mapping process}

During the interactive mapping exercise, participants most commonly sketched regions in or near the urban core as areas where increased urban agriculture would be particularly beneficial. Two participants also noted that underutilized land in the Experimental Farm could be shared with the community for urban agriculture (even temporarily), while one participant identified the Hunt Club neighbourhood, noting that there are many $\mathrm{OCH}$ communities in this area. When identifying areas where urban agriculture would be particularly beneficial, common reasons cited by participants included areas with high population densities and small amounts of public green space, low-income neighbourhoods, and demonstrated community interest.

Comparing the areas digitized from the interactive mapping process with the lands identified in the inventory reveals 71 hectares that are potentially suitable for urban agriculture. Of this, 32 hectares is in the Hunt Club area, and is comprised largely of municipal park land categorized as passive recreation.

Thirty-six hectares of potentially suitable land were located in areas identified by participants in or near the urban core. Most of these sites were smaller than half a hectare, 
but some exceptions exist. The areas identified through interactive mapping intersected with almost six hectares of underutilized land on the grounds of the federal office complex at Tunney's Pasture. Tunney's Pasture is currently a 49-hectare site dedicated to federal offices; however, a 25-year redevelopment plan was approved in 2014, which will incorporate retail space, a public park, and housing units with government offices. While the redevelopment plan will likely be denser than the current development, incorporating space for urban agriculture could represent a partnership opportunity between the federal government and the surrounding community. Moreover, since the redevelopment is a longterm plan, urban agriculture could be incorporated as an interim land use. This location has the added benefit of being in close proximity to Hintonburg-Mechanicsville, a neighbourhood which has shown prolonged community interest in establishing a community garden. Almost 10 hectares were identified on NCC lands, mostly south of the Ottawa River, in the neighbourhoods of Hintonburg-Mechanicsville, Lebreton, and Island Park, while an additional ten hectares on municipally-owned land in the urban core was identified, much of which was located in public parks. As noted earlier, some of these neighbourhoods are already having difficulties meeting their park targets, so the use of parks for urban agriculture in these areas may be unfeasible. A municipally-owned lot several hectares in size currently sits vacant in Hintonburg-Mechanicsville, which could be another opportunity for interim urban agriculture.

\subsubsection{Urban Agriculture in Hydro Corridors}

The large tracts occupied by hydro corridors in many Ontarian cities, including Ottawa, may represent a significant amount of underutilized land that could be productively used 
for urban agriculture. In the city of Toronto, Ontario, eight allotment gardens and four community gardens are located in hydro corridors (Danyluk, 2009). In 2014, a community garden was established in a hydro corridor in Kanata, an Ottawa suburb, marking the first community garden in a hydro corridor in the city. ${ }^{9}$

However, some concern exists regarding the impacts of electromagnetic fields (EMF) on human health, including the potential association between living in close proximity to hydro transmission corridors and increased levels of childhood leukemia. In 2002, the International Agency for Research on Cancer (a branch of the World Health Organization) published a review on the potential of EMF exposure to cause cancer. Their overall evaluation was that "extremely low-frequency magnetic fields are possibly carcinogenic to humans" (WHO IARC, 2002, p. 338), based on limited evidence of the carcinogenicity of EMFs in relation to childhood leukemia at EMF levels above 3 or 4 milligauss (mg). They also concluded that inadequate evidence exists regarding correlations between EMF exposure and all other cancers. In 2008, Toronto Public Health released an assessment of health implications associated with exposure to EMF from hydro corridors, balancing the potential health benefits associated with trails, community gardens, and other recreational opportunities in hydro corridors. They concluded that if an individual spends time gardening in a hydro corridor (based on 30 minutes a day, every day of the week, for six months of the year), the health benefits outweigh any potential health risk associated with the increased EMF exposure, which would result in a $1 \mathrm{mg}$ increase in daily exposure averaged over one year (Toronto Public Health, 2008). Due to

\footnotetext{
${ }^{9}$ Kanata is outside of the study area for this research, but was mentioned since the community garden sets a precedent for community gardens in hydro corridors in Ottawa.
} 
the uncertainty related to EMF exposure in hydro corridors, however, further research may be warranted. In addition, there may be safety concerns related to risks associated with herbicides that are used to manage vegetation in hydro corridors.

\subsubsection{Limitations of Land Inventory}

As with any GIS analysis, the results of the inventory depend on how accurate and up-todate the input data are. While access to an existing water source was identified as a key consideration in planning for urban agriculture, the water infrastructure data available were not sufficiently detailed to allow the identification of existing water access. Further, the land use dataset is nearly five years old, which presented another limitation. While classification of aerial imagery was used to identify recent urban developments on underutilized land, there was some confusion in the classification between bare soil and urban development. Further, this approach was not used for vacant land, since removing impermeable sites from vacant properties would have also removed some potentially suitable sites (e.g. paved vacant land). Visual inspection of aerial imagery did reveal that some properties classified as vacant have in fact been developed.

The lack of information regarding future development plans is another limitation in the inventory, as in the cases of Tunney's Pasture, the former CFB Rockcliffe Base, and other planned developments. It would be useful to identify lands that are slated for development in the near future, so that some form of urban agriculture could be incorporated in the planning process. This approach has been taken by Windmill Development Group, who, in their development plans for the "Zibi" sustainable community planned for Ottawa and Gatineau, have set a target of at least $25 \%$ of residents 
having access to on-site food growing opportunities.

As other research using land inventories for urban agriculture has noted (e.g. Kremer \& DeLiberty, 2011; McClintock et al., 2013), this approach represents only a preliminary assessment in the process of identifying lands that may be suitable for urban agriculture. Further investigation would be required, on a site-by-site basis, to evaluate the actual suitability of lands. Individual site evaluation could be informed through visual analysis of current Google Satellite imagery, to determine whether recent development has occurred, or whether sites are obviously unsuitable for other reasons, but site visits and community consultations would also be required, to gain insights regarding factors such as shade, site access, and community support.

This approach does not intend to suggest that all land that could be suitable for urban agriculture should be used as such, since multiple demands on urban green space exist, such as space for active and passive recreation, space for cultural or artistic uses, and space for nature appreciation, need to be balanced. Rather, it aims to offer a preliminary assessment tool for those who are planning for urban agriculture. The results of the inventory help to illustrate Mougeot's (2006) argument that there is a significant amount of land that could be available for urban agriculture, whether the land is dedicated to the practice, or incorporated as part of multifunctional spaces. As Lovell (2010) notes, "the challenge (and opportunity) is to design urban agriculture spaces to be multifunctional, matching the specific needs and preferences of local residents, while also protecting the environment" (p. 2499). 


\subsection{Conclusion}

This chapter began with a discussion of the organizational network of urban agriculture in Ottawa, highlighting the significance of interaction and cooperation among municipal government departments, food justice organizations, and community development organizations. Sites of urban agriculture were then presented as spaces where acts of community development and food justice take place, illustrating that an ethics of care is evident in the activities of many urban agriculture initiatives. A conceptualization of community gardens as spaces that are not entirely private yet not entirely public was then presented, followed by a discussion of competition for space, with a particular focus on the tensions that can arise when community gardens are situated in public parks.

Based on findings from interviews and information collected from community garden coordinators, public demand for urban agriculture was assessed. Responses from community garden coordinators revealed that over $90 \%$ of gardens in the study area maintain a waiting list, and several gardens, particularly those in the urban core, reported that it can take several years for would-be gardeners to receive a plot. A challenge in planning for urban agriculture involves reconciling the demand for space for food production in the urban core with the challenge of finding available space in these dense areas.

The remainder of this chapter focused on findings from the GIS analysis. Initial exploratory mapping of community and school gardens with income data revealed that while community garden locations are associated with low-income neighbourhoods, there are actually more community garden plots in higher income neighbourhoods. School 
gardens were also more often located in neighbourhoods with a lower prevalence of lowincome individuals. The results of hot spot analyses for each of the forms of urban agriculture were then presented, revealing hotspots of community garden plots in periurban areas, and school garden hotspots in two neighbourhoods where the school garden program is well-established. The analysis of edible trees revealed a hotspot in the highincome neighbourhood of Rockcliffe, and a cool spot in the largely low-income neighbourhoods of Sandy Hill and Vanier.

Regression analyses were conducted using each of the three urban agriculture practices (community gardens, school gardens, and edible trees) as the dependent variables. The global analysis of community gardens had an adjusted $r^{2}$ value of 0.24 . Unemployment rate, the percentage of female lone-parent families, and the percentage of the population with a Bachelor's degree or higher had a positive association with the number of community garden locations, while percentage of rented dwellings, median household income, and the percentage of the population who are immigrants had a negative association. Using school gardens as the dependent variable, the adjusted $r^{2}$ value was 0.24 , and median dwelling value, the percentage of families with children, and the percentage of apartment-style dwellings had a positive association with the number of school garden locations, while the percentage of the population with a Bachelor's degree or higher, the percentage of the population who are immigrants, and the percentage of lowincome individuals had a negative correlation. The global analysis using edible trees as the dependent variable showed a positive association with median household income, median dwelling value, and the percentage of the population who are immigrants, and a negative association with the percentage of the population with a Bachelor's degree or 
higher, distance to urban centre, and average residential parcel size. While local models for community and school gardens did not show an improvement over the global models, the adjusted $\mathrm{r}^{2}$ value for the number of edible tree locations increased from 0.61 for the global model to 0.72 using geographically weighted regression. The local model also revealed a range in the coefficient values for most of the independent variables.

Finally, the results of the inventory of potentially suitable land for urban agriculture were presented and discussed. The land inventory identified 1,380 hectares of land in the study area that could potentially be used for urban agriculture, with $76 \%$ located on underutilized land, and $24 \%$ located on vacant land. Nearly $40 \%$ of the land identified was located on lands either owned or managed by the National Capital Commission. The lands identified in the inventory were then compared to areas identified by urban agriculture practitioners as places where increased urban agriculture would be particularly beneficial.

Limitations of the land inventory were then presented, including data quality issues as well as the lack of incorporation of future development plans in the inventory. The land inventory approach is intended as a preliminary assessment of land that may be available for urban agriculture, recognizing that more in-depth assessments would be required on a site-by-site basis to determine actual suitability, and that not all of the land identified could or should be used for urban agriculture, since multiple demands exists for the use of urban space.

Based on findings presented in this chapter, and a review of secondary data, Chapter 5 will provide policy-related considerations for further promoting and supporting an equitable system of urban agriculture in Ottawa. 


\section{Chapter: Policy Considerations}

\subsection{Introduction}

Until recently, urban agriculture was largely absent from municipal planning initiatives. However, over the past several years, municipalities in Canada and elsewhere in the global North (including Waterloo, Ontario and North Vancouver, British Columbia) have begun to integrate urban agriculture into municipal planning (Huang \& Drescher, 2015), in recognition of the community development, food security, and other social and environmental benefits it provides. This chapter will build upon the results presented in the previous chapter, discussing the implications of this research as they relate to policy considerations for expanding urban agriculture in Ottawa and helping to ensure it is broadly accessible. Since this research is concerned with the availability of public space for urban food production, a particular focus will be on policies that are relevant from a land use perspective. Due to Ottawa's position as a national capital, policies relevant to both municipal and federal land use as it relates to urban agriculture will be reviewed. Throughout the chapter, successful policies from other North American municipalities, including Edmonton, Alberta, Richmond, British Columbia, and San Francisco, California will be drawn on as exemplary cases.

\subsection{Municipal and Federal Policies Affecting Urban Agriculture in Ottawa}

In order for food production to thrive in urban spaces, a balance is required between topdown, government planning measures and community support from urban inhabitants. While the city's support is instrumental in helping with such things as start-up funding, negotiating bureaucratic requirements, and gaining access to land, the long-term success 
of a garden depends on sustained community support. Ultimately, for both community and school gardens, the goal is for these initiatives to become largely self-sufficient. Purcell \& Tyman (2014) echo this sentiment, arguing that the state should not manage gardens on behalf of residents in the long term, since in Lefebvre's view, "The right to the city is... a struggle by inhabitants to become such capable managers of urban space that the state becomes obsolete" (p. 12). While the role of the state may not become entirely unnecessary, community and school gardens may evolve to be largely self-sufficient, in that operations are managed by a dedicated group of community members, with local government providing support only when needed.

Municipalities have the ability not only to shape policies and regulations that support urban agriculture, but also, as significant landowners, to encourage food production on land under their management. As the nation's capital, Ottawa is unique in the Canadian context; with a large area of land under federal management, policies related to the use of federal land also play a role in planning for urban agriculture. The results of the land inventory revealed nearly 540 hectares of potentially suitable sites on land managed by the National Capital Commission (either NCC properties or properties under the authority of other federal departments), and over 350 hectares on land owned by the City of Ottawa (see Figure 25). Both the NCC and the City of Ottawa have policy documents that are relevant to urban agriculture: the City's support of urban agriculture is largely guided not only by the Community Garden Action Plan (2004), which supports the development of community gardens, but also by the City's Official Plan. The use of federal land holdings within urban Ottawa is guided by the NCC's Capital Urban Lands Master Plan. 


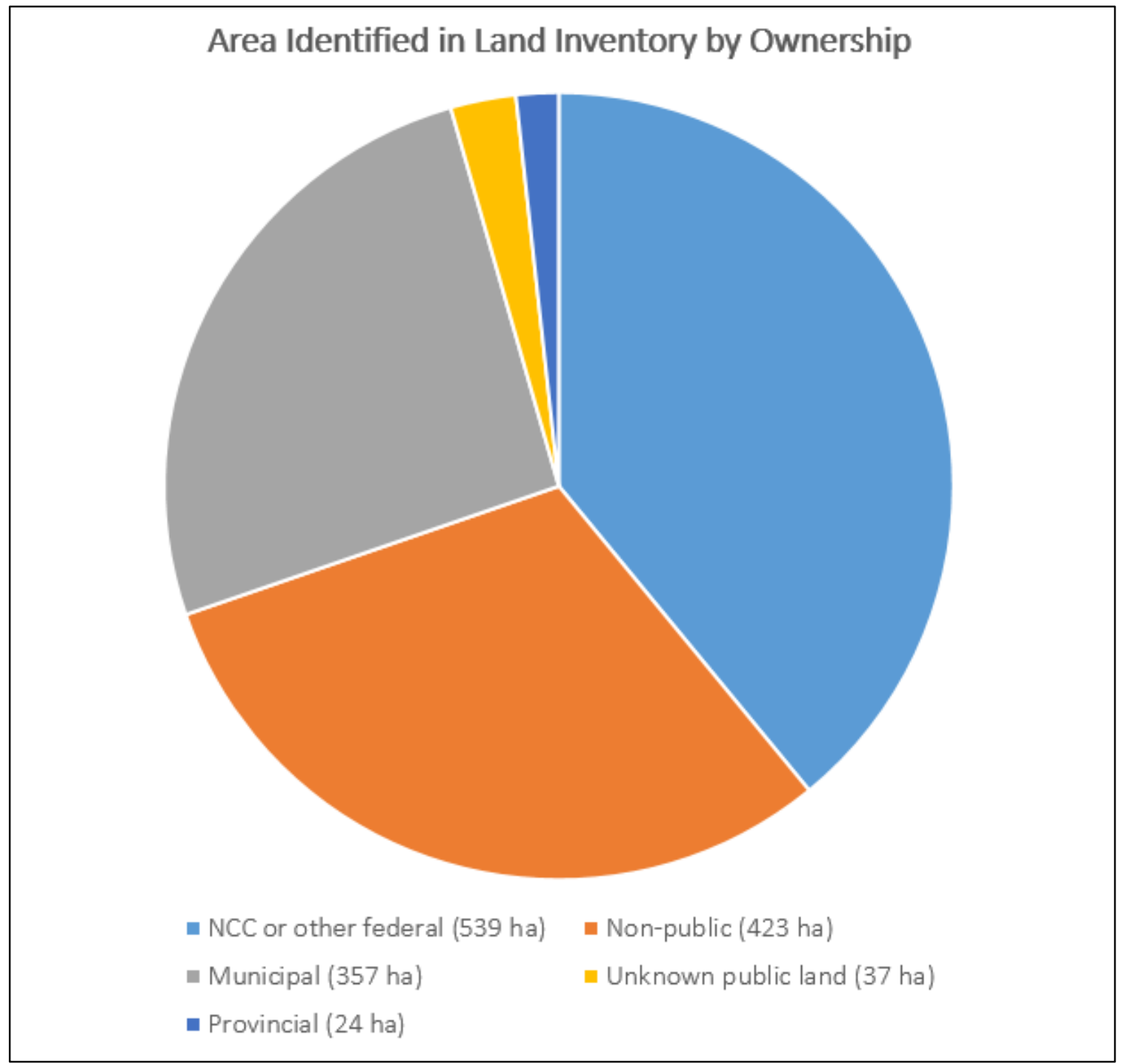

Figure 25 - Land identified in inventory by ownership.

The City of Ottawa's Community Garden Action Plan (CGAP) and Official Plan

As discussed in previous chapters, the main way the city promotes urban agriculture in Ottawa is through their support of the Community Garden Action Plan. Through the CGAP, the City has ensured that community gardens remain: a permitted use in all land use zones (except those that are dedicated to the protection of the natural environment), 
and a priority use for City surplus lands. The CGAP ensures that community gardens fall under a standardized licence of occupation, which has a 180-day cancellation clause, giving gardeners a measure of land tenure security. As a condition of the Community Garden Bylaw, gardeners may not sell produce grown in community gardens for commercial benefit.

The Ottawa Food Policy Council has noted that the City's perception of urban agriculture remains somewhat limited, as it relates mainly to community gardens. While the City's support has been crucial to the expansion of the Community Garden Network, when local governments define urban agriculture narrowly (for example, as only community gardens), "they miss urban agriculture's complexity and diversity and may not embrace the policies and programs necessary to support it in different community contexts" (Hodgson et al., 2011). A more complex urban agriculture could include not only community gardens, but also edible landscaping, rooftop gardens, and market gardens. In the case of Ottawa, a city with ample green space, particularly outside of the urban core, there may be opportunities for an even wider array of practices, such as urban farms and orchards. The Just Food Farm (discussed in the following section) provides an example of the potential complexity in forms of urban agriculture. Napawan (2014) also emphasizes the importance of defining multiple urban agriculture typologies, in order to meet both community and city goals, recognize the complexity and diversity of the practice, and maximize sites that are considered as suitable for urban agriculture.

Some Canadian cities are embracing this wider definition of urban agriculture. Edmonton, Alberta, recently proposed a bylaw amendment that would enable all types of urban agriculture within city limits (while including conditions to limit negative impacts on neighbours), broadly defining urban agriculture as "the cultivation and processing of 
plant and animal products", and including related activities such as storage, composting, on-site sales, and structures for the operation of agricultural sites and the extension of the growing season (City of Edmonton, 2015).

When urban agriculture is defined more broadly to include things such as edible landscaping, rooftop gardening, and container gardening, it opens up additional possibilities for integrating food production into the urban landscape. One interview participant suggested a novel idea of reconceptualising community gardens - as opposed to plots concentrated in a single location, an alternative could be individual plots scattered throughout densely populated residential neighbourhoods, yet still connected as part of a network. While this could pose logistical difficulties (e.g. access to water and composting facilities), it could also enable individual plots to be closer to gardeners' residences, a model that could be particularly beneficial in neighbourhoods with lower socio-economic status, where residents may face barriers related to time and access.

Several interview participants noted that a focus on the income generation potential of urban agriculture, such as selling produce or prepared foods, could help contribute to community economic development. As mentioned above, the sale of produce from community gardens is prohibited in Ottawa, due in part to the public subsidies that these gardens receive. Expanding the City's perception of urban agriculture beyond community gardens could help to 'scale-up' and 'scale-out' urban agriculture in Ottawa, potentially allowing for increased economic development opportunities. A municipal focus on the commercial benefits of urban agriculture is also advocated by Huang \& Drescher (2015).

A 2013 amendment to the City of Ottawa's Official Plan recognizes the importance of integrating community-based food production into urban areas to help build more 
"sustainable, liveable and resilient communities" (City of Ottawa, 2013) and contribute to quality of life for residents. This amendment, which references not only community gardens, but also edible landscapes and small- and mid-scale urban farms, may be an indication that the City is beginning to expand its definition of urban agriculture. However, implementation tools, such as zoning by-laws, do not yet reflect this broader understanding of the practice. As Huang \& Drescher (2015) conclude in their research on Canadian urban agriculture policies in Ontario and British Columbia, there is a need for municipalities to address gaps between official plans and implementation tools, in order to reflect the urban agriculture policies set out in their official plans.

\section{The National Capital Commission's Capital Urban Lands Master Plan (CULMP)}

All federal land holdings in urban Ottawa (including NCC-owned properties and properties under the authority of other federal departments) are subject to the NCC's land use and approval process, which is guided by the Capital Urban Lands Master Plan (a preliminary version of which was released in March 2014). According to the Master Plan, these lands "convey the images of Canada and its Capital and symbolize Canadians' values and deep attachment to their country, in addition to showcasing Canada's rich natural and cultural heritage" (NCC, 2014, p. 20). The urban lands are categorized according to their principal use, and include designations such as major federal employment area, capital urban greenspace, capital park, and urban redevelopment. Each land designation has a particular set of guidelines, specifying goals, planning orientations, and authorized and unauthorized uses.

The Strategic Framework as outlined in the Master Plan has three roles for urban 
lands: providing contact with nature; providing pleasant, welcoming, and animated spaces; and contributing to urban and regional viability and quality of life. Allowing urban agriculture on lands managed by the NCC could further each of these goals; indeed, the phrase "urban agriculture" is mentioned twice in the Master Plan, as an authorized use under two land designations. As discussed throughout this thesis, urban agriculture, whether in the form of gardens or edible trees, provides an opportunity for urban residents to connect with nature, while also creating pleasant spaces and contributing to environmental and social components of urban life.

The Master Plan notes that "to be truly viable, the Capital must be at the forefront of urban thinking and development. Thus, planning of the Capital urban lands is founded on principles of sustainable urbanism and environmental stewardship" (NCC, 2014, p. 54). It further states that the planning of federal employment areas and other government facilities should support urban intensification, and encourage the creation of "complete communities", or diverse neighbourhoods supporting a variety of land uses and activities, including housing, transportation, employment, retail, recreation, and food. By building social capital and contributing to food security and community development, urban agriculture can have a positive impact on both urban viability and quality of life, while contributing to more sustainable cities.

Among other goals, the NCC seeks to preserve and enhance scenic views and vistas to showcase the natural beauty of the National Capital Region, for the benefit of both residents and visitors. While this limitation on visual impediments could be a point of contention when considering urban agriculture as a land use, there are certain land designations where urban agriculture would be less of an aesthetic concern than others. 
The Master Plan notes that "according to specific conditions and in certain locations" (NCC, 2014, p. 89) urban agriculture is an authorized use on lands designated by the NCC as capital urban greenspace or capital pathways. These conditions and locations are not elaborated upon in the Master Plan; however, of the 540 hectares of land identified in the inventory presented herein on lands owned or managed by the NCC, over 200 hectares were located in areas designated as either capital urban greenspace or along capital pathways.

While the inclusion of urban agriculture as an accepted land use for capital urban greenspace and capital pathways is promising, the practice could also help to further the goals of other land designations. The "major federal employment areas" designation refers to lands that are laid out in campus settings or as multi-building complexes (such as Tunney's Pasture). The goals of this land designation include "encouraging their integration into the broader urban context" (NCC, 2014, p. 94), while the planning orientations refer to encouraging mixed-uses by introducing functions and services that complement the neighbouring environment. A related land designation is the "other federal facilities" category, which refers to stand-alone federal buildings or complexes, and has very similar planning orientations to those of the major federal employment areas designation. In total, over 70 hectares of potentially suitable land were located on federal office buildings, complexes, or institutional land. The inclusion of urban agriculture into these spaces could clearly contribute to quality of life and to integrating these federal employment areas with neighbouring urban areas.

Several large NCC properties are set aside for urban redevelopment. These include the former CFB Rockcliffe lands, areas near Hurdman Station, and the Booth Street federal 
employment complex. Due to the proximity of some of these properties to light rail stations, the major planning orientation for these lands is the conversion to transit-oriented, mixed-use redevelopment. However, the extent of these lands and the NCC's overall policies of responsible planning and integration of lands into the broader urban context would support the inclusion of some urban agriculture activities in these areas, particularly if urban agriculture were integrated as a multifunctional land use.

Several interview participants noted that the NCC has a strong potential role to play in supporting urban agriculture in Ottawa, and that the formulation of an organizational urban agriculture policy and designation of a staff person responsible for dealing with urban agriculture are important steps in realizing this potential. Interestingly, the NCC once played a very strong role in fostering urban agriculture, renting almost 2,000 allotment plots on various properties throughout Ottawa in the 1970s, according to a 1973 Globe and Mail article (Bell, 1973). However, by the early 1980s, the NCC withdrew from this role, citing declining interest among gardeners and a conflict with the NCC's national mandate (Deachman, 2011). The management of some of these allotment gardens was transferred to either the City of Ottawa or to allotment garden associations. The inclusion of urban agriculture in the 2014 Capital Urban Lands Master Plan may be an indication that the NCC is revisiting urban agriculture as an acceptable land use on federally-owned lands. In 2014, the NCC signed a 25-year lease allowing Just Food to operate a 150-acre organicallycertified community farm on lands located in the National Capital Greenbelt, illustrating further support for sustainable agriculture. 


\subsection{Further Considerations for Supporting Urban Agriculture in Ottawa}

\subsubsection{Use of Space}

Utilizing space more efficiently, both horizontally and vertically, is one strategy that could be used to promote urban agriculture, by integrating food production with existing land uses, or by supporting the practice as a temporary land use. As Mougeot (2006) has argued, "Unused urban space is a wasted opportunity — an asset denied to a community's wellbeing and a brake on the city's development" (p. 64). While urban agriculture as an interim land use does include an element of insecurity that could deter gardeners from investing time and resources into a site, sites of temporary food production could also be perceived as an opportunity. In post-industrial American cities, notably Detroit and Cleveland, urban agriculture has received municipal support as an interim land use on vacant or abandoned properties. Several other North American cities have also supported urban agriculture as a land use on vacant public lands. The City of Richmond, British Columbia, runs an Adopta-Garden program, whereby residents "adopt" sites on vacant city-owned lots or along streets or boulevards, and create or maintain food or flower gardens. In the 1970s, New York City began their Green Thumb program, initiated as a result of a financial crisis that left a significant amount of public and private land abandoned. This program has continued to the present day, and provides residents with license agreements to create gardens on vacant city-owned lots. In June of 2015, a Saskatoon, Saskatchewan organization that promotes access to healthy food (CHEP Good Food Inc.) received permission to implement an urban agriculture operation on an empty city lot. Since the site was adjacent to train tracks and the soil was contaminated, the lot was considered undesirable for most purposes; however, food is being grown on site in large barrels (Morin, 2015). Through this program 
(named Askiy, a Cree word meaning "earth" or "land"), proponents have illustrated the possibilities for urban agriculture on vacant land that would otherwise be considered undesirable.

The City of San Francisco has extended support of food production on vacant land to include privately-owned properties, by providing tax reductions for owners of vacant property who agree to dedicate their land to agriculture for a minimum of five years. Since the land is assessed based on the agricultural, rather than the commercial or residential value of the property, owners can benefit from significant property tax reductions. While the incentive does not specify that the public must have access to space for food production, landowners applying for the tax reduction must demonstrate that they will benefit the greater community through public activities such as community gardens, outreach and education, or donations or sales of agricultural products to residents (City and County of San Francisco, 2015). This support of urban agriculture on privately owned land could help San Francisco meet its commitment to reduce waiting list times of residences seeking access to a community garden plot to one year.

In Ottawa, the land inventory identified over 330 hectares of publically- and privately- owned vacant land that could potentially be used for food production (see Figure 26); while this area may fluctuate over time, it represents a substantial amount of land where food could be grown as an interim land use. Implementing programs to support urban agriculture on city-owned vacant lots, as the cities of Richmond and New York have done, or providing private developers with tax incentives for temporarily allowing urban agriculture on vacant properties, could help make a considerable amount of space available for urban food production. 
In addition to vacant land, much of the land identified in the inventory could represent an opportunity to integrate urban agriculture with existing land uses. Mougeot (2006) has argued that:

setting aside areas in or around the city for the exclusive and permanent use by UA [urban agriculture] is unrealistic and self-defeating. For one thing, it ignores the economic reality of land prices in growing cities. More importantly, it misses out on the interactions that UA can have (and should have if it is to prosper) with other urban activities (p. 65).

The land inventory identified over 165 hectares on school, hospital, or other institutional properties; 139 hectares on utilities land; and 64 hectares on federal government office complexes (see Figure 26). In total, this represents 368 hectares of land where food production could be integrated with existing land uses. Integrating urban agriculture as a multi-functional land use could not only help to balance multiple demands for urban space, but also, as Mougeot points out, to increase the interactions that urban agriculture can have with other activities that take place in the urban environment. These interactions could take the form of educational opportunities on school grounds, therapeutic benefits on the grounds of health care facilities (such as an initiative at Glengarry Memorial Hospital in Alexandria, Ontario looking at the physiotherapy benefits of gardening for recovering patients), or increased integration of federal office complexes with neighbouring urban areas. 


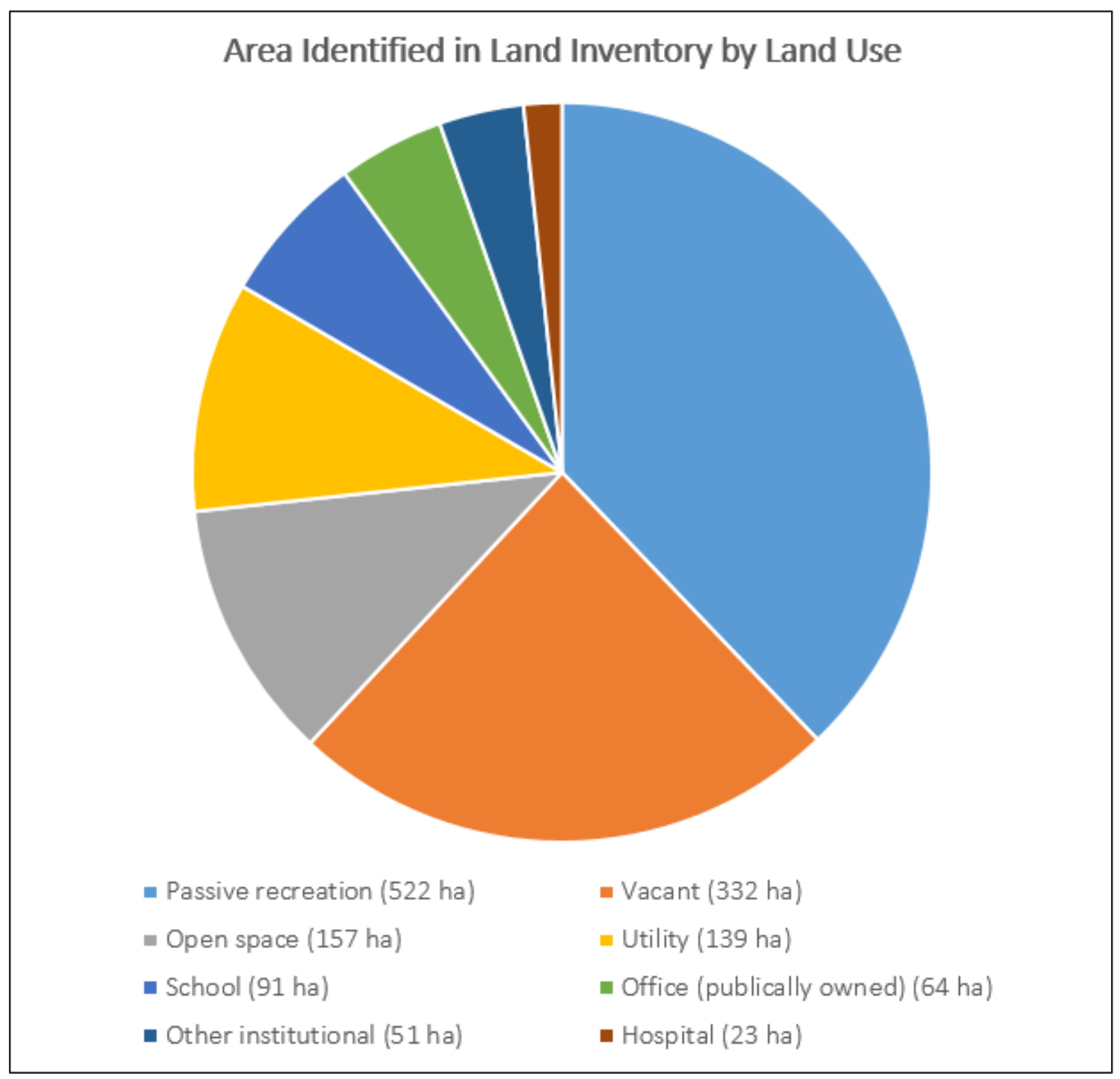

Figure 26 - Land identified in inventory by land use.

\subsubsection{Socio-economic Considerations}

During interviews with urban agriculture practitioners, a number of strategies to promote urban agriculture in Ottawa emerged. The need to increase access for marginalized groups was a common theme among interview participants, who noted that getting involved in community gardens can be more difficult for people who are already struggling with dayto-day activities. Although annual fees for community gardens are low, and many gardens provide tools for gardeners to share, the costs of annual fees and purchasing seed can be 
prohibitive, as can the opportunity cost of time spend gardening. If gardens are not located in a gardener's immediate neighbourhood, transportation can be an added time and financial burden. However, interviewees noted that in mid- and high-income neighbourhoods, residents are more likely to drive or take public transit, so travelling a greater distance to garden, while not ideal, may not be such a burden. This points to a greater need to consider proximity of urban agriculture initiatives to places of residence, particularly in lower-income communities.

A number of policy-related considerations can be drawn from the analysis of patterns between locations of urban agriculture activities and socio-economic conditions. In some respects, the regression analyses supported the expectation that community gardens tend to be located in areas with lower socio-economic status, as unemployment rates and the percentage of female lone-parent families were positively associated with community garden locations, while median household income was negatively associated with garden locations. However, close to half of the community garden plots in the study area $(43.6 \%)$ were located in census tracts with a relatively low prevalence of low-income individuals. While the establishment of community gardens in Ottawa tends to favour lowincome urban neighbourhoods in practice, the locations of the number of community garden plots in relation to income levels suggests that greater importance should be given to the establishment of large gardens in these areas. This of course is difficult, since the need to balance demand with available space is most pronounced in the urban core. However, the results of the land inventory help to illustrate that there may be more land available in the urban core than is generally recognized, and that the integration of urban agriculture in multi-functional spaces could be a means of reconciling this challenge. The 
land identified through the inventory was distributed very evenly among each of the income quartiles, with between $23-26 \%$ of the land located in each of the four regions. From a food justice perspective, this is promising, since it indicates that potentially suitable land is equally available across income lines.

An interesting finding of the regression analysis was the positive correlation between high education levels and locations of community gardens, and the negative correlation between this variable and locations of school gardens and edible trees. I would postulate that this trend could be attributed to the high numbers of students living in lowerincome neighbourhoods near the two major universities in Ottawa. This points to a need for policy-makers to consider the needs of communities composed of highly mobile populations, including students and other short-term residents, in order to help ensure that access to space for food production is accessible across the spectrum of the population. Due to the itinerant nature of residents in such neighbourhoods, however, a challenge in ensuring access to urban agriculture could be the lack of ongoing community support. While initiatives such as individual plots in community gardens might be difficult to implement, other forms of urban agriculture, such as fruit- and nut-bearing trees, edible landscaping, and communal gardens, might provide a more sustainable alternative, which provides further support for the notion of expanding the city's perception of urban agriculture beyond community gardens.

The regression modeling of school gardens provided support that these gardens are associated with neighbourhoods with higher socio-economic characteristics. The global regression analysis showed a positive correlation between the dependent variable and median dwelling value, families with children, and the percentage of apartment-style 
dwellings, and a negative association with the percentage of the population who are immigrants, and the percentage of low-income individuals. As mentioned in Chapter 4, this trend can be attributed to the fact that the Growing Up Organic program uses an opportunistic strategy based on the program spreading through word-of-mouth. However, it may also indicate that schools located in higher socio-economic neighbourhoods may have a greater capacity to initiate and support school gardens, since most schools rely on parents to volunteer to care for gardens in the summer and to engage in fundraising activities to raise money to start a garden.

The Community Gardening Network does provide funding towards the start-up costs of new school gardens, with about half of participating schools paying for start-up costs themselves, one quarter receiving partial funding support, and one quarter receiving full support. The regression analysis indicates that lower socio-economic neighbourhoods might benefit from incorporating a strategic element in the establishment of new school gardens, in order to help ensure that the experiential education benefits of school gardens are more widely available.

The analysis of food-bearing trees revealed a hot spot in the neighbourhoods of Rockcliffe Park and New Edinburgh, and a cool spot in the neighbourhoods of Sandy Hill and Vanier. The regression analysis provided some support that locations of food-bearing trees are associated with higher socio-economic indicators, including strong positive correlations with median household income and median dwelling value. Food-bearing trees on public property were also more likely to be located in the urban core, as opposed to more peri-urban areas.

As mentioned previously, an increased focus on food-bearing trees could help to 
ensure that opportunities for publically-accessible food are more broadly available, particularly in neighbourhoods where larger spaces for food production are limited. In 2009, the City of Calgary embarked on a five-year community orchard research project, planting food-bearing trees and shrubs around the city in order to increase opportunities for increased urban food production (City of Calgary, 2015). As part of this pilot project, the city tested several different community orchard models, including orchards attached to existing community gardens, orchards in parks, regional orchards (large orchards with a focus on education and testing), fruit trees along pedestrian routes, and fruit trees on private residential properties. Each of these models provides different opportunities for community stewardship, food distribution, public accessibility, and educational opportunities. At the end of the pilot project, City of Calgary officials found that orchards adjacent to community gardens fared better than those in public parks, due to the existing association with a community group (Nordahl, 2014), indicating that maintenance support by city staff may be required in some circumstances.

The potential food security benefits of food-bearing trees on public property can be significant. A study of urban food forests in Burlington, Vermont showed that under various planting scenarios, between 109 and 3,277 edible tons of apples could be produced on publicly accessible urban space, with the most ambitious planting and yield estimate providing over $100 \%$ of the recommended minimum fruit intake for all residents in the city (Clark \& Nicholas, 2013). In Ottawa, the potential of food-bearing trees is beginning to be realized. Hidden Harvest Ottawa, which began operating in 2012, harvested over 2,700 $\mathrm{kg}$ of fruit and nuts in 2013, nearly one third of which was donated to local food agencies (Hidden Harvest Ottawa, 2013). 


\subsection{Conclusion}

In order for food production in urban spaces to become more widely available, support is needed from both state actors and urban inhabitants. This chapter has reviewed municipal and federal policies related to urban agriculture and the use of urban lands. The City of Ottawa has demonstrated considerable support for community gardening through its commitment to the Community Garden Action Plan. However, broadening the City's perception of urban agriculture beyond community gardens, as alluded to in a recent amendment to the Official Plan, could be helpful in fostering alternative forms of the practice.

The strategic framework for the management of NCC urban lands as outlined in the recently released Capital Urban Lands Master Plan could also be furthered through urban agriculture. While the inclusion of urban agriculture as an accepted use for two land use designations is promising, the goals of other land use designations, notably federal employment areas and areas slated for urban redevelopment, could also be supported by considering urban agriculture as a multifunctional land use in these spaces.

This chapter then turned to policy recommendations for urban agriculture related to the use of space and socio-economic conditions. Several North American cities, including Richmond, British Columbia, and San Francisco, California, have implemented policies to support urban agriculture as an interim land use on vacant land, whether publicly or privately owned. The amount of vacant land identified in the land inventory (over 330 hectares) represents a substantial area that could be utilized for urban agricultural practices, whether on an interim or permanent basis, demonstrating an opportunity to make use of 
space that is currently underutilized. Additionally, over 360 hectares of land were identified where urban agriculture could be integrated with existing land uses, such as institutions and federal office space. Integrating food production with existing land uses in these urban landscapes could not only lessen the burden of negotiating multiple demands for space, but also increase the interactions that urban agriculture has with other activities, contributing to the ability of the practice to increase social capital.

In order to help ensure that access to space for food production is available across the spectrum of the population, a number of socio-economic factors should be taken into consideration. While proximity of gardens to places of residence is desirable as a general rule, it is particularly important in areas with lower socio-economic status. Further, this research pointed to a need for policy-makers to consider communities comprised of highly mobile populations when planning for urban agriculture, and recommended that a consideration of a more complex urban agriculture could be particularly beneficial in neighbourhoods where community capacity may be limited. 


\section{Chapter: Conclusion}

This research sought to explore the spatial and social implications of publically accessible urban agriculture in Ottawa. Specifically, this study looked at where and in what form urban agriculture currently exists, and how the spatial distributions of urban food production practices relate to local socio-economic conditions. A secondary research question considered the potential for increased urban agriculture, in terms of land availability and suitability. Finally, this study sought to address whether there are policy considerations that could be implemented in order to promote a more equitable system of urban agriculture in Ottawa. In addressing these questions, this research drew on a conceptual framework linking concepts of food justice, the right to the city, and social capital.

This chapter synthesizes the key findings and contributions of this research to a critical urban geography of urban agriculture. It then turns to a discussion of methodological and substantive limitations of this research, and suggestions for directions of future lines of inquiry, before reflecting on the successes and constraints of the methods used.

\subsection{Summary of Key Findings}

This research applied a methodological framework drawing on principles of feminist research and critical GIS, including engaging in action-oriented research, using a combination of qualitative and quantitative methods, and concentrating on the socioeconomic applications of GIS. A mixed- methods approach was employed, combining qualitative and quantitative data collection and analysis. 
Drawing on Tornaghi's (2014) argument that urban agriculture is often embedded with socio-environmental "exclusionary dynamics", this research sought to answer whether opportunities for food production, including community gardens, school gardens, and edible trees, are equally accessible across the spectrum of the population. Analyzing existing urban agriculture practices in Ottawa in relation to socio-economic criteria supports finding from other locations (e.g. Kremer \& DeLiberty, 2011; Smith et al., 2013): notably, that community gardens are more commonly located in lower-income neighbourhoods, and are associated with several demographic criteria associated with lower socio-economic status. However, this finding was complicated by considering community garden plots (rather than locations), which revealed a higher number of plots within higher-income neighbourhoods. Regression analyses of both school gardens and edible trees indicated that these types of urban agriculture are more strongly correlated with demographic factors that are generally associated with higher socio-economic status. An interesting finding was the relationship exhibited between higher levels of education, which displayed an opposite relationship than expected for all urban agriculture practices. A potential explanation was offered by postulating that in Ottawa, high education levels are often associated with low income levels due to the large student population (particularly in neighbourhoods in close proximity to major universities), and that this factor accounted for the unexpected relationship between higher education levels and urban agriculture locations.

Spatial analysis of urban agriculture locations highlighted a need to consider various populations when planning for a system in which the benefits of urban food production are shared equally. This included the need for more community garden plots 
in lower-income neighbourhoods, and the need for more school gardens and food-bearing trees in neighbourhoods with lower socio-economic indicators. It also indicated the importance of considering the needs of mobile populations, such as students, when planning for urban agriculture. In some neighbourhoods, particularly where community capacity is limited, edible trees or communal gardens may offer a more sustainable alternative to individual food production. Such measures could help create a more just local food system in Ottawa.

Public demand for space to grow food in the urban environment is high, with most gardens maintaining lengthy waiting lists, and more applications for new community gardens than funding available. While a lack of available space is often identified as one of the biggest barriers facing urban agriculture, the results of the inventory presented herein help to illustrate that in Ottawa there is a significant amount of land, nearly 1,400 hectares, potentially available for food production. This finding may lend support to Martezello's (2014) claim that urban agriculture may be most effective in smaller urban centres that have more physical space available due to lower population densities. While the land identified in the inventory would need to be assessed on a site-by-site basis to determine suitability, using even a fraction of it for urban agriculture could make space for urban food production opportunities more accessible, allowing urban inhabitants to be active participants in creating a local food system.

While urban agriculture could be a dedicated land use in some cases, many sites were identified where food production could be integrated with existing land uses. Integrating urban agriculture with government and institutional land could allow for more connections between these agencies and urban residents, contributing to the formation of 
both bridging and bonding social capital. Interviews revealed a high level of interconnection among organizations in planning for urban agriculture initiatives in Ottawa. The integration of food production with existing land uses could strengthen these connections by creating physical places where actors from various sectors could interact. This could have the added benefit of fostering collective mobilization related to other community development initiatives (Firth et al., 2011). Integration of food production into the urban landscape could also support the community development, sustainability, and urban viability goals of the City of Ottawa and the National Capital Commission.

\subsection{Directions for Future Research}

This research has identified existing and potential areas for urban food production in public spaces in Ottawa, but has not considered the amount of food that is currently, or that could potentially, be produced in these spaces. Research in other locations (e.g. Colasanti \& Hamm, 2010; MacRae et al., 2010; McClintock et al., 2013) has attempted to quantify the contribution that urban agriculture can make to local produce needs, based on estimates of local growing conditions and nutritional requirements. Combining a similar quantitative approach to production potential with interviews with urban gardeners could be an interesting question for future research, to address to what extent models of productivity align with the actual yields of gardeners, and to determine what factors contribute to productivity (e.g. skill and experience of the gardener, time commitment, proximity of a garden to place of residence, availability of advice, etc.). This line of inquiry could help inform an assessment of the potential of urban agriculture to contribute to individual and community food security. 
Throughout this study, the assumption has been present that urban inhabitants are more likely to participate in urban agriculture practices that are located in close proximity to their place of residence. While this is likely an important consideration, other factors may also play a role in determining access, such as time, financial constraints, perception of safety and security in gardens, childcare responsibilities, accessibility, and availability of gardening skills or information. Based on interviews with community gardeners and other local residents, another interesting line of inquiry would be to examine the extent to which proximity equates to access in the case of urban agriculture (i.e., in determining what barriers affect residents' ability to grow food in urban spaces).

Finally, the land inventory presented herein considered only land-based urban agriculture activities on public or semi-public properties. As a result, the amount of land identified in the inventory does not represent all areas that may be suitable for urban agriculture. Private spaces of food production (such as private yards and balcony gardens) were not considered as potential areas for food production, nor were lands located on the grounds of residential apartment buildings or housing complexes. As the interviews revealed, a number of urban agriculture initiatives exist in social housing complexes in Ottawa, and the potential for increased food production in these spaces was not explored in the current study. Further, due to the difficulties in assessing the suitability of rooftops for urban agriculture across a large extent through GIS analysis, the potential of rooftop gardening was not considered as part of this study. These lines of inquiry could also be a fruitful direction for future research, and could help to shed light on the possibilities for horizontal and vertical scaling-up of urban food production. 


\subsection{Constraints \& Limitations}

Methodological limitations related to regression modeling and the land inventory were discussed in detail in Chapter 4. These included the difficulty of spatial analysis to fully explain complex social processes, as well as the difficulty in representing certain types of data, such as community support, in a GIS. The limitations of the data used in creating the land inventory were also discussed, with a particular focus on the lack of incorporation of future development plans.

Since urban agriculture activities are dynamic, the locations of community and school gardens and edible trees are a snapshot of the most current data available. Each year, new gardens are created, while others occasionally cease to exist due to a lack of community support or development pressures (as in the case of the Carlington Community Garden, discussed in Chapter 4). Community garden locations were verified through site visits and the use of Google Earth; however, it is possible that there are additional publicly accessible gardens that are neither part of the CGN nor located on OCH properties, and were therefore not included in the analysis. However, what appears to be an "unofficial" community garden was detected from aerial imagery during the process of refining the land inventory, so it is likely that any other gardens that were not included in the analysis were relatively small in area, otherwise they would likely have been detected through visual analysis. Also, as mentioned in Chapter 3, the database of fruit- and nut- bearing trees represents trees that are potentially edible, so it is likely an over-estimation of the number of trees that actually produce food.

As part of the feminist / critical GIS approach adopted by this study, some elements 
of participatory action research (PAR) were incorporated. However, due to the time constraints associated with completing a Master's program, the level of participant input was limited, in that participants were not involved with the design of the research. However, by incorporating interactive mapping in the research design, and through a commitment to conducting applied research that will be made available to interested parties, some elements of PAR were incorporated.

\subsection{Reflections on the Use of Mixed-Methods}

As Knigge \& Cope (2006) found in their study combining GIS and ethnographic methods, using both qualitative and quantitative data collection and analysis can support triangulation of evidence, allowing connections to emerge and different forms of data to

inform one other. A similar finding was evident in this research. Interviews with urban agriculture practitioners informed the creation of the land inventory; however, they also informed other aspects of the analysis, sometimes in unexpected ways. The interview process aided in the creation of a more complete database of existing urban agriculture practices, and also provided insight into the socio-spatial distribution of these practices, such as the preference among practitioners to support community garden locations in lower-income neighbourhoods. Additionally, the interactive mapping exercise enhanced the interview process; the exercise of sketching on maps seemed to allow participants with not only an alternate means of conveying information, but also an opportunity to reflect on their answers.

GIS-based analyses and visualizations were also useful in providing direction for policy recommendations that could help promote a more equitable system of urban 
agriculture in Ottawa. As Pavlovskaya (2006) has argued, mapping patterns and phenomena helps to make them more visible, and can therefore attribute them with more significance at a policy level. In the case of this research, mapping socio-spatial relationships was an effective means of summarizing patterns between urban agriculture and socio-economic factors, while mapping the land identified through the inventory effectively communicated the extent of land that may be available for expanding urban agriculture in Ottawa.

While a mixed-methods approach is not without difficulties, notably those that relate to writing up research findings in a coherent manner, combining qualitative and quantitative analysis can help to reveal more complete explanations of social processes, while, as Kwan (2002) notes, allowing for more nuanced understandings to emerge. In the case of this research, GIS was an appropriate method for beginning to answer questions related to the socio-spatial distribution of urban agriculture and land potentially available for such activities; however, the inclusion of interviews, interactive mapping, and policy analysis contributed to a richer, more comprehensive understanding of the research questions than would have been possible using a single method.

\subsection{Conclusion}

Urban agriculture practices can be viewed as a form of resistance against the dominant food system, but also as practices that promote an ethic of care, the development of social capital, and the use of urban space in ways that align with the myriad needs of residents. This research has indicated that existing urban agriculture practices in Ottawa may not be equally accessible across the spectrum of the population, and has offered policy 
prescriptions to help create a system of urban food production that is more equitable. It has also argued that whether urban agriculture takes the form of a dedicated land use, is integrated as part of multi-functional spaces, or is an interim land use on vacant properties, there is potential to increase the amount of food production in urban Ottawa. While urban agriculture is not a complete solution to creating a more just and sustainable food system in Ottawa, it is an important component of such a system. 


\section{Appendices}

\section{Appendix A - Interview Guide}

1. Can you tell me how your organization is involved in urban agriculture initiatives in Ottawa?

2. Can you tell me a bit about your understanding of the role other organizations in Ottawa play in promoting/supporting urban agriculture initiatives in Ottawa?

3. What role do you think public or semi-public urban agriculture initiatives (such as community gardens, collective rooftop gardens, or gleaning from edible trees on public property) currently play in contributing to a local food system in Ottawa?

4. What role do you think public or semi-public urban agriculture initiatives currently play in contributing to community development in Ottawa?

5. In your experience, what factors are important in determining whether a location is suitable for public forms of urban agriculture? Some examples may include land use, land ownership, slope, aspect, soil type / contamination, access to public transit, demographics (but don't feel limited by these examples).

6. In your view, are there certain factors that are absolute requirements in selecting a particular site for urban agriculture?

For the following interview question, participants will be provided with a base map of the study area on which they can sketch their responses.

1. Are there particular neighbourhoods or areas that you feel would benefit from increased urban agriculture initiatives? Why did you select these locations? 


\section{References}

Agriculture and Agri-Food Canada. (2007). Local and regional food economies in Canada: Status report. Retrieved from http://www4.agr.gc.ca/resources/prod/doc/pol/pub/econ_can/pdf/econ_can_e.pdf.

Alaimo, K., Packnett, E., Miles, R. A., \& Kruger, J. (2008). Fruit and vegetable intake among urban community gardeners. Journal of Nutrition, Education, and Behaviour, 40 (2), 94-101.

Allen, P. (2004). Together at the table: Sustainability and sustenance in the American agrifood system. University Park, PA: The Pennsylvania State University Press.

Allen, P. (2010). Realizing justice in local food systems. Cambridge Journal of Regions, Economy and Society, 3, 295-308.

Andrée, P., Ballamingie, P., \& Sinclair-Waters, B. (2014). Neoliberalism and the making of food politics in Eastern Ontario. Local Environment: The International Journal of Justice and Sustainability, 1-21. doi: 10.1080/13549839.2014.908277.

Ballamingie, P., \& Walker, S. M. L. (2013). Field of dreams: Just Food's proposal to create a community food and sustainable agriculture hub in Ottawa, Ontario. Local Environment, 18(5), 529-542.

Beacon Environmental. (2012). Ecological buffer guideline review: Prepared for Credit Valley Conservation. Retrieved from http://www.creditvalleyca.ca/wpcontent/uploads/2013/08/Ecological-Buffer-Guideline-Review.pdf.

Bedore, M. (2010). Just urban food systems: A new direction for food access and urban social justice. Geography Compass, 4 (9), 1418-1432.

Bell, P. (1973, September 6). Pounds of food from \$10 plots. The Globe and Mail.

Bell, S. \& Reed, M. (2004). Adapting to the machine: Integrating GIS into qualitative research. Cartographica, 39 (1), 55-66.

Bell, S. \& Wei, T. (2014). Mapping the spatial pattern of the uncertain data: A comparison of global non-response rate (GNR) between metropolitan and nonmetropolitan area. Paper presented at the Spatial Knowledge and Information Conference, Banff, Alberta, Canada. Retrieved from http://rose.geog.mcgill.ca/ski/system/files/fm/2014/bell.pdf.

Born, B. \& Purcell, M. (2006). Avoiding the local trap: Scale and food systems in planning research. Journal of Planning Education and Research, 26, 195-207. 
Brown, K. H. \& Jameton, A. L. (2000). Public health implications of urban agriculture. Journal of Public Health Policy, 21 (1), 20-39.

Calgary Food Committee. (2012). Calgary food system assessment and action plan. Retrieved from http://www.calgary.ca/CA/cmo/Documents/CalgaryEATS!\%20FULL\%20Food\% 20System $\% 20$ Assessment $\% 20 \% 20$ Action $\% 20$ Plan $\% 20$ for $\% 20$ Calgary $\% 20$ May 2 012.pdf.

Chang, K. (2010). Introduction to geographic information systems. New York, NY: McGraw-Hill.

Charlton, M. \& Fotheringham, A. S. (2009). Geographically weighted regression: A tutorial on using GWR in ArcGIS 9.3. Retrieved from http://ncg.nuim.ie/ncg/gwr/GWR_Tutorial.pdf.

City and County of San Francisco, Department of Public Health. (2015). Application packet for an urban agriculture incentive zone. Retrieved from http://sfrecpark.org/wp-content/uploads/Urban-Agriculture-Application-040915fillable.pdf.

City of Calgary. (2015). Community orchards. Retrieved from http://www.calgary.ca/CSPS/Parks/Pages/Programs/Community-orchards.aspx.

City of Edmonton. (2015). Urban agriculture and the zoning bylaw. Retrieved from http://www.edmonton.ca/city_government/documents/Urban_Agriculture and th e Zoning_Bylaw.pdf.

City of Ottawa. (2014). 2013 Annual development report. Retrieved from http://documents.ottawa.ca/en/node/394.

City of Ottawa. (2013). Official plan amendment \#150 to the Official Plan of the City of Ottawa. Retrieved from http://documents.ottawa.ca/sites/documents.ottawa.ca/files/documents/opa 150 e $\underline{\text { n.pdf. }}$

City of Ottawa. (2011). City of Ottawa official plan: A component of Ottawa 20/20, the city's growth management strategy (Publication 1-28). Retrieved from http://ottawa.ca/en/city-hall/planning-and-development/official-plan-and-masterplans/official-plan.

Clark, K. H. \& Nicholas, K. A. (2013). Introducing urban food forestry: A multifunctional approach to increase food security and provide ecosystem services. Landscape Ecology, 28, 1649-1669. 
Colasanti, K. J. A. \& Hamm, M. W. (2010). Assessing the local food supply capacity of Detroit, Michigan. Journal of Agriculture, Food Systems, and Community Development, 1(2), 41-58.

Colasanti, K. J. A., Hamm, M. W., \& Litjens, C. M. (2012). The city as an "agricultural powerhouse"? Perspectives on expanding urban agriculture from Detroit, Michigan. Urban Geography, 33(3), 348-369.

Corrigan, M. P. (2011). Growing what you eat: Developing community gardens in Baltimore, Maryland. Applied Geography, 31(4), 1232-1241.

Dale, A. (2005). Social capital and sustainable community development: Is there a relationship? In A. Dale \& J. Onyx (Eds.), A dynamic balance: Social capital \& sustainable community development (pp. 13-30). Vancouver, BC: UBC Press.

Danyluk, M. (2009). Cultivating potential: Planning for urban agriculture in Toronto's hydro corridors. Retrieved from http://tfpc.to/wordpress/wpcontent/uploads/2013/01/2008-09-Cultivating-Potential-Urb-Agri-in-HydroCorridors-DANYLUK.pdf.

Deachman, B. (2011, August 14). The allotment gardener: When the NCC pulled out of community gardening 30 years ago, George Bushell stepped in to help save Blackburn Hamlet. Ottawa Citizen.

Dunn, K. (2010). Interviewing. In I. Hay (Ed.), Qualitative research methods in human geography ( $3^{\text {rd }}$ ed., pp. 101-138). Don Mills, Ontario: Oxford University Press.

Dupuis, E. M. \& Goodman, D. (2005). Should we go "home" to eat? Toward a reflexive politics of localism. Journal of Rural Studies, 21, 359-371.

Ecological Stratification Working Group. (1995). A national ecological framework for Canada (Cat. No. A42-65/1996E). Ottawa, ON: Canadian Soil Information System.

Elwood, S. (2006a). Beyond cooptation or resistance: Urban spatial politics, community organizations, and GIS-based spatial narratives. Annals of the Association of American Geographers, 96 (2), 323-341.

Elwood, S. (2006b). Negotiating knowledge production: the everyday inclusions, exclusions, and contradictions of participatory GIS research. The Professional Geographer (58), 2, 197-208.

Elwood, S. \& Cope, M. (2009). Introduction: Qualitative GIS: Forging mixed methods through representations, analytical innovations, and conceptual engagements. In S. Elwood \& M. Cope (Eds.), Qualitative GIS: A mixed methods approach (pp.112). Thousand Oaks, California: SAGE Publications, Inc. 
Esri (2014). ArcGIS for Desktop (Version 10.2.2). [Software].

Ferris, J., Norman, C. \& Sempik, J. (2001). People, land and sustainability: Community gardens and the social dimension of sustainable development. Social Policy \& Administration, 35 (5), 559-586.

Firth, C., Maye, D., \& Pearson, D. (2011). Developing “community” in community gardens. Local Environment, 16 (6), 555-568.

Flyvbjerg, B. (2006). Five misunderstandings about case-study research. Qualitative Inquiry, 12 (2), 219-245.

Fotheringham, A. S., Brunsdon, C., \& Charlton, M. (2002). Geographically weighted regression: The analysis of spatially varying relationships. West Sussex, England: John Wiley \& Sons Ltd.

Glover, T. D. (2004). Social capital in the lived experiences of community gardeners. Leisure Sciences, 26, 143-162.

Goodchild, M.F. (2006). Geographic information systems. In S. Aitken \& G. Valentine (Eds.) Approaches to human geography (pp. 251-262). Thousand Oaks, California: SAGE Publications, Inc.

Gottlieb, R. \& Joshi, A. (2013). Food justice. Boston, MA: MIT Press.

Harvey, D. (2003). The right to the city. International Journal of Urban and Regional Research, 27 (4), 939-941.

Harvey, D. (2008). The right to the city. New Left Review, 53, 23-53.

Hidden Harvest Ottawa. (2013). The results are in. Year End Specials \& Our 2013 Results. Retrieved from http://us4.campaignarchive1.com/?u=b40bb57d1ccafaeba138ee482\&id=bd2f4d8138.

Hinrichs, C. \& Allen, P. (2008). Selective patronage and social justice: Local food consumer campaigns in historical context. Journal of Agricultural and Environmental Ethics, 21, 329-352.

Hinrichs, C. \& Kremer, K. S. (2002). Social inclusion in a Midwest local food system project. Journal of Poverty, 6 (1), 65-90.

Hodgson, K., Campbell, M. C., \& Bailkey, M. (2011). Urban agriculture: Growing healthy, sustainable places. Chicago, IL: American Planning Association. 
Horst, M. (2008). Growing green: An inventory of public lands suitable for community gardening in Seattle, Washington. Retrieved from http://www.seattle.gov/Neighborhoods/ppatch/pubs/MHORST_GROWINGGRE EN.pdf.

Howard, E. (1965). Garden cities of tomorrow. In F. J. Osborn (Ed.). Cambridge, MA: The M.I.T. Press. (Original work published 1898).

Huang, D. \& Drescher, M. (2015). Urban crops and livestock: The experiences, challenges, and opportunities of planning for urban agriculture in two Canadian provinces. Land Use Policy, 43, 1-15.

Hubley, T. A. (2011). Assessing the proximity of healthy food options and food deserts in a rural area of Maine. Applied Geography, 31, 1224-1231.

Hynes, H. P. \& Howe, G. (2002). Urban horticulture in the contemporary United States: Personal and community benefits. Acta Horticulturae (ISHS), 643, 171-181.

Jermé, E. S. \& Wakefield, S. (2013). Growing a just garden: Environmental justice and the development of a community garden policy for Hamilton, Ontario. Planning Theory \& Practice, 14 (3), 295-314.

Just Food. (2014a). Community gardening on private land and City of Ottawa land. Retrieved from http://justfood.ca/ottawa-food-action-plan/community-gardeningon-private-land-city-of-ottawa-land/.

Just Food. (2014b). About Just Food. Retrieved from http://justfood.ca/about/.

Kindon, S. (2010). Participatory action research. In I. Hay (Ed.), Qualitative research methods in human geography ( $3^{\text {rd }}$ ed., pp. 259-277). Don Mills, Ontario: Oxford University Press.

Kingsley, J. Y. \& Townsend, M. (2006). 'Dig in' to social capital: Community gardens as mechanisms for growing urban social connectedness. Urban Policy and Research, 24 (4), 525-537.

Knigge, L., \& Cope, M. (2006). Grounded visualization: Integrating the analysis of qualitative and quantitative data through grounded theory and visualization. Environment and Planning A, 38(11), 2021-2037.

Kremer, P., \& DeLiberty, T. L. (2011). Local food practices and growing potential: Mapping the case of Philadelphia. Applied Geography, 31(4), 1252-1261.

Kwan, M. (2002). Feminist visualization: Re-envisioning GIS as a method in feminist geographic research. Annals of the Association of American Geographers, 92(4), 645-661. 
Lafary, E. W., Gatrell, J. D. \& Jensen, R. R. (2007). People, pixels and weights in Vanderburgh County, Indiana: Toward a new urban geography of humanenvironment interactions. Geocarto International, 23 (1), 53-66.

Larson, J. T. (2006). A comparative study of community garden systems in Germany and the United States and their role in creating sustainable communities. Aboricultural Journal: The International Journal of Urban Forestry, 29 (2), 121-141.

Levkoe, C. Z. (2006). Learning democracy through food justice movements. Agriculture and Human Values, 23, 89-98.

Levkoe, C. Z. (2011). Towards a transformative food politics. Local Environment, 16 (7), 687-705.

Lillesand, T. M., Kiefer, R. W. \& Chipman, J. W. (2008). Remote sensing and image interpretation. Hoboken, NJ: John Wiley \& Sons, Inc.

Lovell, S. T. (2010). Multifunctional urban agriculture for sustainable land use planning in the United States. Sustainability, 2, 2499-2522.

MacRae, R., Gallant, E., Patel, S., Michalak, M., Bunch, M., \& Schaffner, S. (2010). Could Toronto provide $10 \%$ of its fresh vegetable requirements from within its own boundaries? Matching consumption requirements with growing spaces. Journal of Agriculture, Food Systems, and Community Development, 1-23. doi: 10.5304/jafscd.2010.012.008.

Marcuse, P. (2009). From critical urban theory to the right to the city. City, 13 (2-3), 185 197.

Martellozzo, F., Landry, J. S., Plouffe, D., Seufert, V., Rowhani, P. \& Ramankutty, N. (2014). Urban agriculture: A global analysis of the space constraint to meet urban vegetable demand. Environmental Research Letters, 9, 1-8.

Martin, R. (2001). Geography and public policy: the case of the missing agenda. Progress in Human Geography, 25 (2), 189-210.

Massey, D. (1994). Space, Place, and Gender. Minneapolis, MN: University of Minnesota Press.

Megler, V., Banis, D. \& Chang, H. (2014). Spatial analysis of graffiti in San Francisco. Applied Geography, 54, 63-73.

Mendes, W., Balmer, K., Kaethler, T., \& Rhoads, A. (2008). Using land inventories to plan for urban agriculture: Experiences from Portland and Vancouver. Journal of the American Planning Association, 74(4), 435-449. 
McClintock, N. (2014). Radical, reformist, and garden-variety neoliberal: Coming to terms with urban agriculture's contradictions. Local Environment, 19 (2), 147171.

McClintock, N., Cooper, J., \& Khandeshi, S. (2013). Assessing the potential contribution of vacant land to urban vegetable production and consumption in Oakland, California. Landscape and Urban Planning, 111, 46-58.

McLafferty, S. (2005). Women and GIS: Geospatial technologies and feminist geographies. Cartographica, (40) 4, 37-45.

Milbourne, P. (2012). Everyday (in)justices and ordinary environmentalisms: Community gardening in disadvantaged urban neighbourhoods. Local Environment, 17 (9), 943-957.

Mok, H. F., Williamson, V. G., Grove, J. R., Burry, K., Barker, S. F., \& Hamilton, A. J. (2014). Strawberry fields forever? Urban agriculture in developed countries: A review. Agronomy for Sustainable Development, 34, 21-43.

Morin, C. (2015, June 11). Urban agriculture blooms on Saskatoon's empty lots. The StarPhoenix. Retrieved from http://www.thestarphoenix.com/life/Urban+agriculture+blooms+Saskatoon+empt $\mathrm{y}+$ lots/11129250/story.html\# federated $=1$.

Mougeot, L. J. A. (2006). Growing better cities: Urban agriculture for sustainable development. Ottawa, ON: International Development Research Centre.

Napawan, N.C. (2014). Complexity in urban agriculture: The role of landscape typologies in promoting urban agriculture's growth. Journal of Urbanism: International Research on Placemaking and Urban Sustainability, 1-20. doi: 10.1080/17549175.2014.950317.

National Capital Commission. (2014). Capital urban lands: Master plan (Preliminary). Retrieved from http://www.ncc-ccn.gc.ca/sites/default/files/pubs/culmp-march2014.pdf.

National Capital Commission. (n.d.). About the NCC. Retrieved from http://www.nccccn.gc.ca/about-ncc.

Newman, L. (2008). Extreme local food: Two case studies in assisted urban small plot intensive agriculture. Environments, (36) 1, 33-43.

Newman, L. \& Dale, A. (2005). The role of agency in sustainable local community development. Local Environment, 10 (5), 477-486. 
Nordahl, D. (2014). Public produce: Cultivating our parks, plazas, and streets for healthier cities. Washington, DC: Island Press.

Onyx, J. (2005). Introduction. In A. Dale \& J. Onyx (Eds.), A dynamic balance: Social capital \& sustainable community development (pp. 1-10). Vancouver, BC: UBC Press.

Ostry, A., \& Morrison, K. (2008). Developing and utilizing a database for mapping the temporal and spatial variation in the availability of "local foods" in British Columbia. Environments Journal, 36 (1), 19-31.

Ottawa Food Bank. (n.d.). Community Harvest. Retrieved from http://ottawafoodbank.ca/programs/community-harvest/.

Ottawa Food Policy Council. (2013). The Ottawa Food Policy Council. Retrieved from http://www.ofpc-cpao.ca/.

Pavlovskaya, M. (2006). Theorizing with GIS: A tool for critical geographies? Environment and Planning A, 38(11), 2003-2020.

PCI Geomatics (2014). Focus (Version 2014-08-01). [Software].

Philips, L. J. (1998). Combining quantitative and qualitative approaches to social research in human geography - an impossible mixture? Environment and Planning, 30, 261-276.

Port, C. M. \& Moos, M. (2014). Growing food in the suburbs: Estimating the land potential for suburban agriculture in Waterloo, Ontario. Planning, Practice \& Research, 29 (2), 152-170.

Pudup, M. B. (2008). It takes a garden: Cultivating citizen-subjects in organized garden projects. Geoforum, 39, 1228-1240.

Pugliese, D. (2014, February 19).What is happening with the former Canadian Forces Base Rockcliffe?. Ottawa Citizen. Retrieved from http://ottawacitizen.com/news/national/defence-watch/what-is-happening-withthe-former-canadian-forces-base-rockcliffe.

Purcell, M. (2002). Excavating Lefebvre: The right to the city and its urban politics of the inhabitant. GeoJournal, 58, 99-108.

Purcell, M. \& Tyman, S. K. (2014). Cultivating food as a right to the city. Local Environment, 1-16. doi: 10.1080/13549839.2014.903236.

Putnam, R. (1995). Bowling alone: America's declining social capital. Journal of Democracy, 6 (1), 65-78. 
Reed, M. (2003). Appendix: Describing and reflecting on research methods. Taking stands: Gender and the sustainability of rural communities (pp. 233-252). Vancouver, BC: UBC Press.

Roehr, D. \& Kunigk, I. (2009). Metro Vancouver: Designing for urban food production. Berkeley Planning Journal, 22 (1), 61-70.

Rosenshein, L., Scott, L. \& Pratt, M. (2011). Finding a meaningful model. ArcUser, Winter 2011. Retrieved from http://www.esri.com/news/arcuser/0111/files/findmodel.pdf.

Russell, S. E., \& Heidkamp, C. P. (2011). 'Food desertification': The loss of a major supermarket in New Haven, Connecticut. Applied Geography, 31, 1197-1209.

Saumel, I., Kotsyuk, I., Holscher, M., Lenkereit, C., Weber, F. \& Kowarik, I. (2012). How healthy is urban horticulture in high traffic areas? Trace metal concentrations in vegetable crops from plantings within inner city neighbourhoods in Berlin, Germany. Environmental Pollution, 165, 124-132.

Schmelzkopf, K. (1995). Urban community gardens as contested space. Geographical Review, 85 (3), 364-381.

Schuurman, N. (2009). Critical GIS. In International Encyclopedia of Human Geography, 363-368. Amsterdam, The Netherlands: Elsevier.

Sciarra, R. (2007). Narratives of a 'lived' urban space: An investigation of community gardens in the City of Ottawa (Unpublished master's thesis). Carleton University: Ottawa, ON.

Smit, J. \& Nasr, J. (1992). Urban agriculture for sustainable cities: Using wastes and idle land and water bodies as resources. Environment and Urbanization, 4(2), 141152.

Smith, V. M, Greene, R. B., \& Silbernagel, J. (2013). The social and spatial dynamics of community food production: A landscape approach to policy and program development. Landscape Ecology, 28, 1415-1426. doi: 10.1007/s10980-0139891-z.

Statistics Canada. (2012a). Census Dictionary. Retrieved from https://www12.statcan.gc.ca/census-recensement/2011/ref/dict/index-eng.cfm.

Statistics Canada. (2012b). Final report on the 2016 census options: Proposed content determination framework and methodology options. Retrieved from http://www12.statcan.gc.ca/census-recensement/fc-rf/reports-rapports/r2_indexeng.cfm. 
Sumner, J. (2012). Conceptualizing sustainable food systems. In M. Koc, J. Sumner \& A. Winson. (Eds.), Critical perspectives in food studies (pp. 326-336). Don Mills, Ontario: Oxford University Press.

Taylor, J., Paine, C., \& Fitzgibbon, J. (1995). From greenbelts to greenways: four Canadian case studies. Landscape and Urban Planning, 33, 47-64.

Taylor, J. R., \& Lovell, S. T. (2012). Mapping public and private spaces of urban agriculture in Chicago through the analysis of high-resolution aerial images in Google Earth. Landscape and Urban Planning, 108(1), 57-70.

Teddlie, C., \& Tashakkori, A. (2011). Mixed methods research: Contemporary issues in an emerging field. In N. K. Denzin \& Y. S. Lincoln (Eds.), The SAGE handbook of qualitative research ( $4^{\text {th }}$ ed., pp. 285-299). Thousand Oaks, California: SAGE Publications, Inc.

Tzoulas, K., Korpela, K., Venn, S., Yli-Pelkonen, V., Kazmierczak, A., Niemela, J., \& James, P. (2007). Promoting ecosystem and public health in urban areas using green infrastructure: A literature review. Landscape and Urban Planning, 81 (3), 167-178.

Tornaghi, C. (2014). Critical geography of urban agriculture. Progress in Human Geography. Advance online publication. doi: 10.1177/0309132513512542.

Toronto Public Health. (2008). An assessment of health implications associated with exposures to electromagnetic fields in and next to hydro corridors in the City of Toronto. Toronto, ON.

Veall, M. R. (2010). 2B or not 2B? What should have happened with the Canadian long form census? What should happen now? Canadian Public Policy, 36 (3), 395399.

Vitiello, D. (2008). Growing edible cities. In E. L. Birch \& S. M. Wachter (Eds.), Growing greener cities: Urban sustainability in the twenty-first century (pp. 259280). Philadelphia: University of Pennsylvania Press.

Wakefield, S., Yeudall, F., Taron, C., Reynolds, J. \& Skinner, A. (2007). Growing urban health: Community gardening in South-East Toronto. Health Promotion Journal, 22 (2), 92-101.

Weigeldt, N. (2012). Chickens in the city: The urban agriculture movement. In A. Dale, W. T. Dushenko, \& P. Robinson (Eds.), Urban sustainability: Reconnecting space and place (pp. 149-170). Toronto: University of Toronto Press. 
Wekerle, G. R. (2004). Food justice movements: Policy, planning, and networks. Journal of Planning and Education Research, 23, 378-386.

World Health Organization International Agency for Research on Cancer. (2002). IARC monographs on the evaluation of carcinogenic risks to humans: Volume 80 nonionizing radiation, part 1: Static and extremely low-frequency (ELF) electric and magnetic fields. Retrieved from http://monographs.iarc.fr/ENG/Monographs/vol80/mono80.pdf.

Willing, J. (2014, October 9). Ottawa Mayor Jim Watson wants more trees, gardens. Ottawa Sun. Retrieved from http://www.ottawasun.com/2014/10/09/ottawamayor-jim-watson-wants-more-trees-gardens.

Winchester, H. P. M. \& Rofe, M. W. (2010). Qualitative research and its place in human geography. In I. Hay (Ed.), Qualitative research methods in human geography ( $3^{\text {rd }}$ ed., pp. 3-25). Don Mills, Ontario: Oxford University Press.

Xuereb, M. (2005). Food miles: Environmental implications of food imports to Waterloo Region (Region of Waterloo Public Health). Retrieved from http://chd.region.waterloo.on.ca/en/researchResourcesPublications/resources/Foo dMiles_Report.pdf. 